Supporting information for

\title{
Synthesis of Oligodeoxynucleotides Containing Electrophilic Groups
}

Xi Lin,${ }^{\dagger}$ Jinsen Chen,${ }^{\dagger}$ Shahien Shahsavari, ${ }^{\dagger}$ Nathanael Green, Deepti Goyal, and Shiyue Fang*

${ }^{\dagger}$ X. L., J. C. and S. S. contributed equally

Department of Chemistry, Michigan Technological University, 1400 Townsend Drive, Houghton, MI 49931 USA

Email: shifang@mtu.edu

\section{Table of Contents}

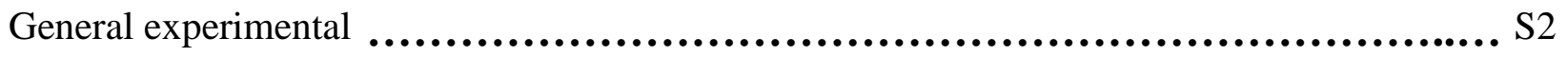

Linker and phosphoramidite synthesis $\quad$...........................................S2

ODN deprotection and cleavage experiment $\quad$...........................................S9

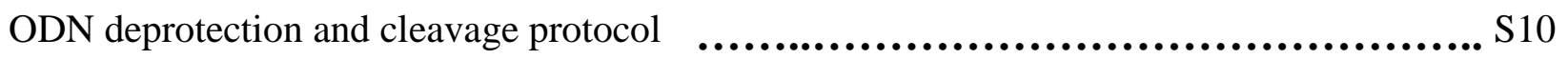

NMR spectra

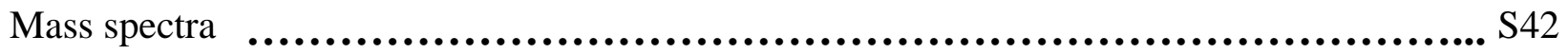

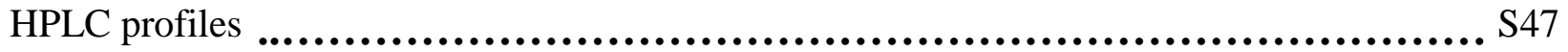

Experiments for comparing Dmoc-amidites with commercial amidites ................... S50

Confirm incompatibility of thioester and $\alpha$-chloroacetyl groups with $\mathrm{K}_{2} \mathrm{CO}_{3} / \mathrm{MeOH}$.......... S57 
General Experimental: All reactions were performed in oven-dried glassware under a nitrogen atmosphere using standard Schlenk techniques. Reagents and solvents available from commercial sources were used as received unless otherwise noted. $\mathrm{CH}_{2} \mathrm{Cl}_{2}$, pyridine, and toluene were distilled over $\mathrm{CaH}_{2}$. THF was distilled over Na/benzophenone. Thin layer chromatography (TLC) was performed using Sigma-Aldrich TLC plates, silica gel 60F-254 over glass support, 0.25 $\mu \mathrm{m}$ thickness. Flash column chromatography was performed using Selecto Scientific silica gel, particle size $32-63 \mu \mathrm{m} .{ }^{1} \mathrm{H},{ }^{13} \mathrm{C}$ and ${ }^{31} \mathrm{P}$ NMR spectra were measured on Varian UNITY INOVA spectrometer at 400, 100 and $162 \mathrm{MHz}$, respectively; chemical shifts $(\delta)$ were reported in reference to solvent peaks (residue $\mathrm{CHCl}_{3}$ at $\delta 7.24 \mathrm{ppm}$ for ${ }^{1} \mathrm{H}$ and $\mathrm{CDCl}_{3}$ at $\delta 77.00 \mathrm{ppm}$ for ${ }^{13} \mathrm{C}$, and $\mathrm{H}_{3} \mathrm{PO}_{4}$ at $\delta 0.00 \mathrm{ppm}$ for $\left.{ }^{31} \mathrm{P}\right)$. ODNs were synthesized on ABI 394 (20-22) and MerMade 6 (29-30) solid phase synthesizers. RP HPLC was performed on a JASCO LC-2000Plus System: pump, PU2089Plus Quaternary Gradient; detector UV-2075Plus. A C-18 reverse phase analytical column (5 $\mu \mathrm{m}$ diameter, $100 \AA$, $250 \times 3.20 \mathrm{~mm}$ ) was used. Solvent A: $0.1 \mathrm{M}$ triethylammonium acetate, $5 \%$ acetonitrile. Solvent B: $90 \%$ acetonitrile. All profiles were generated by detection of absorbance of ODN at $260 \mathrm{~nm}$ using the linear gradient solvent system: solvent B (0\%-45\%) in solvent A over $60 \mathrm{~min}$ followed by solvent B (45\%-100\%) in solvent A over $20 \mathrm{~min}$ at a flow rate of $0.5 \mathrm{~mL} / \mathrm{min}$. Lcaa-CPG (pore size $497 \AA$ ) was a gift from Prime Synthesis, Inc. D-Salt ${ }^{\mathrm{TM}}$ dextran desalting column (5K MWCO, $10 \mathrm{~mL}$ ) was purchased from Pierce Biotechnology, Inc. Polyacrylamide desalting column $(5 \mathrm{~K}$ MWCO, $10 \mathrm{~mL}$ ) was from Thermo Scientific. Amicon® centrifugal filter units (3K NMWL) were purchased from Sigma-Aldrich.

Compound 7: To a solution of 1,3-dithiane (3.25 g, 27.1 $\mathrm{mmol})$ in dry THF $(50 \mathrm{~mL})$ was added $t \mathrm{BuLi}(1.7 \mathrm{M}$ in pentane, 16.0 $\mathrm{mL}, 27.1 \mathrm{mmol})$ dropwise at $-78{ }^{\circ} \mathrm{C}$. The mixture was stirred under nitrogen while warming to $-40{ }^{\circ} \mathrm{C}$ gradually. After stirring at this temperature for $1 \mathrm{~h}$, it was cooled to $-78^{\circ} \mathrm{C}$, and a solution of $\mathbf{6}(4.88$ $\mathrm{g}, 22.6 \mathrm{mmol})$ in dry THF $(30 \mathrm{~mL})$ was added slowly via cannula.

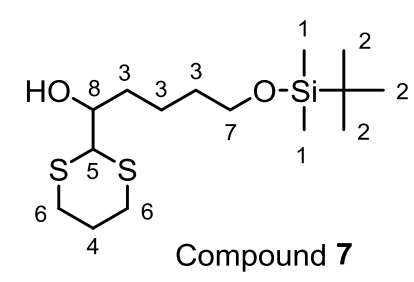
Stirring was continued at $-78{ }^{\circ} \mathrm{C}$ for $15 \mathrm{~min}$, and the reaction was then quenched with sat. $\mathrm{NH}_{4} \mathrm{Cl}(50 \mathrm{~mL})$. The organic layer was separated and the aqueous layer was extracted with EtOAc $(50 \mathrm{~mL} \times 3)$. The combined organic layer was washed with water and brine, dried over anhydrous $\mathrm{Na}_{2} \mathrm{SO}_{4}$, filtered, and concentrated. Flash column chromatography $\left(\mathrm{SiO}_{2}, 9: 1\right.$ hexanes/EtOAc) gave 7 as a colorless oil $(5.40 \mathrm{~g}, 71 \%): \mathrm{R}_{\mathrm{f}}=0.2(9: 1$ hexanes/EtOAc); ${ }^{1} \mathrm{H}$ NMR $\left(400 \mathrm{MHz}, \mathrm{CDCl}_{3}\right) \delta 0.02$ (s, 6H, H-1), 0.86 (s, 9H, H-2), 1.38-1.48 (m, 1H, H-3), 1.491.59 (m, 4H, H-3), 1.77-1.84 (m, 1H, H-3), 1.89-1.98 (m, 1H, H-4), 2.01-2.10 (m, 1H, H-4), 2.43 (d, $J=3.6 \mathrm{~Hz}, 1 \mathrm{H}, \mathrm{H}-5), 2.68-2.78$ (m, 2H, H-6), 2.86-2.94 (m, 2H, H-6), 3.59 (t, $J=10.4 \mathrm{~Hz}, 2 \mathrm{H}$, $\mathrm{H}-7), 3.80-3.85(\mathrm{~m}, 1 \mathrm{H}, \mathrm{H}-8), 3.88(\mathrm{~d}, J=6 \mathrm{~Hz}, 1 \mathrm{H}, \mathrm{OH}) ;{ }^{13} \mathrm{C} \mathrm{NMR}\left(100 \mathrm{MHz}, \mathrm{CDCl}_{3}\right) \delta-5.3$, 18.3, 22.1, 25.7, 26.0, 28.0, 28.5, 32.6, 33.8, 52.5, 63.0, 72.2; HRMS (ESI) $\mathrm{m} / \mathrm{z}$ calcd for $\mathrm{C}_{15} \mathrm{H}_{32} \mathrm{O}_{2} \mathrm{~S}_{2} \mathrm{SiH}[\mathrm{M}+\mathrm{H}]^{+}$337.1691, found 337.1695. 
Compound 8: Carbonyldiimidazole (2.61 g, 16.1 mmol), 7 (2.16 g, $6.4 \mathrm{mmol}$ ), $\mathrm{CaH}_{2}$ (90\% grade, $0.75 \mathrm{~g}, 16.1$ $\mathrm{mmol})$ and dry toluene $(100 \mathrm{~mL})$ were combined and stirred at $\mathrm{rt}$ for $8 \mathrm{~h}$. The mixture was filtered, and the filtrate was concentrated. Flash column chromatography $\left(\mathrm{SiO}_{2}, 3: 1\right.$ hexanes/EtOAc) gave $\mathbf{8}$ as a thick oil $(2.83 \mathrm{~g}, 100 \%)$ : $\mathrm{R}_{\mathrm{f}}=0.2$

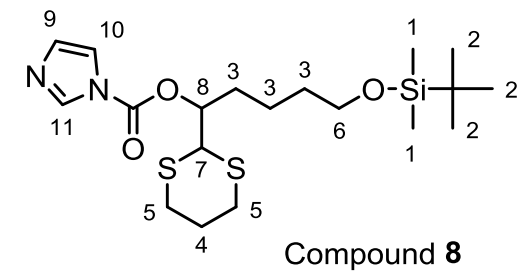
(3:1 hexanes/EtOAc); ${ }^{1} \mathrm{H}$ NMR $\left(400 \mathrm{MHz}, \mathrm{CDCl}_{3}\right) \delta 0.01$ (s, $6 \mathrm{H}, \mathrm{H}-1), 0.82$ (s, 9H, H-2), 1.39-1.56 (m, 4H, H-3), 1.80-2.08 (m, 4H, H-3 and H-4), 2.67-2.78 (m, 2H, H-5), 2.84-2.95 (m, 2H, H-5), 3.57 (t, $J=4 \mathrm{~Hz}, 2 \mathrm{H}, \mathrm{H}-6), 4.10$ (d, $J=4 \mathrm{~Hz}, 1 \mathrm{H}, \mathrm{H}-7)$, 5.28-5.33 (m, 1H, H-8), 7.04 (s, 1H, H-9), 7.40 (s, 1H, H-10), 8.12 (s, 1H, H-11); ${ }^{13} \mathrm{C}$ NMR (100 $\left.\mathrm{MHz}, \mathrm{CDCl}_{3}\right) \delta-5.4,18.2$ 21.7, 25.4, 25.8, 28.4, 28.6, 31.4, 32.2, 48.9, 62.4, 78.4, 117.2, 130.6, 137.2, 148.3; HRMS (ESI) $m / z$ calcd for $\mathrm{C}_{19} \mathrm{H}_{34} \mathrm{~N}_{2} \mathrm{O}_{3} \mathrm{~S}_{2} \mathrm{SiH}[\mathrm{M}+\mathrm{H}]^{+} 431.1858$, found 431.1858 .

Compound 9: 5'-DMTr-thymidine (3.72 g, $6.8 \mathrm{mmol}), 8(1.96 \mathrm{~g}, 4.6 \mathrm{mmol})$ and DBU $(0.21 \mathrm{~g}$, $0.20 \mathrm{~mL}, 1.4 \mathrm{mmol})$ and toluene $(50 \mathrm{~mL})$ were combined and stirred at rt. After $8 \mathrm{~h}$, the mixture was concentrated and purified with flash column chromatography $\left(\mathrm{SiO}_{2}, 3: 1\right.$ hexanes/EtOAc with $\left.0.5 \% \mathrm{Et}_{3} \mathrm{~N}\right)$. Compound 9 was obtained as a white foam (3.14 g, 76\%): m.p. $81.2-82.6{ }^{\circ} \mathrm{C} ; \mathrm{R}_{\mathrm{f}}=0.45$ (1:1 hexanes/EtOAc); ${ }^{1} \mathrm{H}$ NMR $\left(400 \mathrm{MHz}, \mathrm{CDCl}_{3}\right)$ $\delta 0.00$ (s, 6H, H-1), 0.84 (s, 9H, H-2), 1.31 (s, 3H,

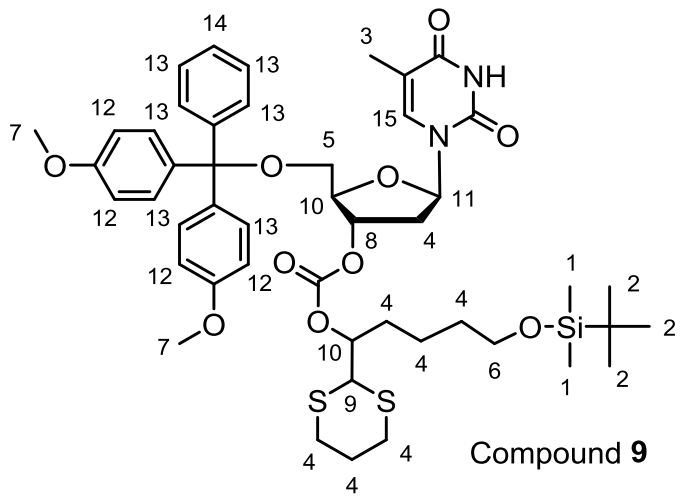
$\mathrm{H}-3), 1.36-2.00(\mathrm{~m}, 8 \mathrm{H}, \mathrm{H}-4), 2.34-2.74(\mathrm{~m}, 4 \mathrm{H}, \mathrm{H}-$ 4), 2.80-2.89 (m, 2H, H-4), 3.41-3.47 (m, 2H, H-5), 3.57 (t, $J=8 \mathrm{~Hz}, 2 \mathrm{H}, \mathrm{H}-6), 3.75$ (s, 6H, H-7), $3.94(\mathrm{~d}, J=8 \mathrm{~Hz}, 1 \mathrm{H}, \mathrm{H}-8), 4.20$ (s, $1 \mathrm{H}, \mathrm{H}-9), 4.91-4.96$ (m, $1 \mathrm{H}, \mathrm{H}-10), 5.35$ (d, $J=8 \mathrm{~Hz}, 1 \mathrm{H}, \mathrm{H}-$ 10), 6.43 (dd, $J=4 \mathrm{~Hz}, 8 \mathrm{~Hz}, 1 \mathrm{H}, \mathrm{H}-11), 6.79$ (d, $J=8 \mathrm{~Hz}, 4 \mathrm{H}, \mathrm{H}-12), 7.18-7.31$ (m, 8H, H-13), 7.31-7.33 (m, 1H, H-14), 7.54 (s, $1 \mathrm{H}, \mathrm{H}-15), 8.08$ (br s, $1 \mathrm{H}, \mathrm{NH}) ;{ }^{13} \mathrm{C} \mathrm{NMR}\left(100 \mathrm{MHz}, \mathrm{CDCl}_{3}\right) \delta$ -5.3, 11.6, 18.3, 21.7, 25.4, 26.0, 28.4, 28.6, 31.6, 32.3, 37.9, 48.9, 55.3, 62.7, 63.7, 78.8, 78.9, 84.0, 84.3, 87.2, 111.5, 113.3, 127.2, 128.0, 128.1, 130.1, 135.2, 135.3, 135.4, 144.2, 150.0, 154.3, 158.8, 163.3; HRMS (ESI) $\mathrm{m} / z$ calcd for $\mathrm{C}_{47} \mathrm{H}_{62} \mathrm{~N}_{2} \mathrm{O}_{10} \mathrm{~S} 2 \mathrm{SiNa}[\mathrm{M}+\mathrm{Na}]^{+}$929.3513, found 929.3497.

Compound 10: To a solution of $9(1.47 \mathrm{~g}, 1.6 \mathrm{mmol})$ in THF $(40 \mathrm{~mL})$ at $0{ }^{\circ} \mathrm{C}$ was added TBAF $(1.95 \mathrm{~mL}, 1.0 \mathrm{M}$ in THF, $1.9 \mathrm{mmol})$ dropwise. The mixture was stirred for $8 \mathrm{~h}$ while warming to rt. The contents were poured into a separation funnel and partitioned between EtOAc $(40 \mathrm{~mL})$ and $\mathrm{H}_{2} \mathrm{O}(40 \mathrm{~mL})$. The aqueous layer was extracted with EtOAc $(30 \mathrm{~mL} \times 2)$. The combined organic layer was dried over anhydrous $\mathrm{Na}_{2} \mathrm{SO}_{4}$, filtered and concentrated. Flash column chromatography $\left(\mathrm{SiO}_{2}, 1: 1\right.$ hexanes/EtOAc) gave 10 as a white foam $(0.96 \mathrm{~g}, 75 \%)$ : m.p. 90.6$92.3{ }^{\circ} \mathrm{C} ; \mathrm{R}_{\mathrm{f}}=0.3\left(1: 3\right.$ hexanes/EtOAc); ${ }^{1} \mathrm{H}$ NMR $\left(400 \mathrm{MHz}, \mathrm{CDCl}_{3}\right) \delta 1.35(\mathrm{~s}, 3 \mathrm{H}, \mathrm{H}-1), 1.41-$ 1.63 (m, 4H, H-2), 1.69-1.81 (m, 2H, H-2), 1.89-2.08 (m, 2H, H-2), 2.37-2.44 (m, 1H, H-2), 2.562.75 (m, 3H, H-2), 2.84-2.93 (m, 2H, H-2), 3.42-3.51 (m, 2H, H-3), 3.61-3.65 (m, 2H, H-4), 3.77 
(s, 6H, H-5), 3.98 (d, J=8 Hz, 1H, H-6), 4.24 (s, 1H, H7), 4.97-5.01 (m, 1H, H-8), 5.34 (d, $J=4 \mathrm{~Hz}, 1 \mathrm{H}, \mathrm{H}-8)$, 6.42 (t, $J=4 \mathrm{~Hz}, 8 \mathrm{~Hz}, \mathrm{H}-9), 6.82$ (d, $J=8 \mathrm{~Hz}, 4 \mathrm{H}, \mathrm{H}-10)$, 7.20-7.34 (m, 8H, H-11), 7.34-7.37 (m, 1H, H-12), 7.58 (s, $1 \mathrm{H}, \mathrm{H}-13), 8.78$ (s, 1H, NH); ${ }^{13} \mathrm{C} \mathrm{NMR}\left(100 \mathrm{MHz}, \mathrm{CDCl}_{3}\right)$ $\delta$ 11.6, 14.2, 21.0, 21.6, 25.4, 28.4, 28.6, 31.6, 32.1, 38.0, $48.9,55.2,60.4,62.4,63.7,78.7,79.1,83.7,84.4,87.2$, $111.6,113.3,127.2,128.0,128.1,130.1,130.1,135.1$, 135.2, 135.3, 144.2, 150.3, 154.2, 158.8, 158.8, 163.5; HRMS (ESI) $m / z$ calcd for $\mathrm{C}_{41} \mathrm{H}_{48} \mathrm{~N}_{2} \mathrm{NaO}_{10} \mathrm{~S}_{2}[\mathrm{M}+\mathrm{Na}]^{+}$

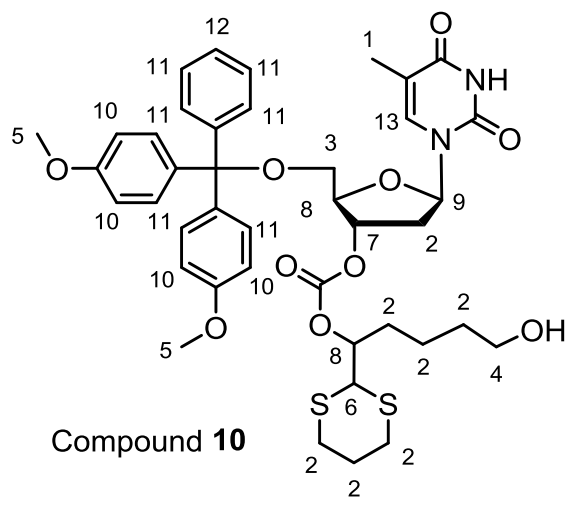
815.2648 , found 815.2636 .

dT-Dmoc-CPG 1: A mixture of 10 (0.10 g, $0.13 \mathrm{mmol})$, succinic anhydride $(0.05 \mathrm{~g}, 0.50$ mmol), and DMAP (0.03 g, $0.25 \mathrm{mmol})$ in anhydrous pyridine $(3 \mathrm{~mL})$ was stirred at $\mathrm{rt}$. After 2 days, the contents were partitioned between EtOAc $(5 \mathrm{~mL})$ and $\mathrm{H}_{2} \mathrm{O}(5 \mathrm{~mL})$. The organic layer was washed with sat. $\mathrm{NaHCO}_{3}$ and brine, dried over anhydrous $\mathrm{Na}_{2} \mathrm{SO}_{4}$, filtered, and concentrated. The residue was dissolved in dry DMF (3 mL), and mixed with amino-lcaa-CPG $(0.251 \mathrm{~g}, 0.027$ mmol, $107 \mu \mathrm{mol} / \mathrm{g}, 497 \AA$, Prime Synthesis, Inc.) and DCC (0.027 mL, $1.0 \mathrm{M}$ in $\mathrm{CH}_{2} \mathrm{Cl}_{2}, 0.027$ mmol). After standing at $\mathrm{rt}$ for 2 days, the supernatant was removed, and the CPG was washed with pyridine $(3 \mathrm{~mL} \times 5)$. To the $\mathrm{CPG}$ was added a capping solution $(0.1 \mathrm{M}$ DMAP in pyridine/ $/ \mathrm{Ac}_{2} \mathrm{O}, 9: 1, \mathrm{v} / \mathrm{v} ; 5 \mathrm{~mL}$ ), and the mixture was allowed to stand at $\mathrm{rt}$ for 2 days. The supernatant was removed and the $\mathrm{CPG}$ was washed with pyridine $(3 \mathrm{~mL} \times 5), \mathrm{MeOH}(3 \mathrm{~mL} \times 3)$, $\mathrm{DMF}(3 \mathrm{~mL} \times 3)$ and acetone $(3 \mathrm{~mL} \times 5)$, and dried under vacuum.

Compound 14: A solution of 5'-DMTr-dC (11, $2.60 \mathrm{~g}, 4.9 \mathrm{mmol})$ and TMSCl (1.60 g, $1.87 \mathrm{~mL}, 14.7$ $\mathrm{mmol})$ in pyridine $(50 \mathrm{~mL})$ was stirred at $\mathrm{rt}$ for $30 \mathrm{~min}$. Compound 13 (3.10 g, $9.8 \mathrm{mmol}$ ) and DMAP (0.30 g, 2.5 $\mathrm{mmol})$ in pyridine $(15 \mathrm{~mL})$ were added via cannula, and the mixture was stirred for $8 \mathrm{~h}$. After cooling to $0{ }^{\circ} \mathrm{C}, \mathrm{H}_{2} \mathrm{O}$ $(10 \mathrm{~mL})$ was added, and the mixture was stirred for $5 \mathrm{~min}$. Concentrated $\mathrm{NH}_{4} \mathrm{OH}(15 \mathrm{~mL})$ was then added, and the mixture was stirred at $0{ }^{\circ} \mathrm{C}$ for an additional $30 \mathrm{~min}$. The

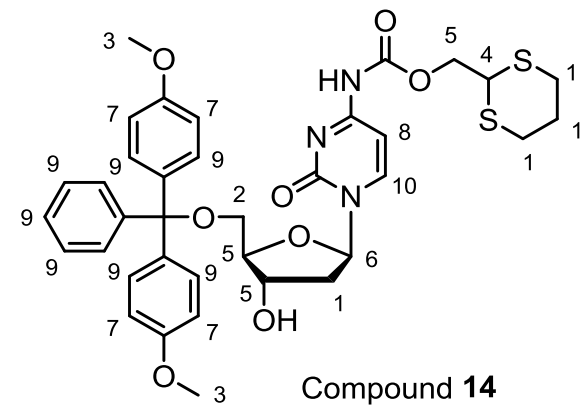
content was poured into a separation funnel containing $5 \%$ $\mathrm{NaHCO}_{3}(30 \mathrm{~mL})$, and extracted with $\mathrm{CH}_{2} \mathrm{Cl}_{2}(30 \mathrm{~mL} \times 2)$. The extracts were dried over anhydrous $\mathrm{Na}_{2} \mathrm{SO}_{4}$, filtered and concentrated. Flash column chromatography $\left(\mathrm{SiO}_{2}\right.$, 1:2:5:2:2:1 hexanes/EtOAc/ $\left.\mathrm{Et}_{2} \mathrm{O} / \mathrm{MeCN} / \mathrm{MeOH} / \mathrm{Et}_{3} \mathrm{~N}\right)$ gave 14 as a white foam (4.02 g, 100\%): m.p. 121.1$123.4{ }^{\circ} \mathrm{C} ; \mathrm{R}_{\mathrm{f}}=0.32\left(1: 2: 5: 2: 2: 1\right.$ hexanes/EtOAc/Et $\left.2 \mathrm{O} / \mathrm{MeCN} / \mathrm{MeOH} / \mathrm{Et}_{3} \mathrm{~N}\right) ;{ }^{1} \mathrm{H} \mathrm{NMR}(400 \mathrm{MHz}$, $\left.\mathrm{CDCl}_{3}\right) \delta 1.93-2.09$ (m, 2H, H-1), 2.21-2.27 (m, 1H, H-1), 2.41 (br s, 1H, OH), 2.62-2.96 (m, 5H, H-1), 3.37-3.41 (m, 2H, H-2), 3.79 (s, 6H, H-3), 4.09 (t, J=6 Hz, 1H, H-4), 4.46-4.48 (m, 4H, H5), 6.23 (t, $J=6 \mathrm{~Hz}, 1 \mathrm{H}, \mathrm{H}-6), 6.83$ (d, $J=8 \mathrm{~Hz}, 4 \mathrm{H}, \mathrm{H}-7), 6.96$ (d, $J=8 \mathrm{~Hz}, 1 \mathrm{H}, \mathrm{H}-8), 7.20-7.39$ 
(m, 9H, H-9), 8.23 (d, $J=8 \mathrm{~Hz}, 1 \mathrm{H}, \mathrm{H}-10) ;{ }^{13} \mathrm{C} \mathrm{NMR}\left(100 \mathrm{MHz}, \mathrm{CDCl}_{3}\right) \delta 15.4,27.3,41.9,42.8$, 55.2, 62.6, 65.6, 70.7, 86.3, 86.9, 113.2, 127.0, 128.0, 128.1, 130.0, 135.3, 135.4, 135.4, 144.2, 158.6, 162.1; HRMS (ESI) $\mathrm{m} / z$, calcd for $\mathrm{C}_{36} \mathrm{H}_{39} \mathrm{~N}_{3} \mathrm{O}_{8} \mathrm{~S}_{2} \mathrm{H}[\mathrm{M}+\mathrm{H}]^{+}$706.2251, found 706.2249.

Dmoc-dC-amidite 2: A round-bottom flask containing 14 (0.69 g, $1.0 \mathrm{mmol})$ and a magnetic stirring bar was evacuated and then refilled with nitrogen. The evacuation and nitrogen-filling cycle was repeated for two more times. Dry $\mathrm{CH}_{2} \mathrm{Cl}_{2}$ (10 mL), 2cyanoethyl- $N, N, N^{\prime}, N^{\prime}$-tetraisopropylphosphoramidite $(\mathbf{1 6}, 0.33 \mathrm{~g}, 0.34 \mathrm{~mL}, 1.09 \mathrm{mmol})$, and a solution of $1 H$ tetrazole in $\mathrm{CH}_{3} \mathrm{CN}(0.45 \mathrm{M}, 2.41 \mathrm{~mL}, 1.09 \mathrm{mmol})$ were added via syringes sequentially. After stirring at $\mathrm{rt}$ for $2 \mathrm{~h}$, the mixture was concentrated to dryness by a nitrogen flow over its surface. The residue was purified

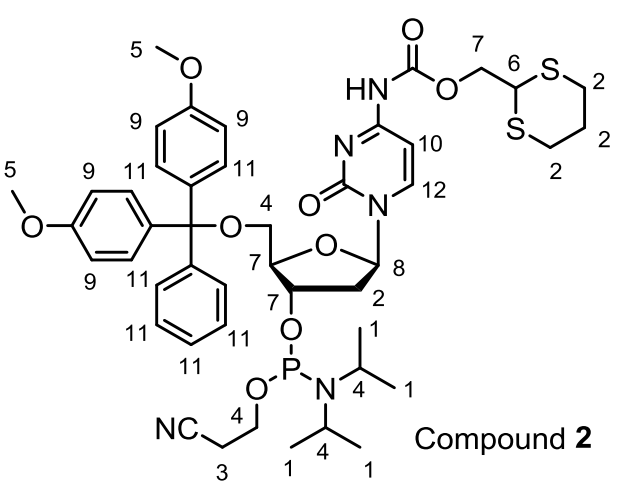
with flash column chromatography ( $\mathrm{SiO}_{2}, 1: 1$ hexanes/EtOAc) giving 2 as a white foam (800 mg, $89 \%): \mathrm{R}_{\mathrm{f}}=0.32(1: 3 \mathrm{hexanes/EtOAc}) ;{ }^{1} \mathrm{H} \mathrm{NMR}\left(400 \mathrm{MHz} \mathrm{CDCl}_{3}\right) \delta 1.14(\mathrm{~d}, J=6 \mathrm{~Hz}, 12 \mathrm{H}, \mathrm{H}-$ 1), 1.90-2.07 (m, 1H, H-2), 2.24-2.30 (m, 1H, H-2), 2.41 (t, J=8 Hz, 2H, H-3), 2.64-2.71 (m, 4H, H-2), 2.88-2.93 (m, 2H, H-2), 3.35-3.57 (m, 6H, H-4), 3.77 (s, 6H, H-5), 4.17-4.18 (m, 1H, H-6), 4.45-4.64 (m, 4H, H-7), 6.22 (t, $J=6 \mathrm{~Hz}, 1 \mathrm{H}, \mathrm{H}-8), 6.81-6.88$ (m, 5H, H-9, H-10), 7.22-7.38 (m, $9 \mathrm{H}, \mathrm{H}-11), 8.27$ (d, $J=8 \mathrm{~Hz}, 1 \mathrm{H}, \mathrm{H}-12) ;{ }^{13} \mathrm{C} \mathrm{NMR}\left(100 \mathrm{MHz}, \mathrm{CDCl}_{3}\right) \delta 20.1,24.6,27.2,29.9$, 40.8, 42.7, 43.3, 55.2, 58.1, 58.3, 61.9, 65.6, 71.6, 85.6, 86.8, 94.5, 113.2, 117.3, 127.0, 127.9, 128.2, 129.6, 130.0, 130.1, 135.2, 135.3, 144.0, 144.3, 158.6, 162.0; ${ }^{31} \mathrm{P} \mathrm{NMR}\left(162 \mathrm{MHz}, \mathrm{CDCl}_{3}\right)$ $\delta$ 150.4; HRMS (ESI) $m / z$ calcd for $\mathrm{C}_{45} \mathrm{H}_{56} \mathrm{~N}_{5} \mathrm{O}_{9} \mathrm{PS}_{2} \mathrm{H}[\mathrm{M}+\mathrm{H}]^{+} 906.3336$, found 906.3342 .

Compound 15: The procedure for 14 was used: White foam; yield $57 \%$; m.p. $108.2-111.4{ }^{\circ} \mathrm{C}$; $\mathrm{R}_{\mathrm{f}}=0.47(1: 2: 5: 2: 2: 1$ hexanes/EtOAc/Et $2 \mathrm{O} / \mathrm{MeCN}$ $\left./ \mathrm{MeOH} / \mathrm{Et}_{3} \mathrm{~N}\right) ;{ }^{1} \mathrm{H} \mathrm{NMR}\left(400 \mathrm{MHz}, \mathrm{CDCl}_{3}\right) \delta 1.89$ 2.04 (m, 2H, H-1), 2.50-2.97 (m, 6H, H-1), 3.37 (d, $J=4 \mathrm{~Hz}, 2 \mathrm{H}, \mathrm{H}-2), 3.72$ (s, 6H, H-3), 4.09-4.16 (m, $1 \mathrm{H}, \mathrm{H}-4), 4.16-4.19$ (m, 1H, H-5), 4.52 (d, J=4 Hz, $2 \mathrm{H}, \mathrm{H}-5), 4.68-4.71(\mathrm{~m}, 1 \mathrm{H}, \mathrm{H}-5), 6.46$ (t, $J=6 \mathrm{~Hz}$,

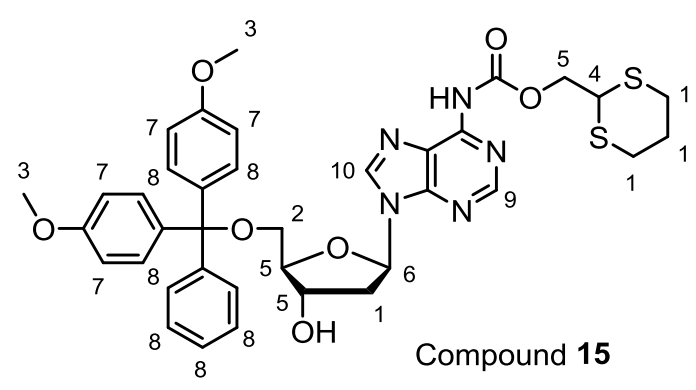
$1 \mathrm{H}, \mathrm{H}-6), 6.73-6.75$ (d, $J=8 \mathrm{~Hz}, 4 \mathrm{H}, \mathrm{H}-7), 7.12-$ 7.35 (m, 9H, H-8), 8.13 (s, 1H, H-9), 8.66 (s, 1H, H-10); ${ }^{13} \mathrm{C} \mathrm{NMR} \mathrm{(100} \mathrm{MHz,} \mathrm{CDCl} 3$ ) $\delta 25.4$, 27.3, 40.2, 43.0, 55.2, 65.3, 72.2, 84.6, 86.2, 86.5, 113.1, 122.3, 126.9, 135.5, 141.4, 149.2, 158.4; HRMS (ESI) $m / z$ calcd for $\mathrm{C}_{37} \mathrm{H}_{39} \mathrm{~N}_{5} \mathrm{O}_{7} \mathrm{~S}_{2} \mathrm{H}[\mathrm{M}+\mathrm{H}]^{+} 730.2364$, found 730.2366.

Dmoc-dA-amidite 3: The procedure for 2 was used: White foam; yield 88\%; $\mathrm{R}_{\mathrm{f}}=0.4$ $(1: 1: 1$ hexanes/EtOAc/Et $3 \mathrm{~N}) ;{ }^{1} \mathrm{H} \mathrm{NMR}\left(400 \mathrm{MHz}, \mathrm{CDCl}_{3}\right) \delta 1.17(\mathrm{~d}, J=6 \mathrm{~Hz}, 12 \mathrm{H}, \mathrm{H}-1), 1.94-$ 2.07 (m, 1H, H-2), 2.41 (t, $J=8 \mathrm{~Hz}, 2 \mathrm{H}, \mathrm{H}-3$ ), 2.52-2.99 (m, 7H, H-2), 3.32-3.41 (m, 2H, H-4), 
3.55-3.72 (m, 4H, H-5), 3.76 (s, 6H, H-6), 4.13 (t, $J=8 \mathrm{~Hz}, 1 \mathrm{H}, \mathrm{H}-7), 4.28-4.31(\mathrm{~m}, 1 \mathrm{H}, \mathrm{H}-8), 4.56$ (d, $J=8 \mathrm{~Hz}, 2 \mathrm{H}, \mathrm{H}-9), 4.74-4.79$ (m, 1H, H-8), 6.45 (t, $J=6 \mathrm{~Hz}, 1 \mathrm{H}, \mathrm{H}-10), 6.77$ (d, $J=8 \mathrm{~Hz}, 4 \mathrm{H}, \mathrm{H}-$ 11), 7.16-7.37 (m, 9H, H-12), 8.16 (s, 1H, H-13), 8.68 (s, $1 \mathrm{H}, \mathrm{H}-14) ;{ }^{13} \mathrm{C} \mathrm{NMR}\left(100 \mathrm{MHz}, \mathrm{CDCl}_{3}\right) \delta$ 20.4, 20.5, 24.7, 24.8, 25.7, 39.7, 43.2, 43.4, 55.4, 63.5, 65.6, 73.6, 73.8, 85.0, 86.2, 86.3, 86.7, 113.3, $117.6,122.7,127.1,128.0,128.4,130.3,135.8$, $135.8,141.7,144.7,149.5,150.8,151.1,152.9$,

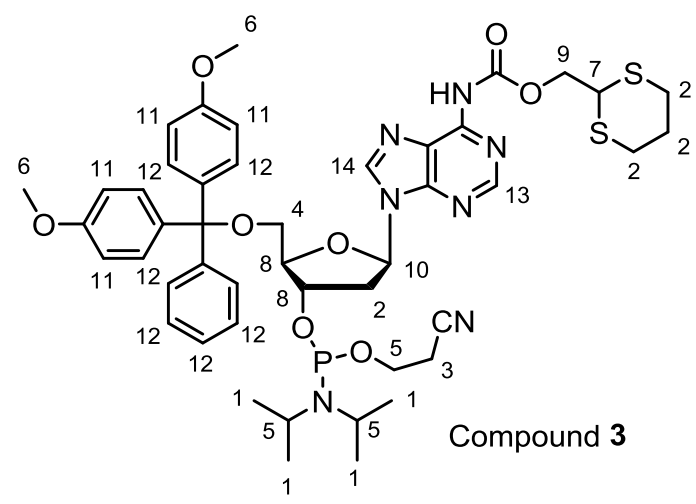
158.7; ${ }^{31} \mathrm{P}$ NMR $\left(162 \mathrm{MHz}, \mathrm{CDCl}_{3}\right) \delta 150.0$; HRMS (ESI) $m / z$ calcd for $\mathrm{C}_{46} \mathrm{H}_{56} \mathrm{~N}_{7} \mathrm{O}_{8} \mathrm{PS}_{2} \mathrm{H}[\mathrm{M}+\mathrm{H}]^{+} 930.3448$, found 930.3441 .

Compound 19: To a solution of compound $17(2.56 \mathrm{~g}, 5.04 \mathrm{mmol})$ in HMPA $(5 \mathrm{~mL})$ and THF $(50 \mathrm{~mL})$ was added tert-butylmagnesium chloride $(1 \mathrm{M}$ in THF, $15.1 \mathrm{~mL}, 15.1 \mathrm{mmol})$ dropwise at $-78^{\circ} \mathrm{C}$. After addition, the mixture was allowed to warm to rt slowly, stirred at $\mathrm{rt}$ for $30 \mathrm{~min}$, and then cooled to $-78{ }^{\circ} \mathrm{C}$ again. A solution of $\mathbf{1 3}(3.97 \mathrm{~g}, 12.6 \mathrm{mmol})$ in THF $(25 \mathrm{~mL})$ was added dropwise. After stirring at $\mathrm{rt}$ for $8 \mathrm{~h}$, the reaction was quenched with $\mathrm{MeOH}(8 \mathrm{~mL})$. Volatiles were evaporated under reduced pressure. The residue was dissolved in EtOAc and washed sequentially with $0.15 \mathrm{M}$ EDTA, saturated $\mathrm{NaHCO}_{3}$, and brine. The organic layer was dried over anhydrous $\mathrm{Na}_{2} \mathrm{SO}_{4}$, filtered and concentrated. Flash chromatography $\left(\mathrm{SiO}_{2}, 19: 1\right.$ $\left.\mathrm{CHCl}_{3} / \mathrm{MeOH}\right)$ gave $18(1.53 \mathrm{~g}, 44 \%)$ as a white solid. To the solution of $18(0.57 \mathrm{~g}, 0.83 \mathrm{mmol})$ in dry pyridine $(10 \mathrm{~mL})$ was added HF-pyridine $(70 \%, 357 \mathrm{mg}, 12.5 \mathrm{mmol})$ at $0{ }^{\circ} \mathrm{C}$. After stirring at $\mathrm{rt}$ for $2 \mathrm{~h}$, excess fluoride was quenched with $\mathrm{MeOSiMe}_{3}(1.30 \mathrm{~g}, 12.5 \mathrm{mmol})$ by stirring at $\mathrm{rt}$ for $8 \mathrm{~h}$. Volatiles were evaporated under reduced pressure. The residue was co-evaporated with dry pyridine $(5 \mathrm{~mL} \times 3)$, and then dissolved in dry pyridine $(20 \mathrm{~mL})$. To the solution, dimethoxytrityl chloride $(0.28 \mathrm{~g}, 0.83 \mathrm{mmol})$ was added. After stirring at $\mathrm{rt}$ for $8 \mathrm{~h}$, the mixture was partitioned between $\mathrm{CH}_{2} \mathrm{Cl}_{2}$ and $5 \% \mathrm{NaHCO}_{3}$. The organic layer was dried over anhydrous $\mathrm{Na}_{2} \mathrm{SO}_{4}$, filtered and concentrated. Flash chromatography $\left(\mathrm{SiO}_{2}, 9: 1 \mathrm{EtOAc} / \mathrm{MeOH}\right)$ gave

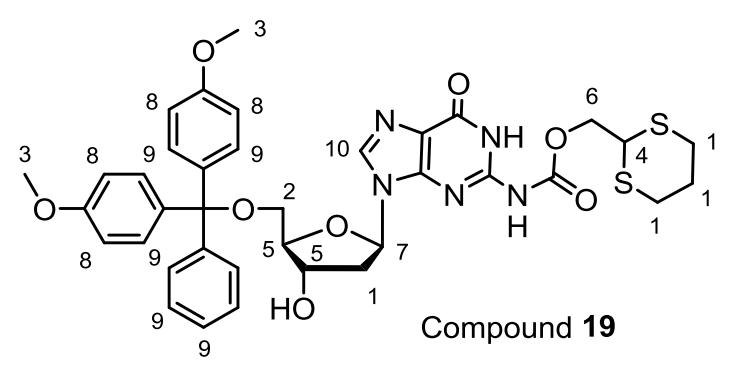
$19(1.06 \mathrm{~g}, 80 \%)$ as a white foam: m.p. $159-161$ ${ }^{\circ} \mathrm{C} ; \mathrm{R}_{\mathrm{f}}=0.2(9: 1 \mathrm{EtOAc} / \mathrm{MeOH}) ;{ }^{1} \mathrm{H}$ NMR $\left(400 \mathrm{MHz}, \mathrm{CDCl}_{3}\right) \delta 1.94-2.06(\mathrm{~m}, 2 \mathrm{H}, \mathrm{H}-1), 2.48-$ 2.59 (m, 2H, H-1), 2.63-2.96 (m, 4H, H-1), 3.27-3.41 (m, 2H, H-2), 3.68 (s, 6H, H-3), 4.10 (t, $J=$ $8 \mathrm{~Hz}, 1 \mathrm{H}, \mathrm{H}-4), 4.15-4.18$ (m, 1H, H-5), 4.57 (d, $J=8 \mathrm{~Hz}, 2 \mathrm{H}, \mathrm{H}-6$ ), 4.87-4.91 (m, 1H, H-5), 6.22 (t, $J=6 \mathrm{~Hz}, 1 \mathrm{H}, \mathrm{H}-7), 6.68$ (dd, $J=9 \mathrm{~Hz}, 3 \mathrm{~Hz}, 4 \mathrm{H}, \mathrm{H}-8), 7.07-7.33$ (m, 9H, H-9), 7.68 (s, 1H, H10); ${ }^{13} \mathrm{C} \mathrm{NMR}\left(100 \mathrm{MHz}, \mathrm{CDCl}_{3}\right) \delta 10.8,14.2,25.4,27.0,40.1,42.6,45.8,55.2,60.4,64.3,65.7$, 71.7, 84.3, 86.4, 86.5, 113.0, 120.9, 126.8, 135.7, 144.5, 148.4, 154.4, 155.8, 158.4; HRMS (ESI) $\mathrm{m} / \mathrm{z}$ calcd for $\mathrm{C}_{37} \mathrm{H}_{39} \mathrm{~N}_{5} \mathrm{O}_{8} \mathrm{~S}_{2} \mathrm{H}[\mathrm{M}+\mathrm{H}]^{+} 746.2313$, found 746.2311. 
Dmoc-dG-amidite 4: The procedure for 2 was used: White foam; yield $77 \% ; \mathrm{R}_{\mathrm{f}}=0.5$ (29:1 EtOAc/MeOH); ${ }^{1} \mathrm{H}$ NMR $(400 \mathrm{MHz}$, $\left.\mathrm{CDCl}_{3}\right) \delta 1.12-1.15(\mathrm{~m}, 12 \mathrm{H}, \mathrm{H}-1), 1.97-2.03(\mathrm{~m}$, $2 \mathrm{H}$ ), 2.32-2.95 (m, 8H, H-2, H-3), 3.33 (d, $J=4$ $\mathrm{Hz}, 2 \mathrm{H}, \mathrm{H}-4), 3.51-3.63$ (m, 4H, H-5), 3.73 (s, $6 \mathrm{H}, \mathrm{H}-6), 3.96$ (t, $J=10 \mathrm{~Hz}, 1 \mathrm{H}, \mathrm{H}-7$ ), 4.24-4.47 (m, 1H, H-8), 4.50 (d, $J=8 \mathrm{~Hz}, 2 \mathrm{H}, \mathrm{H}-9), 4.68-$ 4.74 (m, 1H, H-8), 6.19 (t, $J=6 \mathrm{~Hz}, 1 \mathrm{H}, \mathrm{H}-10$ ), 6.73-6.76 (m, 4H, H-11), 7.13-7.38 (m, 9H, H-

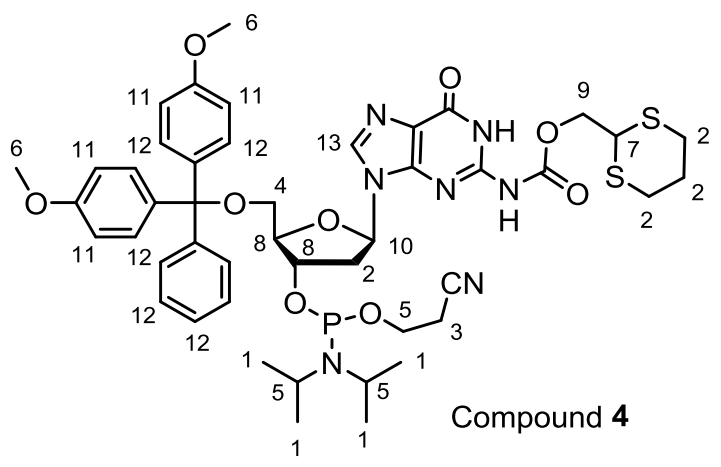
12), 7.74 (s, $1 \mathrm{H}, \mathrm{H}-13) ;{ }^{13} \mathrm{C}$ NMR (100 MHz, $\left.\mathrm{CDCl}_{3}\right) \delta 20.2,20.3,24.5,24.5,24.6,26.8,39.4,42.1,43.2,43.3,55.2,57.8,58.0,63.7,65.6,73.7$, 73.8, 84.6, 86.0, 86.3, 113.1, 117.3, 121.7, 126.9, 127.8, 128.0, 130.0, 135.7, 137.5, 144.5, 146.2, 148.0, 153.0, 158.5; ${ }^{31} \mathrm{P}$ NMR $\left(162 \mathrm{MHz}, \mathrm{CDCl}_{3}\right) \delta 149.4$; HRMS (ESI) $\mathrm{m} / \mathrm{z}$ calcd for $\mathrm{C}_{46} \mathrm{H}_{56} \mathrm{~N}_{7} \mathrm{O}_{9} \mathrm{PS}_{2} \mathrm{H}[\mathrm{M}+\mathrm{H}]^{+}$946.3397, found 946.3405 .

Compound 27: To a solution of 5(acetylthio)pentanoic acid (26, $100 \mathrm{mg}, 0.57 \mathrm{mmol})$ in dry $\mathrm{CH}_{2} \mathrm{Cl}_{2}(10 \mathrm{~mL})$ at $0{ }^{\circ} \mathrm{C}$ was added DCC $(0.63$ $\mathrm{mL}, 1.0 \mathrm{M}$ in $\mathrm{CH}_{2} \mathrm{Cl}_{2}, 0.63 \mathrm{mmol}$ ) dropwise under argon. After stirring at $0{ }^{\circ} \mathrm{C}$ for $20 \mathrm{~min}$, compound 25 (223 mg, $0.57 \mathrm{mmol})$ in dry $\mathrm{CH}_{2} \mathrm{Cl}_{2}(10 \mathrm{~mL})$ was added via cannula and the mixture was stirred for 12 $\mathrm{h}$ while warm to $\mathrm{rt}$ gradually. The content was

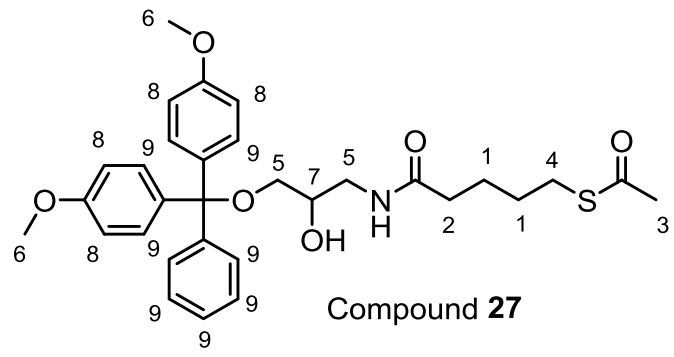
poured into a separatory funnel containing $5 \% \mathrm{NaHCO}_{3}(20 \mathrm{~mL})$, and extracted with $\mathrm{CH}_{2} \mathrm{Cl}_{2}(20$ $\mathrm{mL} \times 2$ ). The extracts were dried over anhydrous $\mathrm{Na}_{2} \mathrm{SO}_{4}$, filtered and concentrated. Flash column chromatography $\left(\mathrm{SiO}_{2}, 1: 1: 0.05\right.$ hexanes/EtOAc/Et $\left.3 \mathrm{~N}\right)$ gave 27 as a white sticky foam $(240 \mathrm{mg}$, 77\%): $\mathrm{R}_{\mathrm{f}}=0.35$ (1:2 hexanes/EtOAc); ${ }^{1} \mathrm{H}$ NMR (400 MHz, $\left.\mathrm{CDCl}_{3}\right) \delta 1.50-1.69$ (m, 4H, H-1), 2.09 (t, $J=7.12 \mathrm{~Hz}, 2 \mathrm{H}, \mathrm{H}-2), 2.29$ (s, 3H, H-3), 2.82 (t, $J=7.12 \mathrm{~Hz}, 2 \mathrm{H}, \mathrm{H}-4), 3.09-3.22$ (m, 3H, H5), 3.49-3.55 (m, 1H, H-5), 3.76 (s, 6H, H-6), 3.84-3.88 (m, 1H, H-7), 5.85 (br t, $J=7.12 \mathrm{~Hz}, \mathrm{NH}$ ), $6.81(\mathrm{~d}, J=6.92 \mathrm{~Hz}, 4 \mathrm{H}, \mathrm{H}-8), 7.19-7.41$ (m, 9H, H-9); ${ }^{13} \mathrm{C} \mathrm{NMR}\left(100 \mathrm{MHz}, \mathrm{CDCl}_{3}\right) \delta 24.8,28.8$, 28.9, 30.9, 35.9, 43.2, 55.4, 64.9, 70.5, 86.4, 113.4, 127.1, 128.1, 128.3, 130.2, 135.9, 144.8, 158.7, 174.0; HRMS (ESI) $m / z$ calcd for $\mathrm{C}_{31} \mathrm{H}_{37} \mathrm{NO}_{6} \mathrm{SNa}[\mathrm{M}+\mathrm{Na}]^{+}$574.2239, found 574.2244.

Compound 23: To the solution of $27(100 \mathrm{mg}, 0.21 \mathrm{mmol})$ in $\mathrm{CH}_{2} \mathrm{Cl}_{2}(2 \mathrm{~mL})$ was added diisopropylammonium tetrazolide (54 $\mathrm{mg}, 0.32 \mathrm{mmol})$ and $16(97 \mathrm{mg}, 0.32 \mathrm{mmol})$, and the reaction mixture was stirred under nitrogen at $\mathrm{rt}$ for $2 \mathrm{~h}$. The mixture was loaded onto a column $\left(\mathrm{SiO}_{2}\right)$ and eluted with the solvent mixture EtOAc/hexanes/Et $3 \mathrm{~N}$ (20:20:1). Compound 23 was obtained as a pale yellow oil $(130 \mathrm{mg}, 82 \%)$ : two diastereoisomers, $\mathrm{R}_{\mathrm{f}}=0.50$ (20:20:1 EtOAc/hexanes/Et $3 \mathrm{~N}) ;{ }^{1} \mathrm{H}$ NMR $\left(400 \mathrm{MHz}, \mathrm{CDCl}_{3}\right) \delta 1.01-1.31(\mathrm{~m}, 12 \mathrm{H}, \mathrm{H}-1), 1.45-4.68(\mathrm{~m}, 4 \mathrm{H}$, H-2), $2.04(\mathrm{t}, J=6.7 \mathrm{~Hz}, 1 \mathrm{H}, \mathrm{H}-3), 2.11(\mathrm{t}, J=6.7 \mathrm{~Hz}, 1 \mathrm{H}, \mathrm{H}-3), 2.29$ (s, 3H, H-4), 2.44 (t, $J=6.3$ 
$\mathrm{Hz}, 1 \mathrm{H}, \mathrm{H}-5), 2.62(\mathrm{t}, J=6.2 \mathrm{~Hz}, 1 \mathrm{H}, \mathrm{H}-5), 2.82$ (t, $J=7.1 \mathrm{~Hz}, 1 \mathrm{H}, \mathrm{H}-6), 2.83(\mathrm{t}, J=7.1 \mathrm{~Hz}, 1 \mathrm{H}, \mathrm{H}-$ 6), 3.05-3.10 (m, 0.5H, H-7), 3.15-3.24 (m, 1H, H7), 3.28-3.36 (m, 0.5H, H-7), 3.41-3.69 (m, $4 \mathrm{H}, \mathrm{H}-$ 7), 3.69-3.80 (m, 1H, H-8), 3.75 (s, 3H, H-9), 3.76 (s, 3H, H-9), 3.81-3.91 (m, 1H, H-8), 3.95-4.08 (m, $1 \mathrm{H}, \mathrm{H}-10), 5.76(\mathrm{t}, J=5.6 \mathrm{~Hz}, 0.5 \mathrm{H}, \mathrm{NH}), 6.05(\mathrm{t}$, $J=5.2 \mathrm{~Hz}, 0.5 \mathrm{H}, \mathrm{NH}), 6.79(\mathrm{~d}, J=7.6 \mathrm{~Hz}, 2 \mathrm{H}, \mathrm{H}-$ $11), 6.81(\mathrm{~d}, J=5.6 \mathrm{~Hz}, 2 \mathrm{H}, \mathrm{H}-11), 6.16-7.29(\mathrm{~m}$,

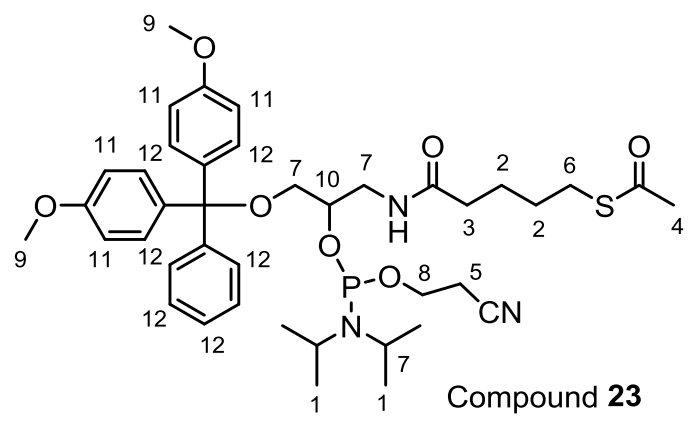
7H, H-12), 7.41-7.43 (m, 2H, H-12); ${ }^{31} \mathrm{P}$ NMR $\left(162 \mathrm{MHz}, \mathrm{CDCl}_{3}\right) \delta 149.9,150.3$; HRMS (ESI) $\mathrm{m} / z$ calcd for $\mathrm{C}_{40} \mathrm{H}_{54} \mathrm{~N}_{3} \mathrm{O}_{7} \mathrm{PSNa}[\mathrm{M}+\mathrm{Na}]^{+}$ 774.3318 , found 774.3316 .

Compound 28: Triethylamine $(0.267 \mathrm{~mL}, 1.92$ mmol) was added to a solution of compound $25(630 \mathrm{mg}, 1.6$ mmol) in dry $\mathrm{CH}_{2} \mathrm{Cl}_{2}(15 \mathrm{~mL})$ and cooled to $-10{ }^{\circ} \mathrm{C}$ under argon. $\alpha$-chloroacetyl chloride was added dropwise over 5 $\min$. The mixture was stirred for $12 \mathrm{~h}$ while warming to $\mathrm{rt}$ slowly. After concentration under reduced pressure, the residue was purified with flash column chromatography $\left(\mathrm{SiO}_{2}, 1: 1: 0.05\right.$ hexanes/EtOAc/Et $\left.3 \mathrm{~N}\right)$. Compound 28 was

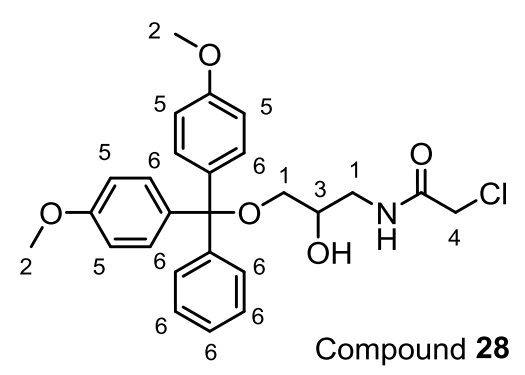
obtained as a white foam $(160 \mathrm{mg}, 21 \%): \mathrm{R}_{\mathrm{f}}=0.30(1: 1$ hexanes/EtOAc). ${ }^{1} \mathrm{H}$ NMR (400 MHz, $\left.\mathrm{CDCl}_{3}\right) \delta 2.92$ (br s, $\left.1 \mathrm{H}, \mathrm{OH}\right), 3.15-3.23(\mathrm{~m}, 2 \mathrm{H}, \mathrm{H}-1), 3.28-$ 3.34 (m, 1H, H-1), 3.56-3.62 (m, 1H, H-1), 3.80 (s, 6H, H-2), 3.88-3.94 (m, 1H, H-3), 4.00 (s, 2H, H-4), 6.85 (d, $J=8.9 \mathrm{~Hz}, 4 \mathrm{H}, \mathrm{H}-5), 6.91$ (t, $J=5.4 \mathrm{~Hz}, 1 \mathrm{H}, \mathrm{NH}$ ), 7.20-7.33 (m, 7H, H-6), 7.43 (dd, $J=11.2,1.4 \mathrm{~Hz}, 2 \mathrm{H}, \mathrm{H}-6) ;{ }^{13} \mathrm{C}$ NMR (100 MHz, $\left.\mathrm{CDCl}_{3}\right) \delta 42.7,43.1,55.4,65.0,70.0,86.6$, 113.4, 127.2, 128.1, 129.4, 135.9, 144.7, 158.8, 167.0; HRMS (ESI) $\mathrm{m} / z$ calcd for $\mathrm{C}_{26} \mathrm{H}_{28} \mathrm{ClNO}_{5} \mathrm{Na}$ $[\mathrm{M}+\mathrm{Na}]^{+}$492.1554, found 492.1558 .

Compound 24: The procedure for $\mathbf{2 3}$ was used: white foam; yield 78\%; two diastereoisomers, $\mathrm{R}_{\mathrm{f}}=0.4$ and 0.5 (2:1 EtOAc/hexanes); ${ }^{1} \mathrm{H}$ NMR $\left(400 \mathrm{MHz}, \mathrm{CDCl}_{3}\right) \delta$ $1.11-1.24(\mathrm{~m}, 12 \mathrm{H}, \mathrm{H}-1), 2.41(\mathrm{t}, J=6.5 \mathrm{~Hz}, 1 \mathrm{H}, \mathrm{H}-2), 2.63$ (t, $J=6.3 \mathrm{~Hz}, 1 \mathrm{H}, \mathrm{H}-2), 3.05-3.09$ (m, 0.5H, H-3), 3.19-3.28 (m, 1H, H-3), 3.33-3.45 (m, 0.5H, H-3), 3.50-3.68 (m, 4H, H-3), 3.50-3.78 (m, 1H, H-5), 3.76 (s, 3H, H-4), 3.77 (s, 3H, $\mathrm{H}-4)$, 3.84-3.94 (m, 1H, H-5), 3.96-4.15 (m, 3H, H-6, H-7), 6.70-6.83 (m, 4H, H-8), 7.17-7.48 (m, 9H, H-9); ${ }^{31} \mathrm{P}$ NMR

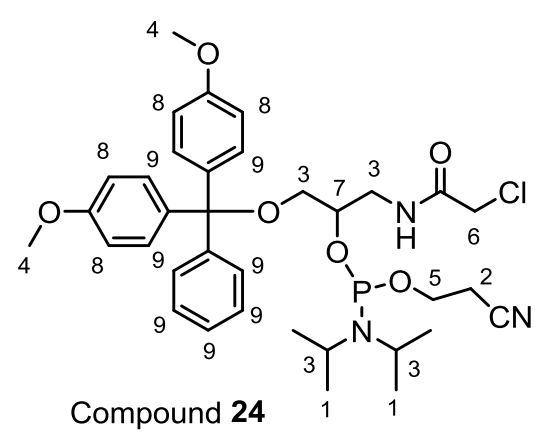
$\left(162 \mathrm{MHz}, \mathrm{CDCl}_{3}\right) \delta 149.90,149.94$; HRMS (ESI) $\mathrm{m} / z$ calcd for $\mathrm{C}_{35} \mathrm{H}_{45} \mathrm{ClN}_{3} \mathrm{O}_{6} \mathrm{PH}[\mathrm{M}+\mathrm{H}]^{+}$670.2813, found 670.2809. 
ODN synthesis, deprotection, cleavage and analysis: The ODNs were synthesized on ABI 394 (20-22, 60 mg CPG used) and MerMade 6 (29-30, 24 mg CPG used) synthesizers using dT-Dmoc-CPG 1, Dmoc amidites 2-4, amidites 23-24 and commercial dT amidite. The conditions suggested by synthesizer manufactures for $1 \mu \mathrm{mol}$ synthesis were used in all cases. The average stepwise coupling yields for 20-22 were 98.6, 98.7, and 98.6\%, respectively. Those for 29-30 were not available as the MerMade synthesizer does not have the reading. After synthesis, the CPG was divided into ten (20-22) or four (29-30) equal portions. One portion was suspended in a solution of DBU in $\mathrm{CH}_{3} \mathrm{CN}\left(1: 9 \mathrm{DBU} / \mathrm{CH}_{3} \mathrm{CN}, \mathrm{v} / \mathrm{v}, 500 \mu \mathrm{L}\right)$, and was gently shaken at rt for $15 \mathrm{~min}$. The supernatant was removed with a pipette, and the $\mathrm{CPG}$ was washed with $\mathrm{CH}_{3} \mathrm{CN}(200 \mu \mathrm{L} \times 3)$. To the CPG, an acidic $\mathrm{NaIO}_{4}$ solution $\left(0.1 \mathrm{M}\right.$ in $970 \mu \mathrm{L} \mathrm{H} \mathrm{H}_{2} \mathrm{O}$ and $\left.30 \mu \mathrm{L} \mathrm{AcOH}, \mathrm{pH} 2\right)$ was added. After shaking in dark at $\mathrm{rt}$ for $3 \mathrm{~h}$, the supernatant was transferred into a centrifugal tube. The CPG was washed with dilute acetic acid (3:97 AcOH/ $\left.\mathrm{H}_{2} \mathrm{O}, \mathrm{v} / \mathrm{v}, \mathrm{pH} 2,200 \mu \mathrm{L} \times 3\right)$. HPLC analysis of the supernatant and washes indicated that the ODN was not cleaved from CPG at this time. To the CPG was added a solution of aniline (3:97 aniline $/ \mathrm{H}_{2} \mathrm{O}, \mathrm{v} / \mathrm{v}, 1 \mathrm{~mL}, \mathrm{pH}$ ), and the suspension was shaken at $\mathrm{rt}$ for $3 \mathrm{~h}$. The supernatant was transferred into a centrifugal tube. The CPG was washed with water $(200 \mu \mathrm{L} \times 3)$. For ODNs 20-22, the combined solution was concentrated to $\sim 500 \mu \mathrm{L}$ (but not to dryness, in some cases, no concentration was carried out), loaded onto a dextran or polyacrylamide desalting column $\left(5 \mathrm{~K}\right.$ MWCO, $10 \mathrm{~mL}$ ), and eluted with $\mathrm{H}_{2} \mathrm{O}$. Fractions containing ODN were combined and concentrated. The ODN was dissolved in $50 \mu \mathrm{L} \mathrm{H}_{2} \mathrm{O}$, and $20 \mu \mathrm{L}$ was injected into RP HPLC to generate the crude ODN trace. The major ODN peak was collected, concentrated, dissolved in $20 \mu \mathrm{L}$ water, and injected into HPLC to generate the pure ODN trace. In several trials, we used Amicon ${ }^{\circledR}$ centrifugal filter units to remove small molecules. The results were similar. For ODNs 29-30, the supernatant and water washes were combined and concentrated to $\sim 50 \mu \mathrm{L}$ (but not to dryness). To the solution, $500 \mu \mathrm{L} n \mathrm{BuOH}$ was added. The mixture was vortexed and centrifuged for $10 \mathrm{~min}$. The supernatant was removed without disturbing with a pipette. The residue was dissolved in $50 \mu \mathrm{L} \mathrm{H}_{2} \mathrm{O}$, and $20 \mu \mathrm{L}$ was injected into RP HPLC to generate the crude ODN trace. The major ODN peak was collected, concentrated to dryness, dissolved in $20 \mu \mathrm{L} \mathrm{H}_{2} \mathrm{O}$, and injected into HPLC to generate the pure ODN trace. All pure ODNs were analyzed with MALDI-TOF MS, and correct molecular masses were observed (see next pages). 


\section{ODN deprotection and cleavage protocol}

Standard procedure should be used for ODN synthesis. No modification of conditions is required. The deprotection and cleavage of $0.1 \mu \mathrm{mol}$ crude ODN is used for the description of the protocol.

1. Place crude $\mathrm{ODN}$ on $\mathrm{CPG}$ in a $1.5 \mathrm{~mL}$ centrifugal tube. Add $500 \mu \mathrm{L}$ DBU solution in $\mathrm{CH}_{3} \mathrm{CN}\left(1: 9 \mathrm{DBU} / \mathrm{CH}_{3} \mathrm{CN}\right)$. Shake gently at rt for $15 \mathrm{~min}$.

2. Spin the tube gently and briefly to bring down CPG (and also the liquids).

3. Remove the supernatant with a pipette.

4. Wash the $\mathrm{CPG}$ with $\mathrm{CH}_{3} \mathrm{CN}(200 \mu \mathrm{L} \times 3)$.

5. Add acidic $\mathrm{NaIO}_{4}$ solution $\left(0.1 \mathrm{M}\right.$ in $970 \mu \mathrm{L} \mathrm{H} \mathrm{H}_{2} \mathrm{O}$ and $\left.30 \mu \mathrm{L} \mathrm{AcOH}, \mathrm{pH} 2\right)$.

6. Wrap the tube with an aluminum foil, and gently shake at $\mathrm{rt}$ for $3 \mathrm{~h}$.

7. Transfer the supernatant to another centrifuge tube. Wash the CPG with dilute acetic acid (3:97 $\mathrm{AcOH} / \mathrm{H}_{2} \mathrm{O}, \mathrm{v} / \mathrm{v}, 200 \mu \mathrm{L} \times 3$. The ODN is still on CPG at this time, but keep the supernatant and washes in case that the ODN falls off. If it falls off, size-exclusion chromatography and Amicon ${ }^{\circledR}$ ultra filtration are options to separate $\mathrm{ODN}$ from $\mathrm{NaIO}_{4}$ and other small molecules).

8. Add aniline solution (3:97 aniline/ $\left.\mathrm{H}_{2} \mathrm{O}, 1 \mathrm{~mL}, \mathrm{pH} 8\right)$ to the $\mathrm{CPG}$, and shake at $\mathrm{rt}$ for $3 \mathrm{~h}$.

9. Transfer the supernatant to another centrifuge tube. Wash the CPG with water $(200 \mu \mathrm{L} \times$ 3). Combine the supernatant and washes.

10. Concentrate (but do not completely dry) the supernatant and washes to $\sim 50 \mu \mathrm{L}$, and add $500 \mu \mathrm{L} n \mathrm{BuOH}$. Vortex for $30 \mathrm{sec}$ and centrifuge for $10 \mathrm{~min}$.

11. Carefully remove the supernatant with a pipette. The residue is crude ODN, which can be purified with RP HPLC.

12. Alternatively, from step 9, load the combined supernatant and washes (concentration is not needed unless the volume exceeds $1.5 \mathrm{~mL}$ ) onto a dextran desalting column (5K MWCO, $10 \mathrm{~mL}$ ), and elute with water. Combine the fractions containing ODN. Evaporate volatiles. The residue is crude ODN, which can be purified with RP HPLC. 


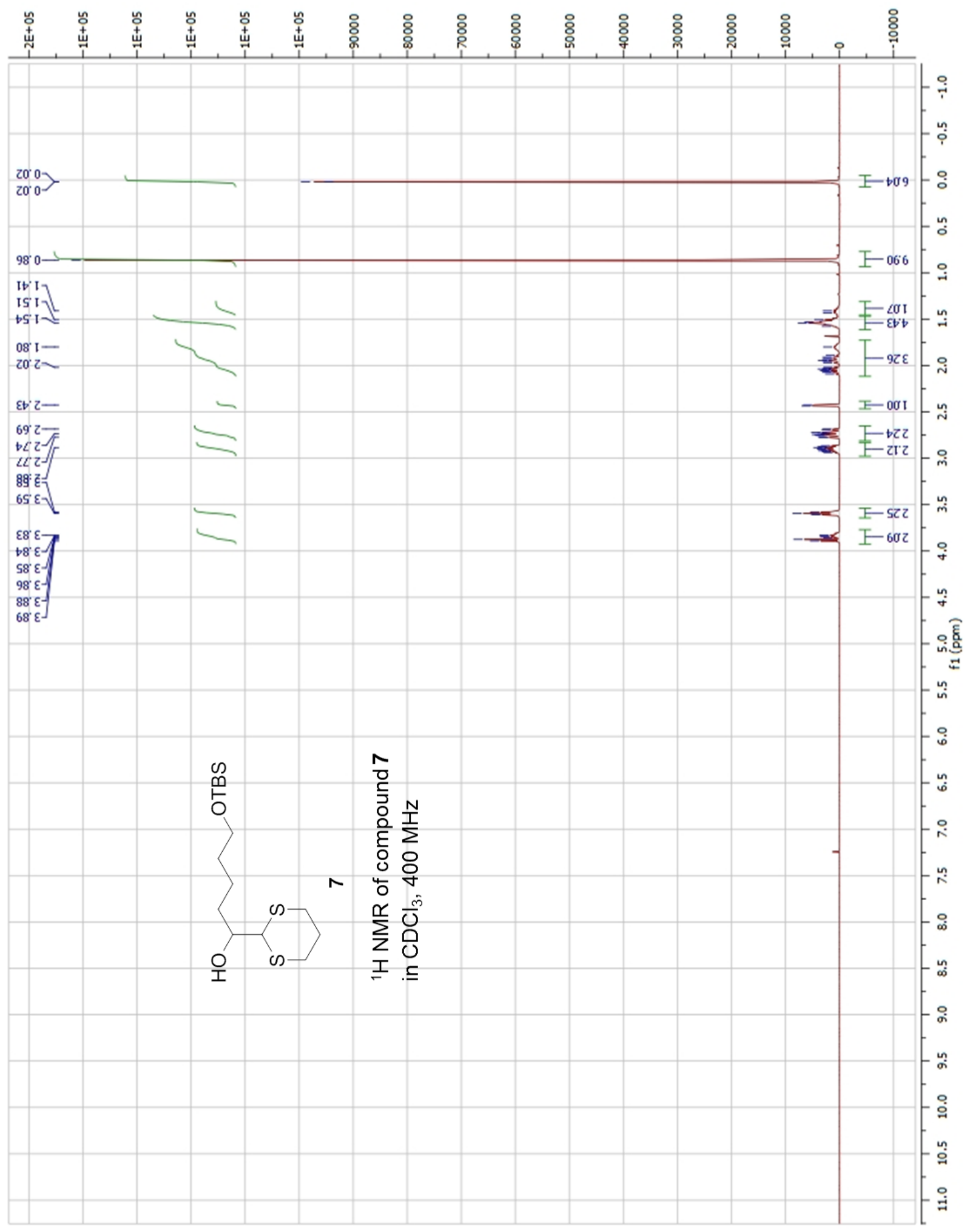




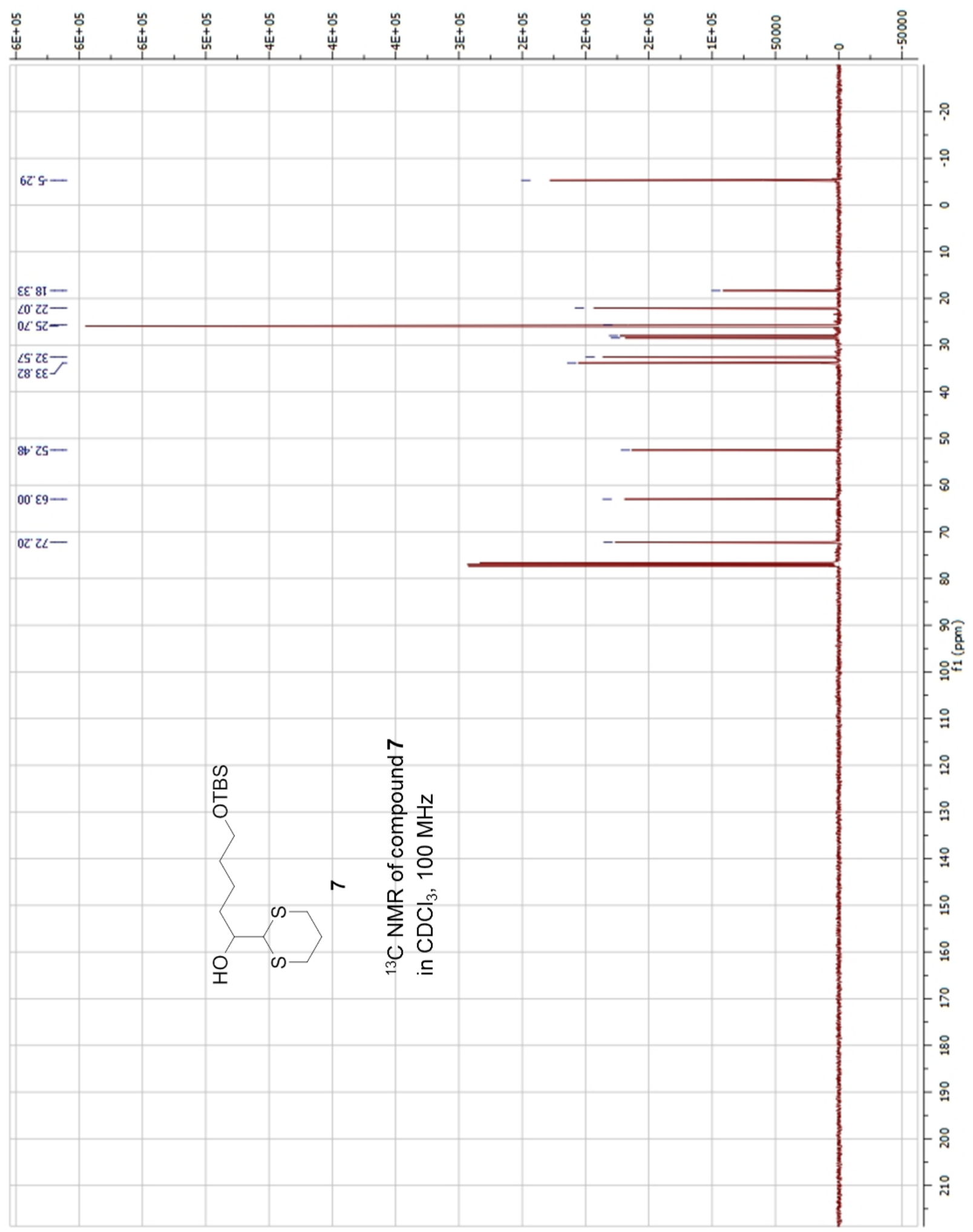




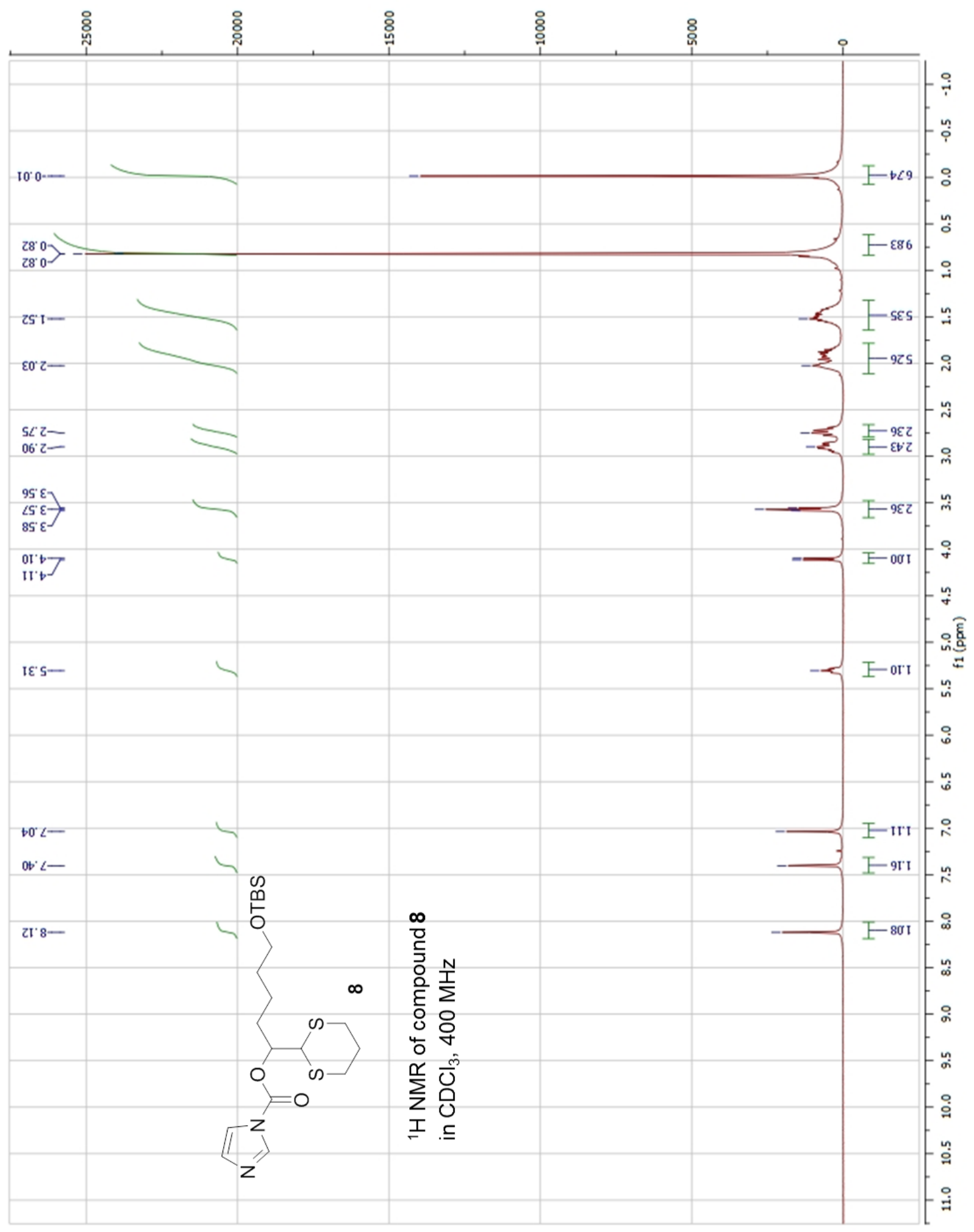




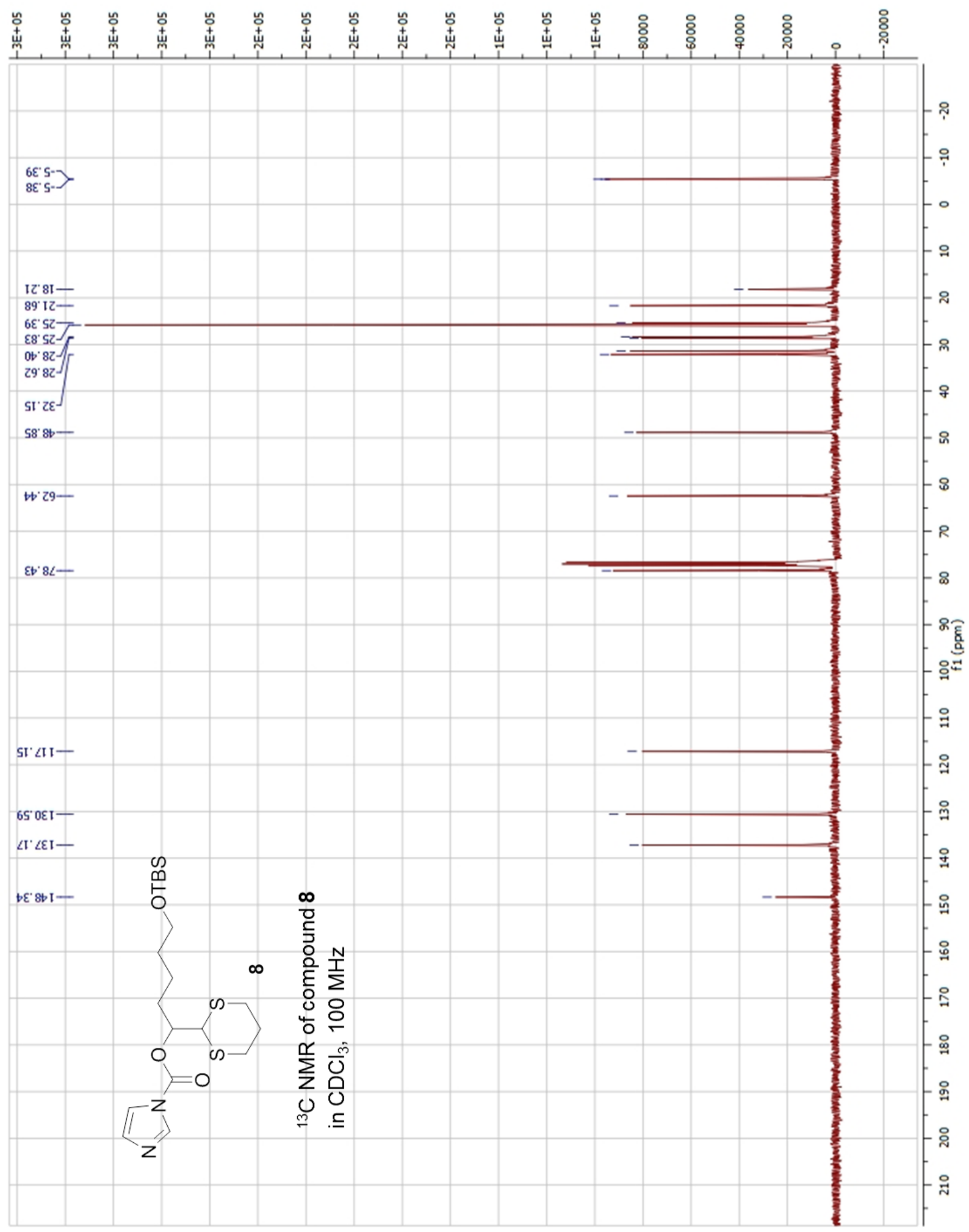




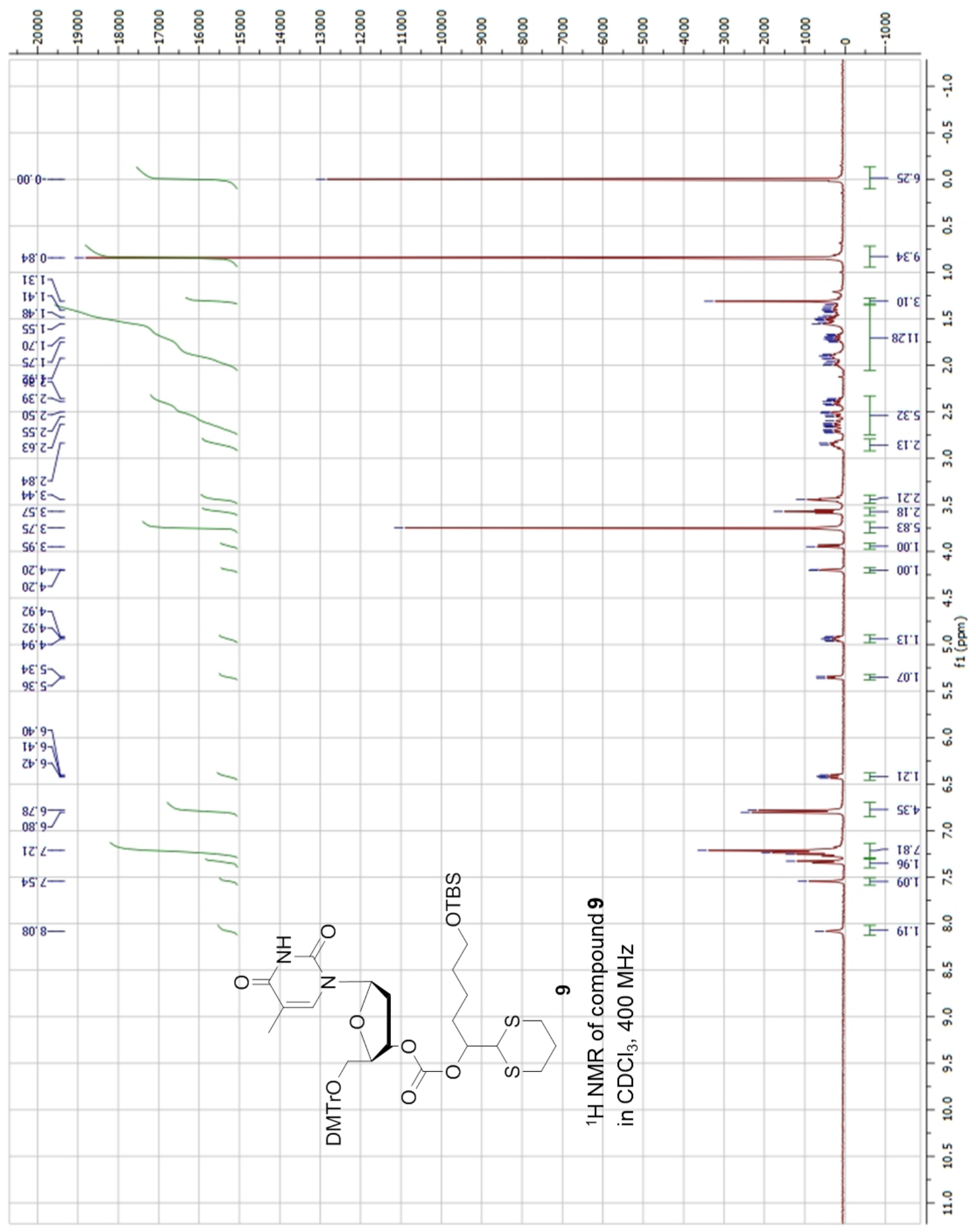




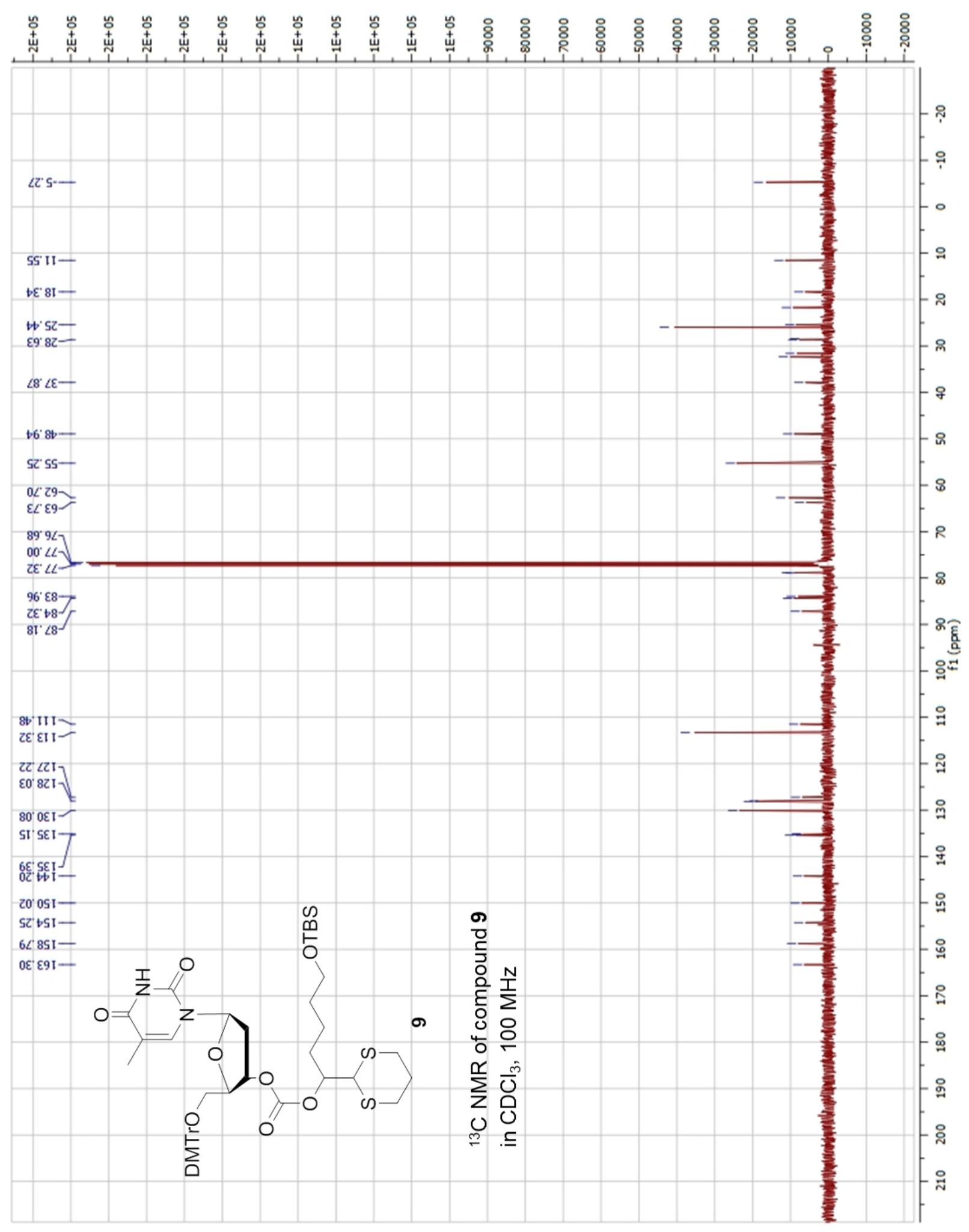




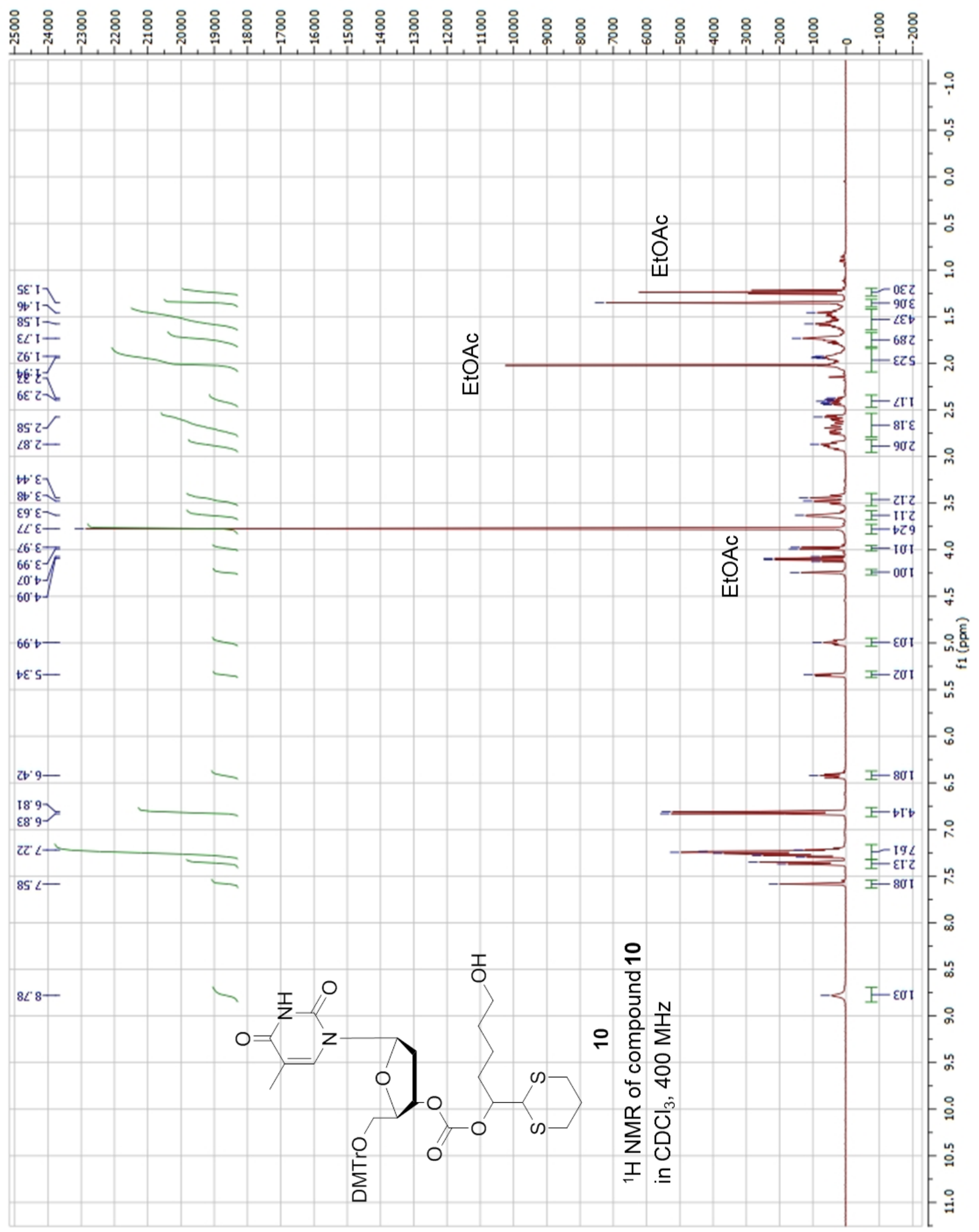




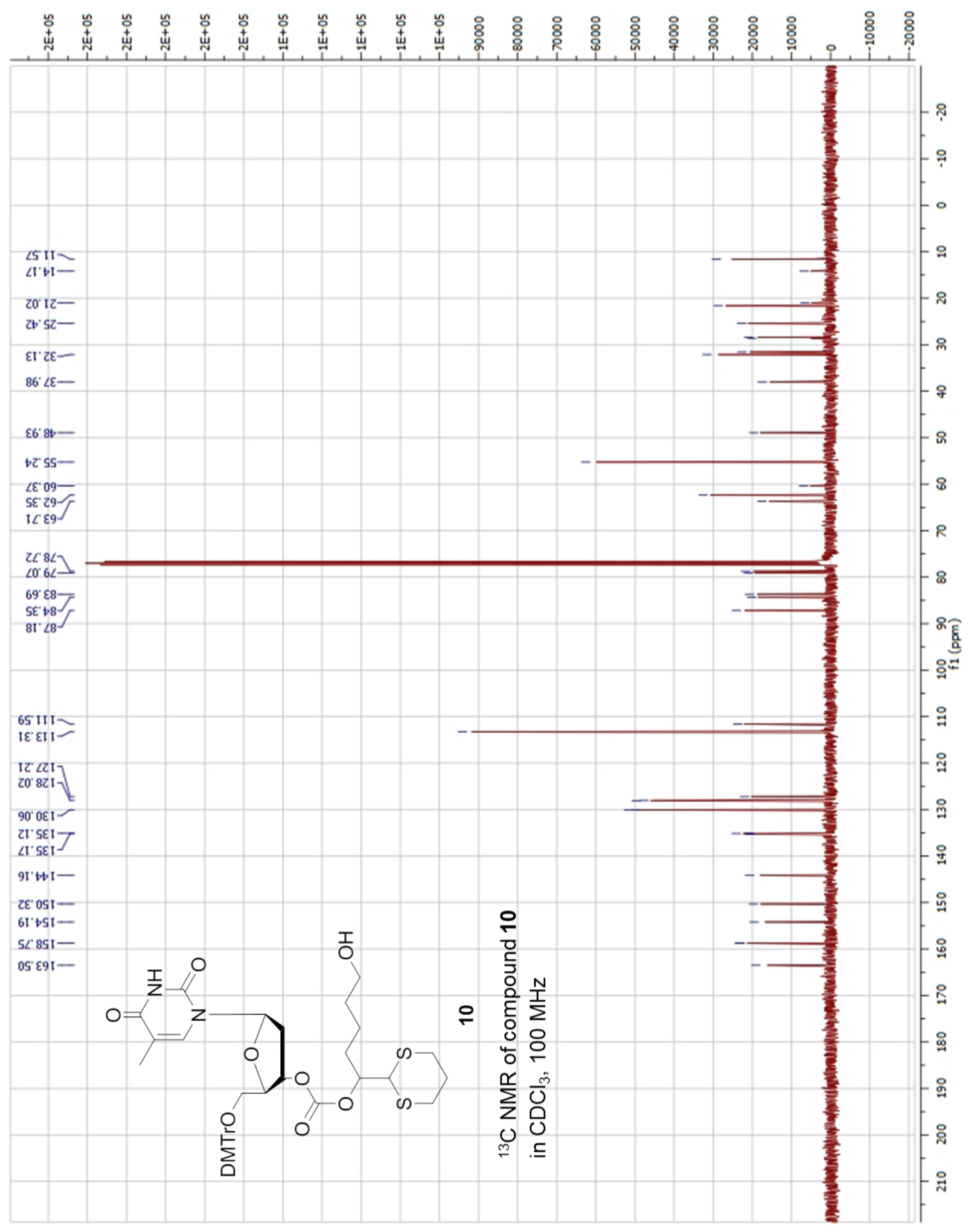




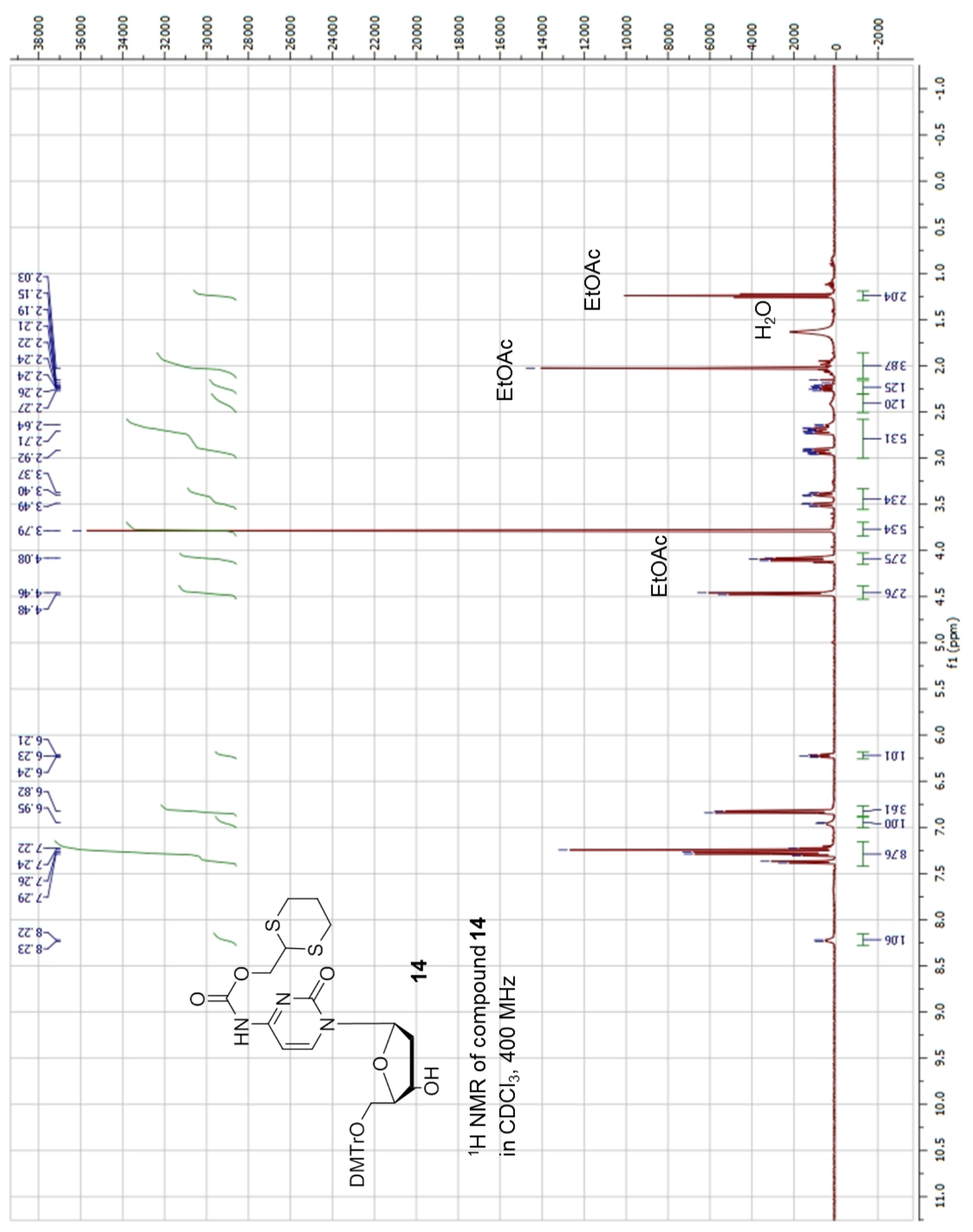




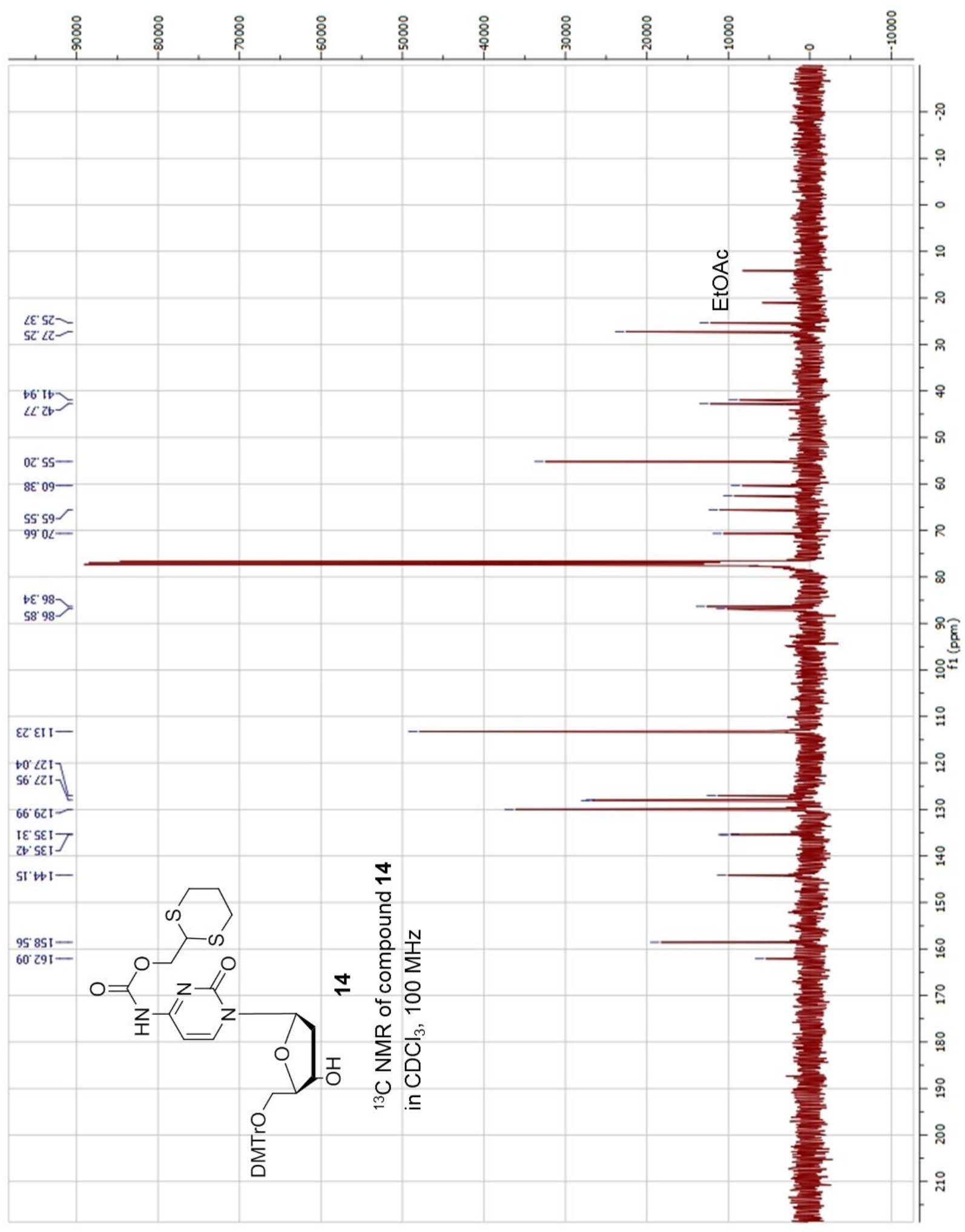




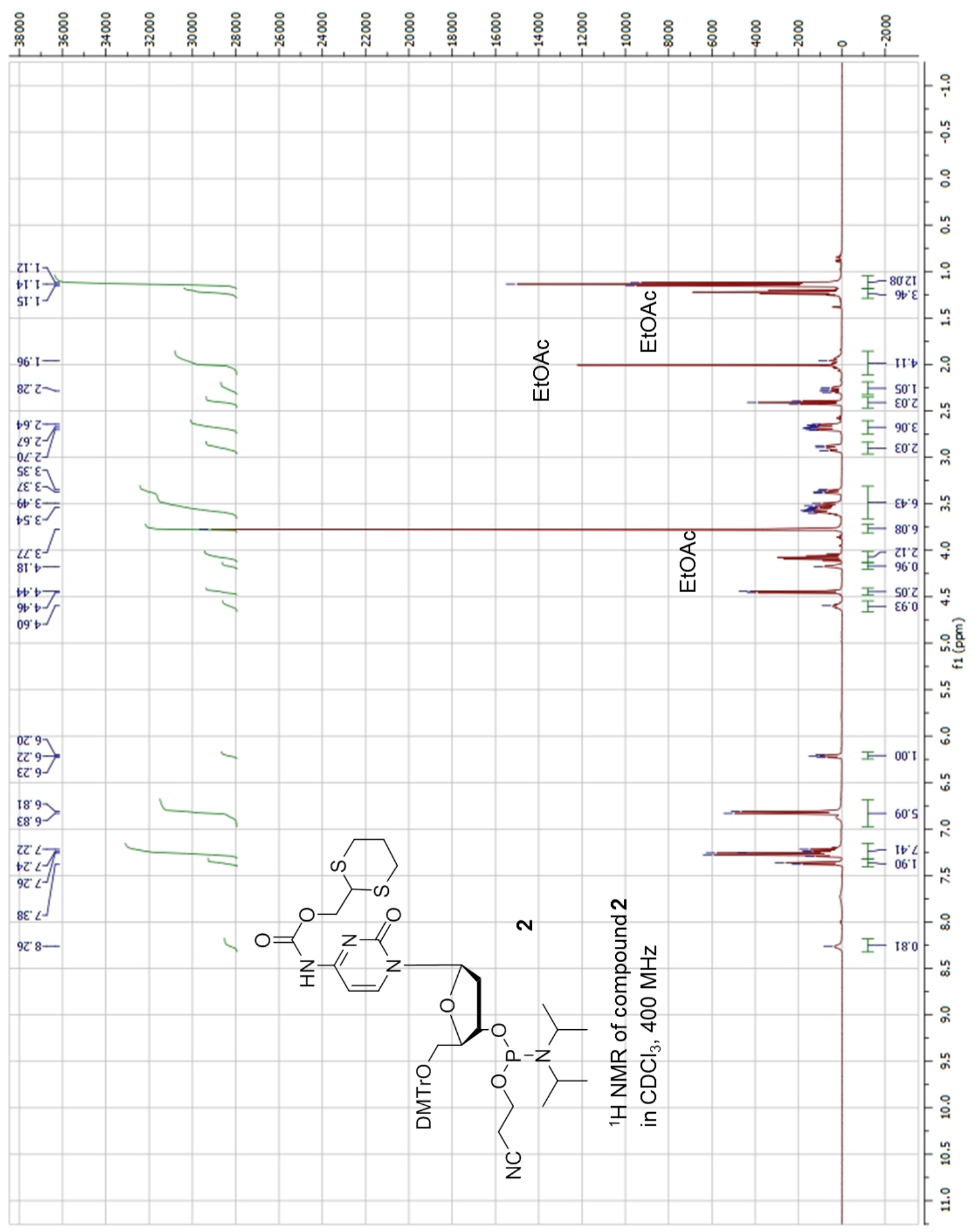




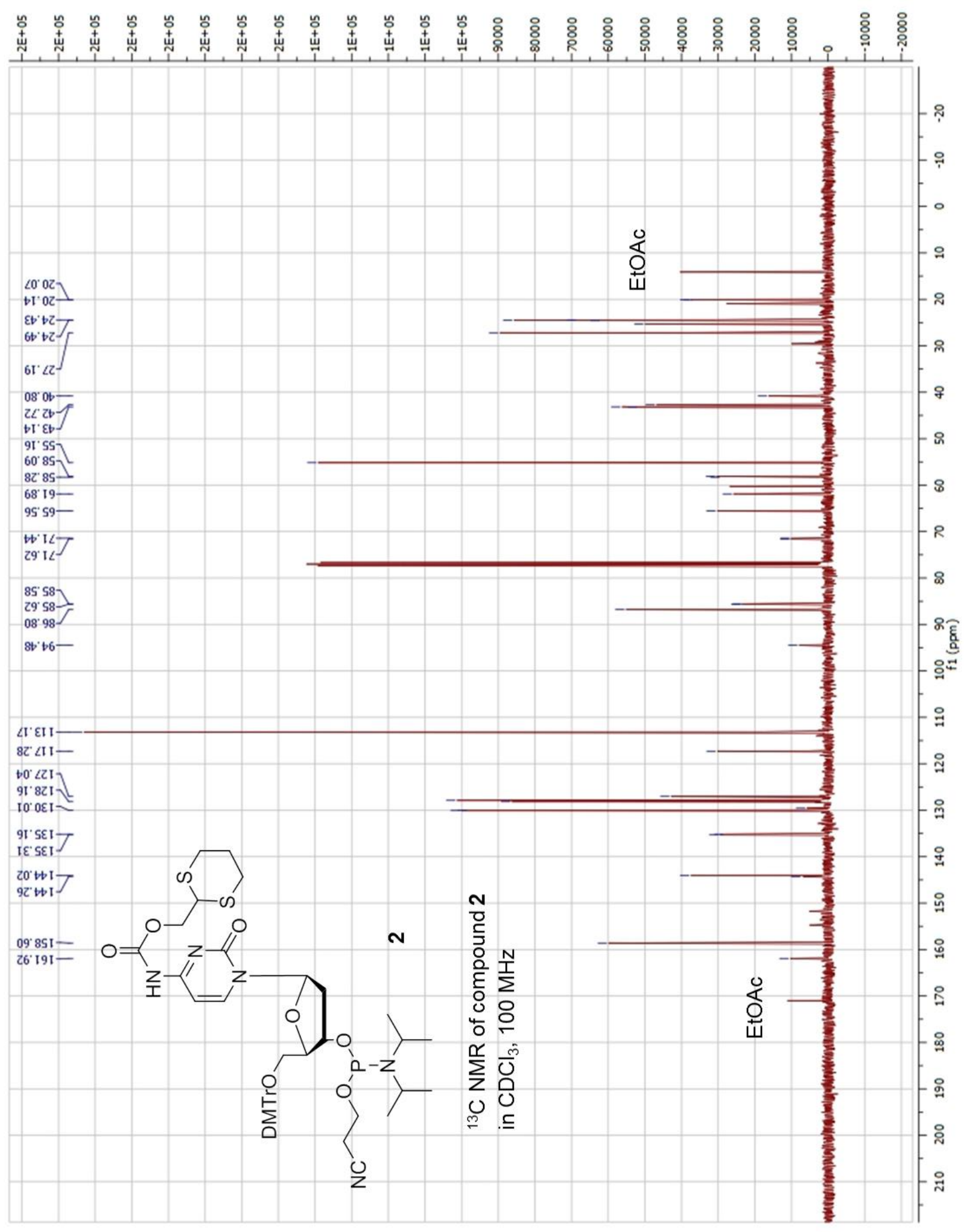




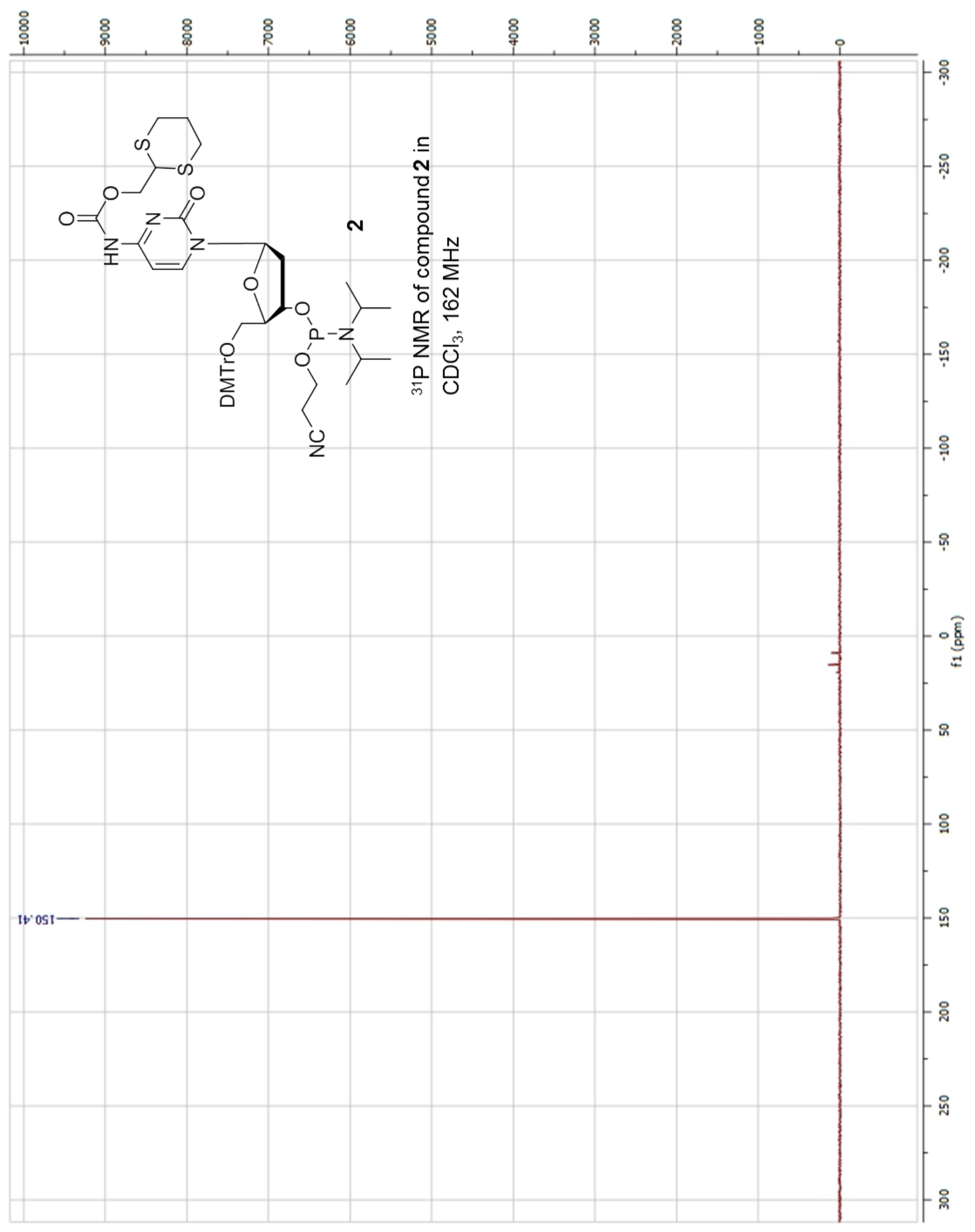




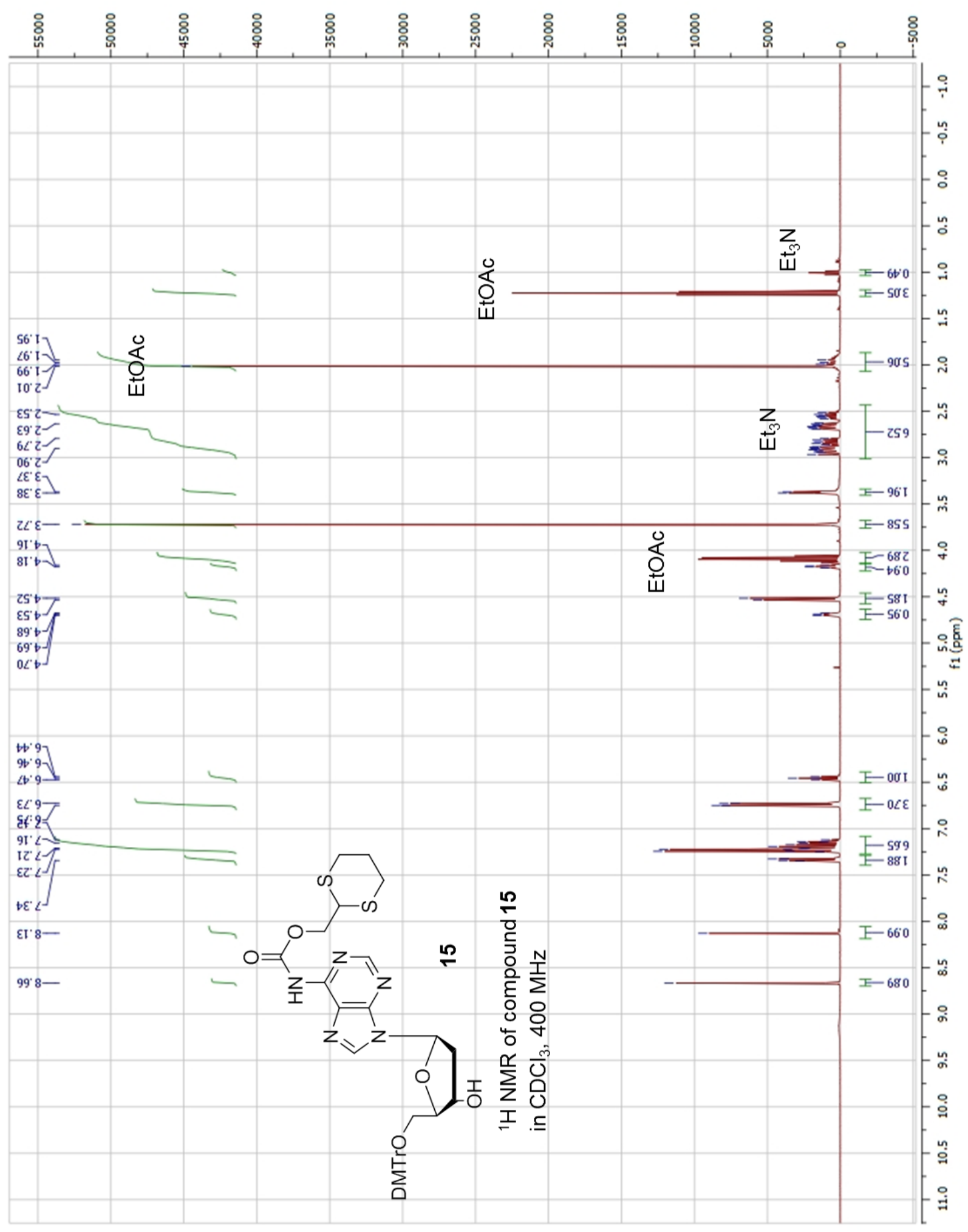




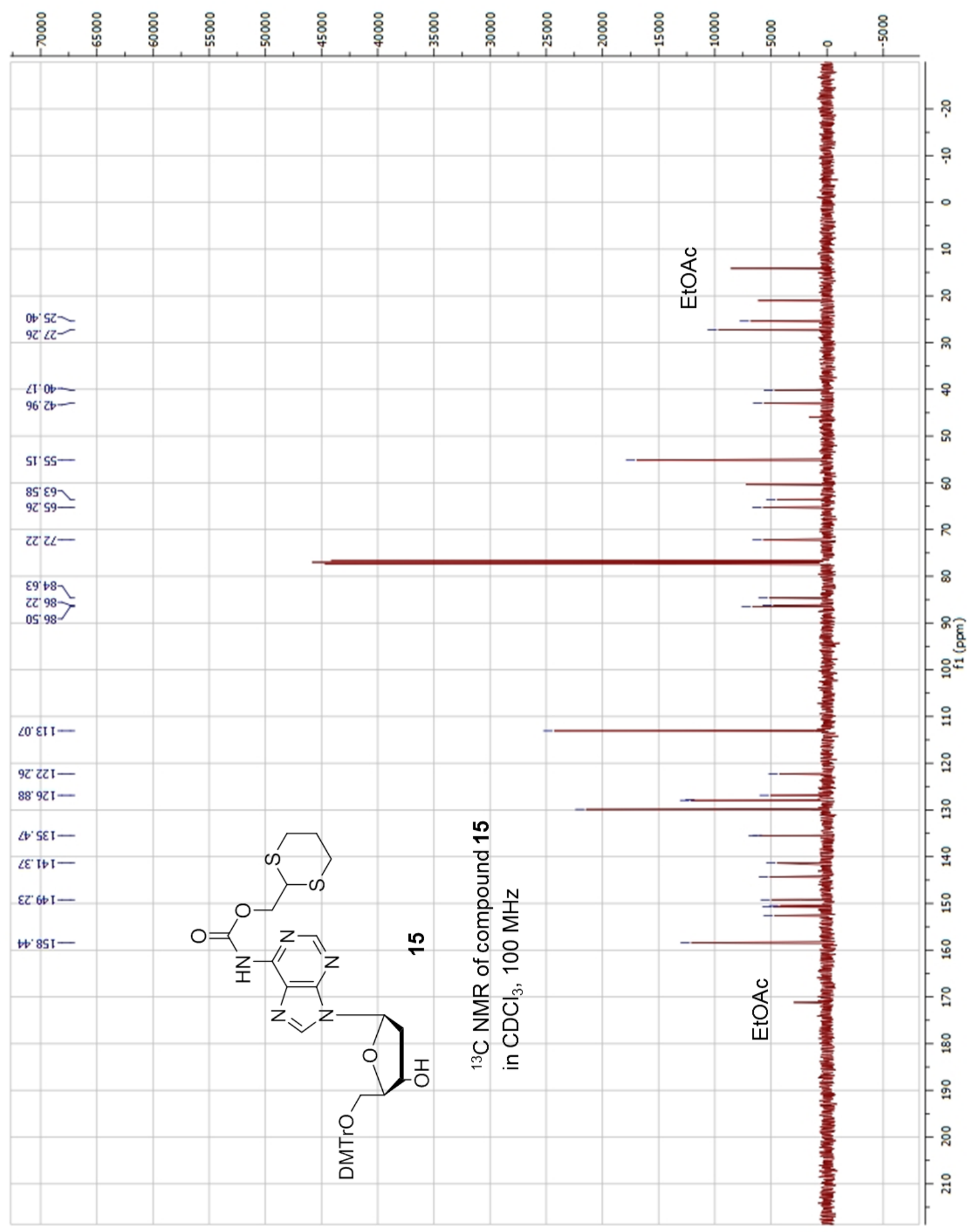




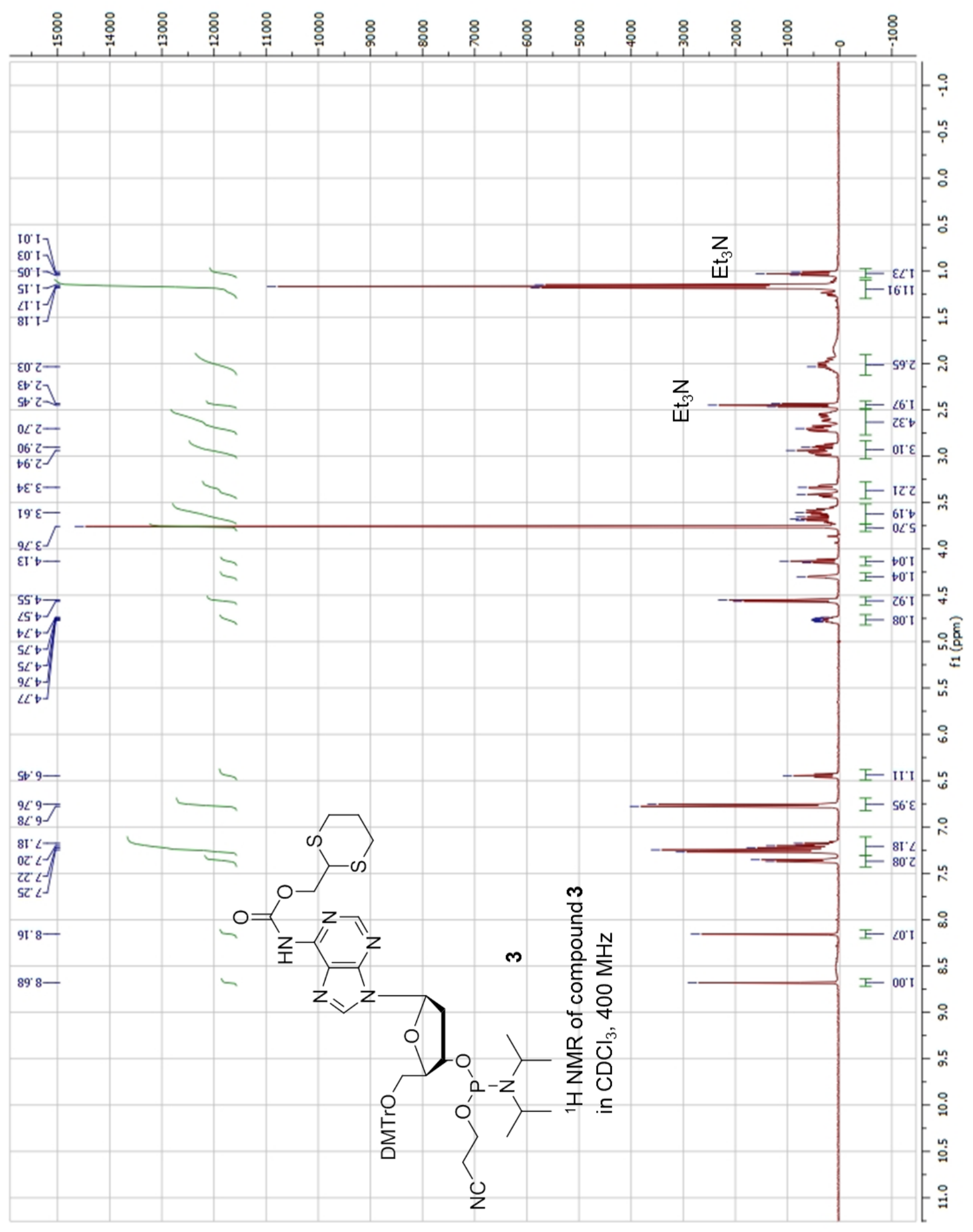




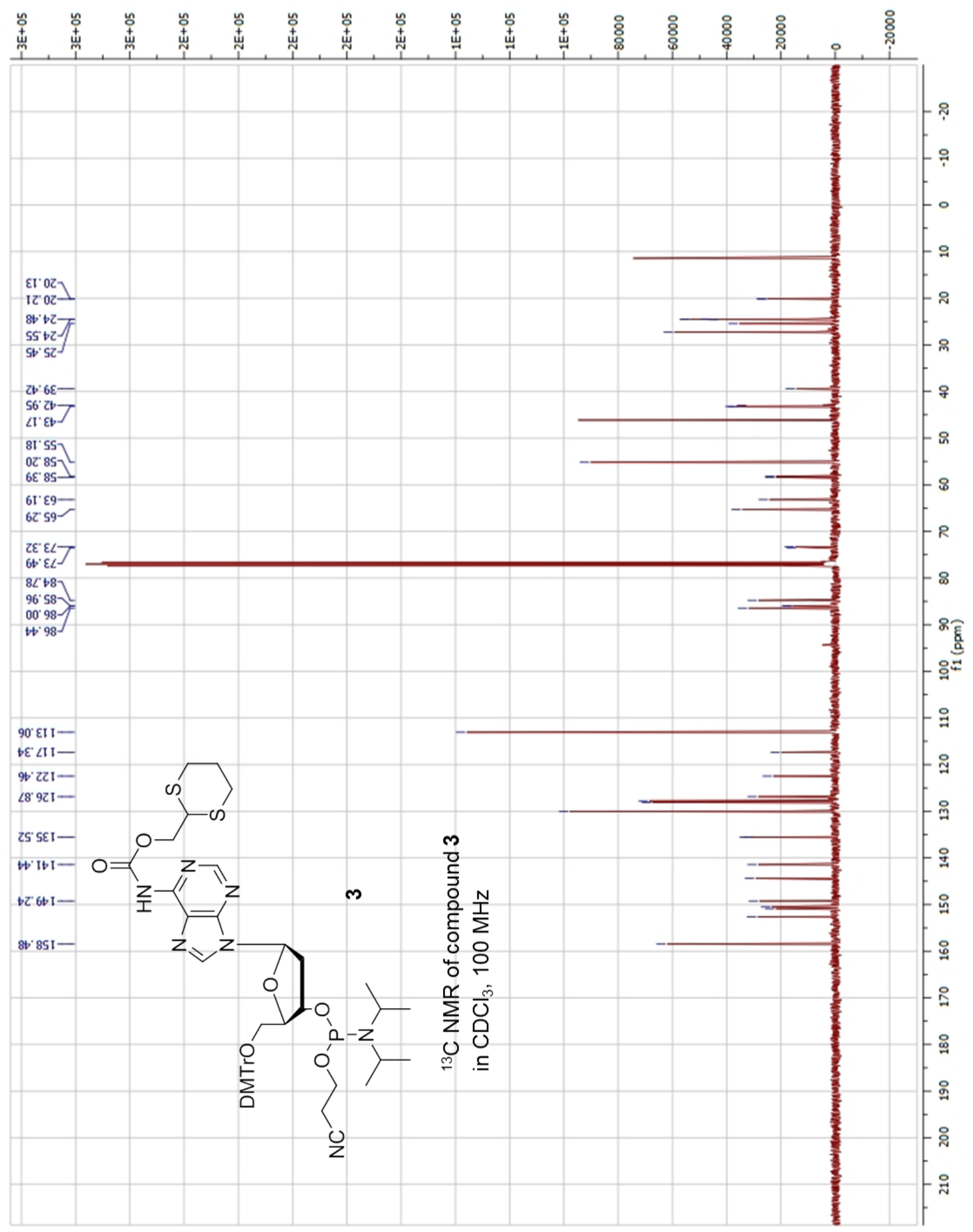




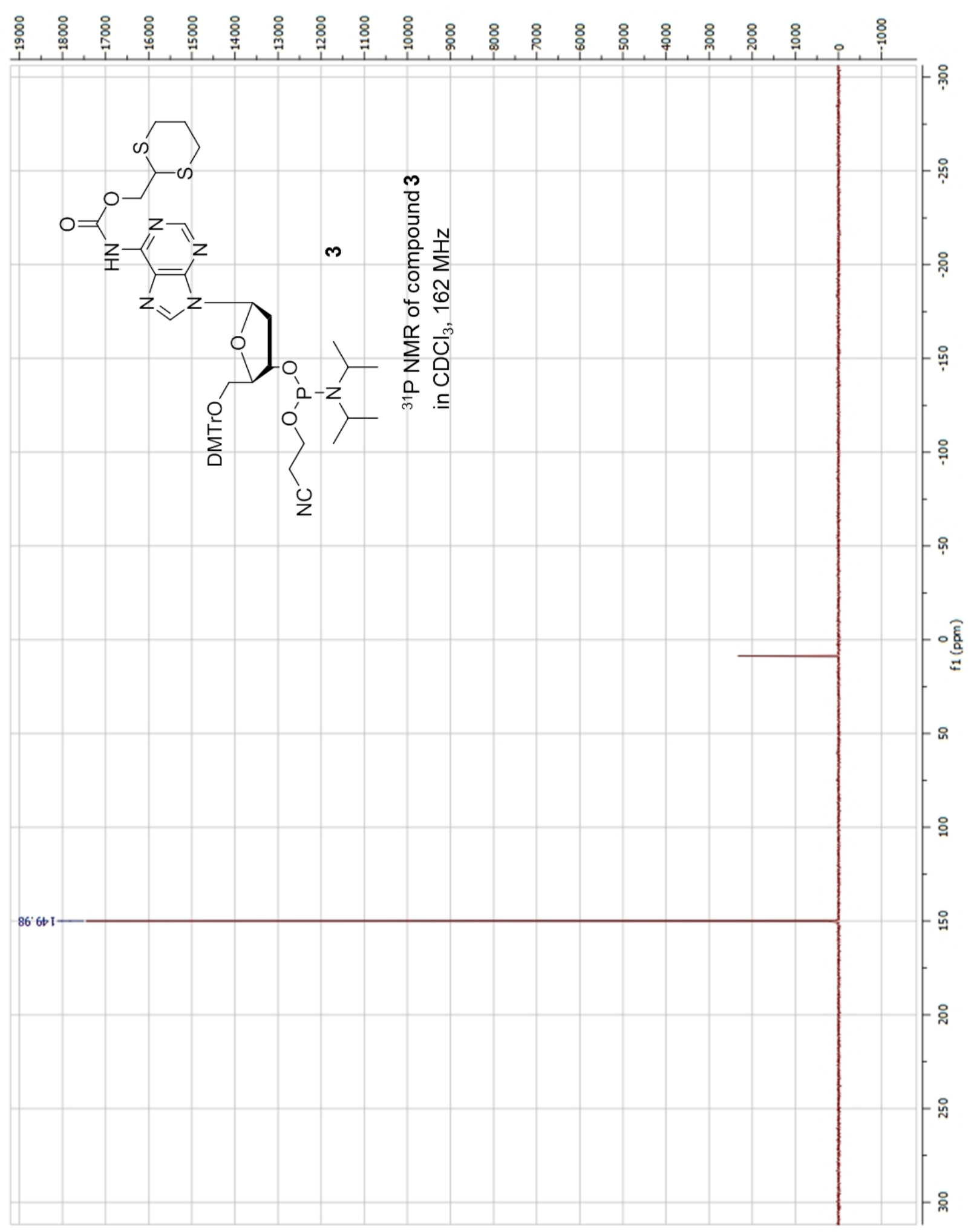




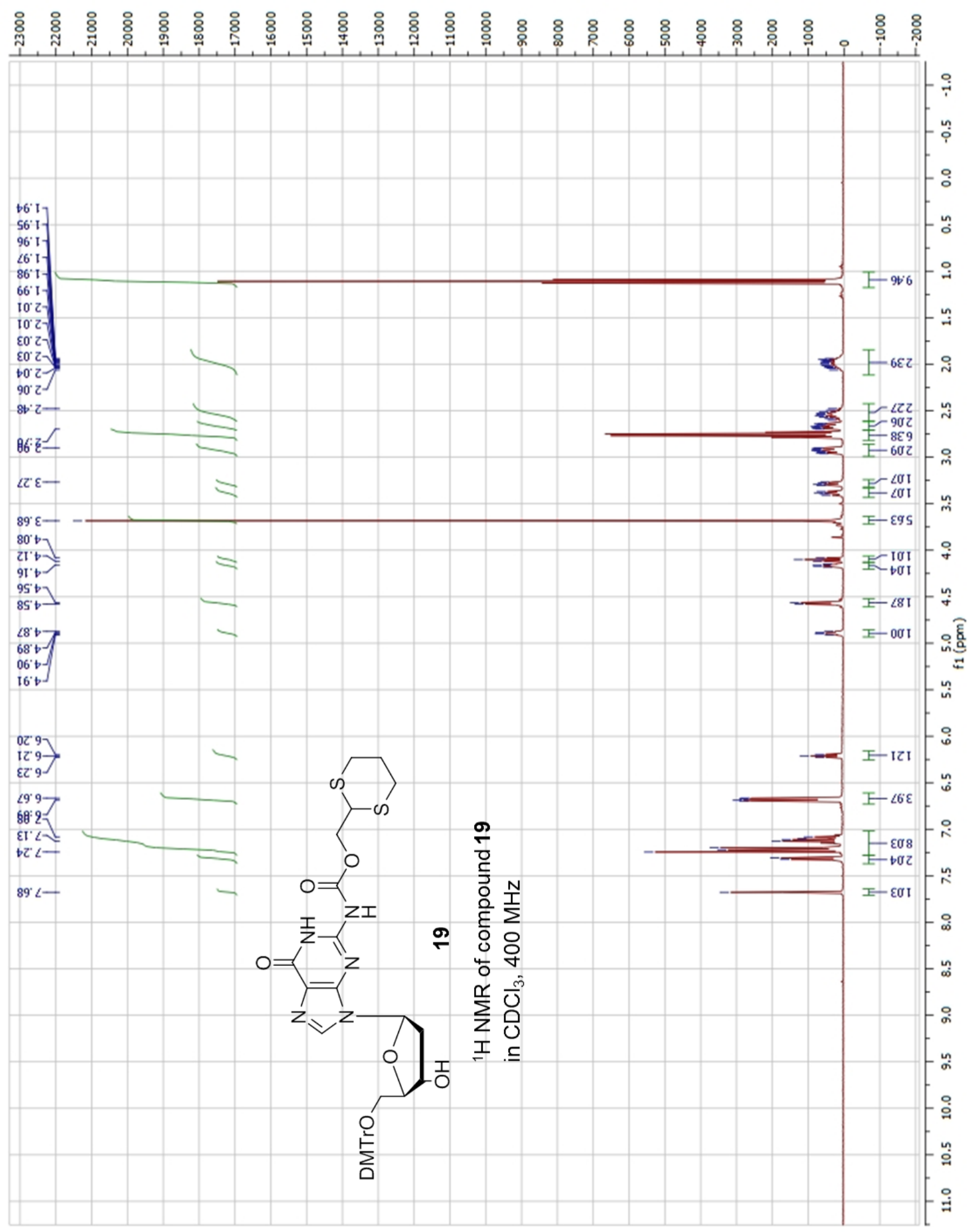




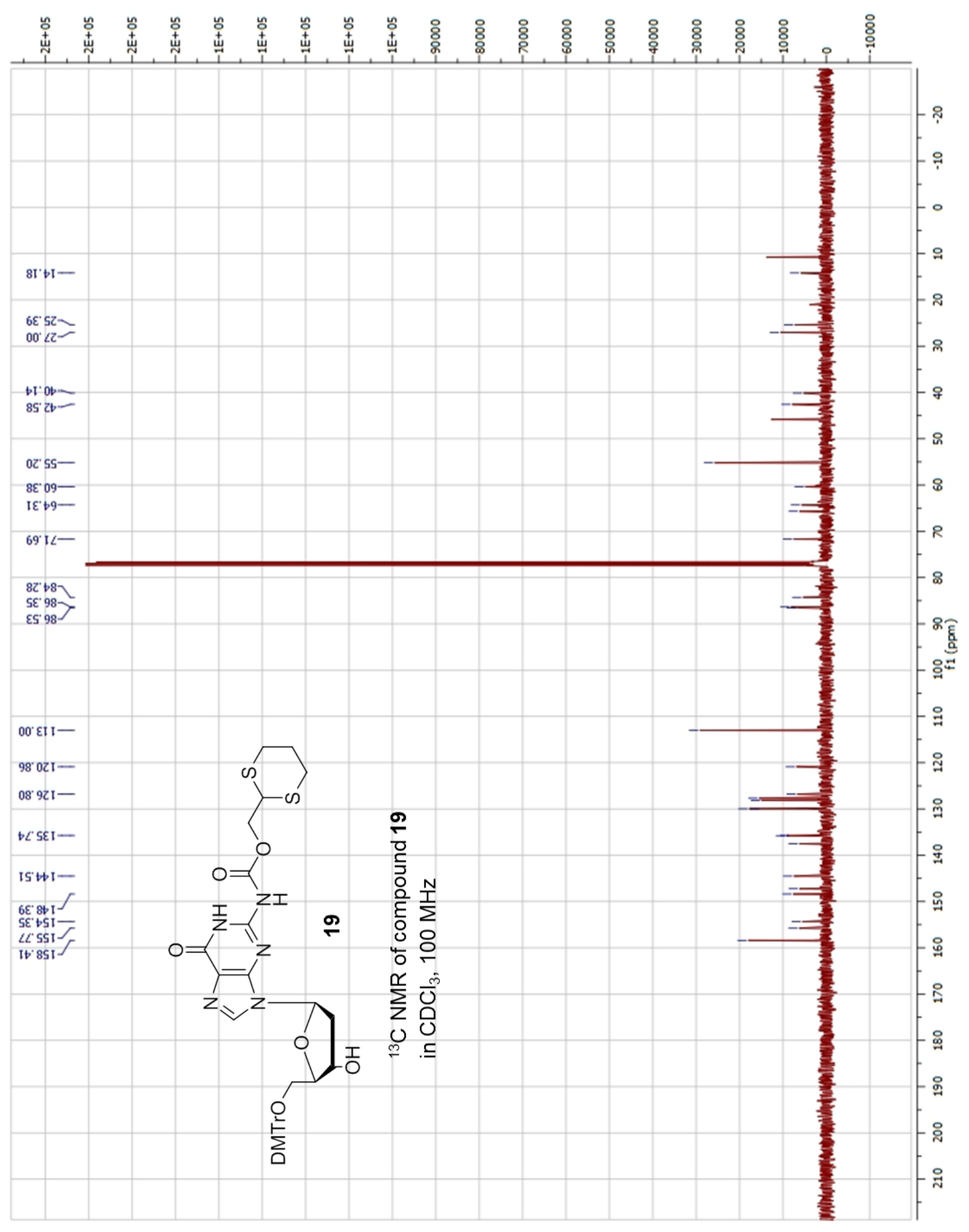




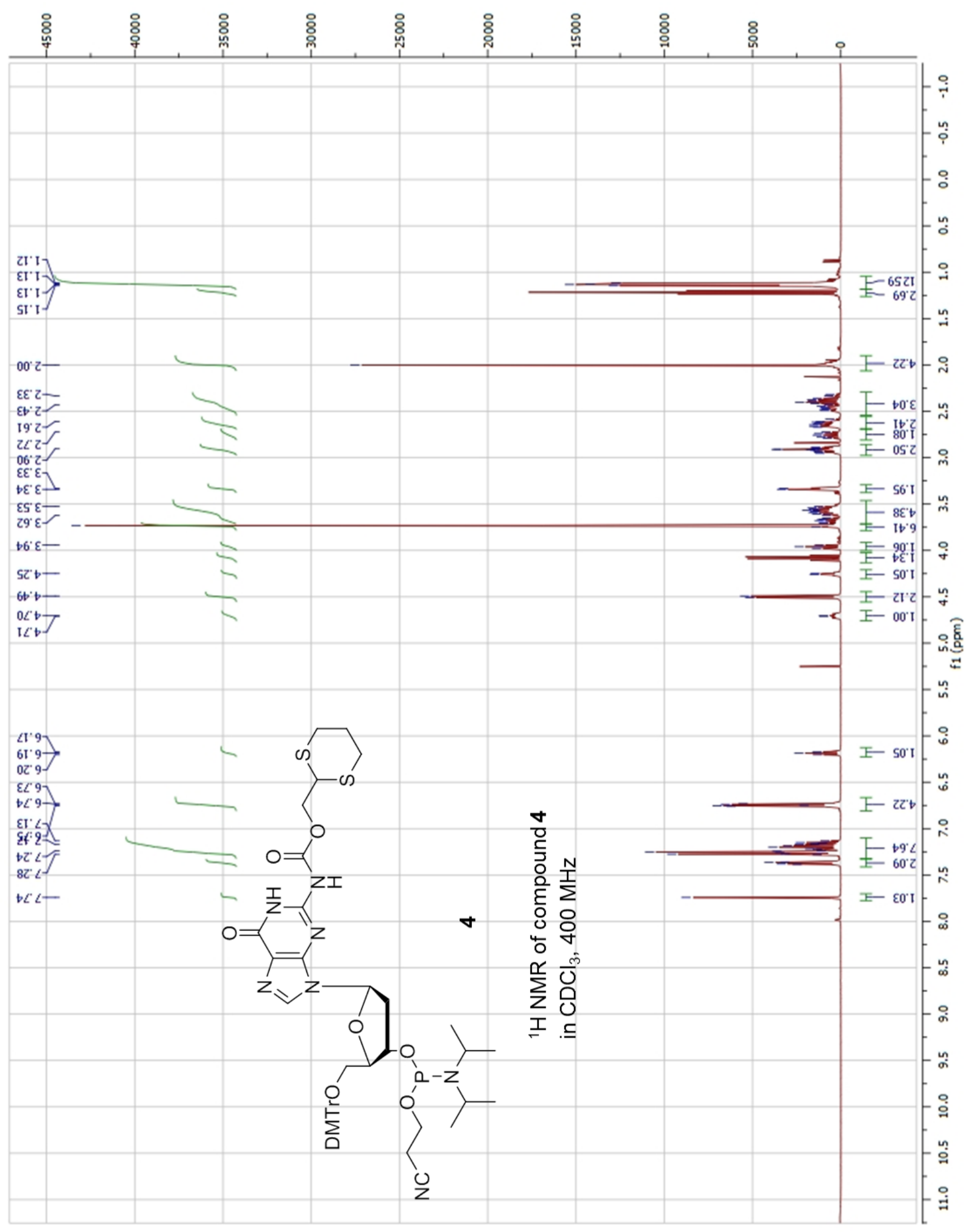




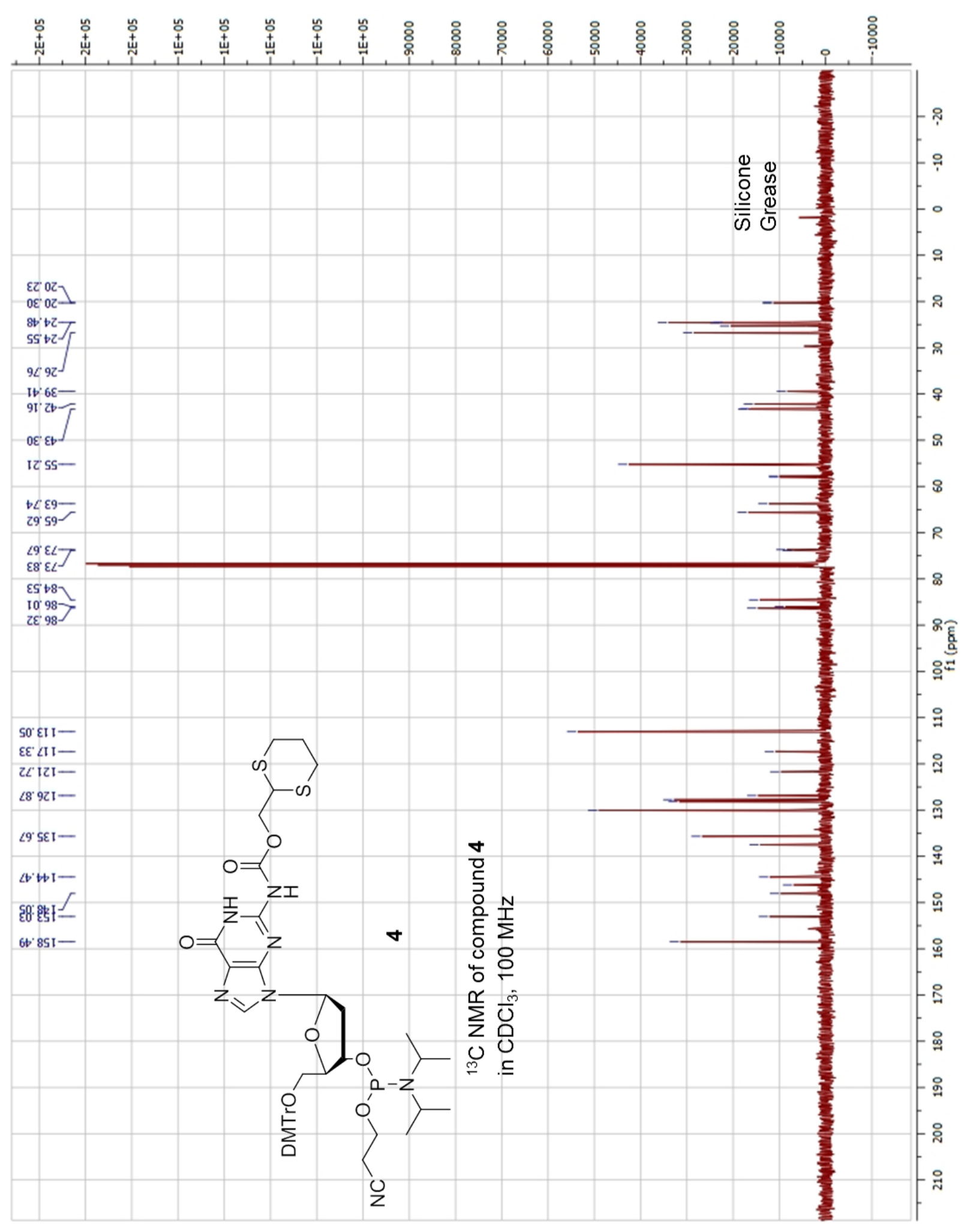




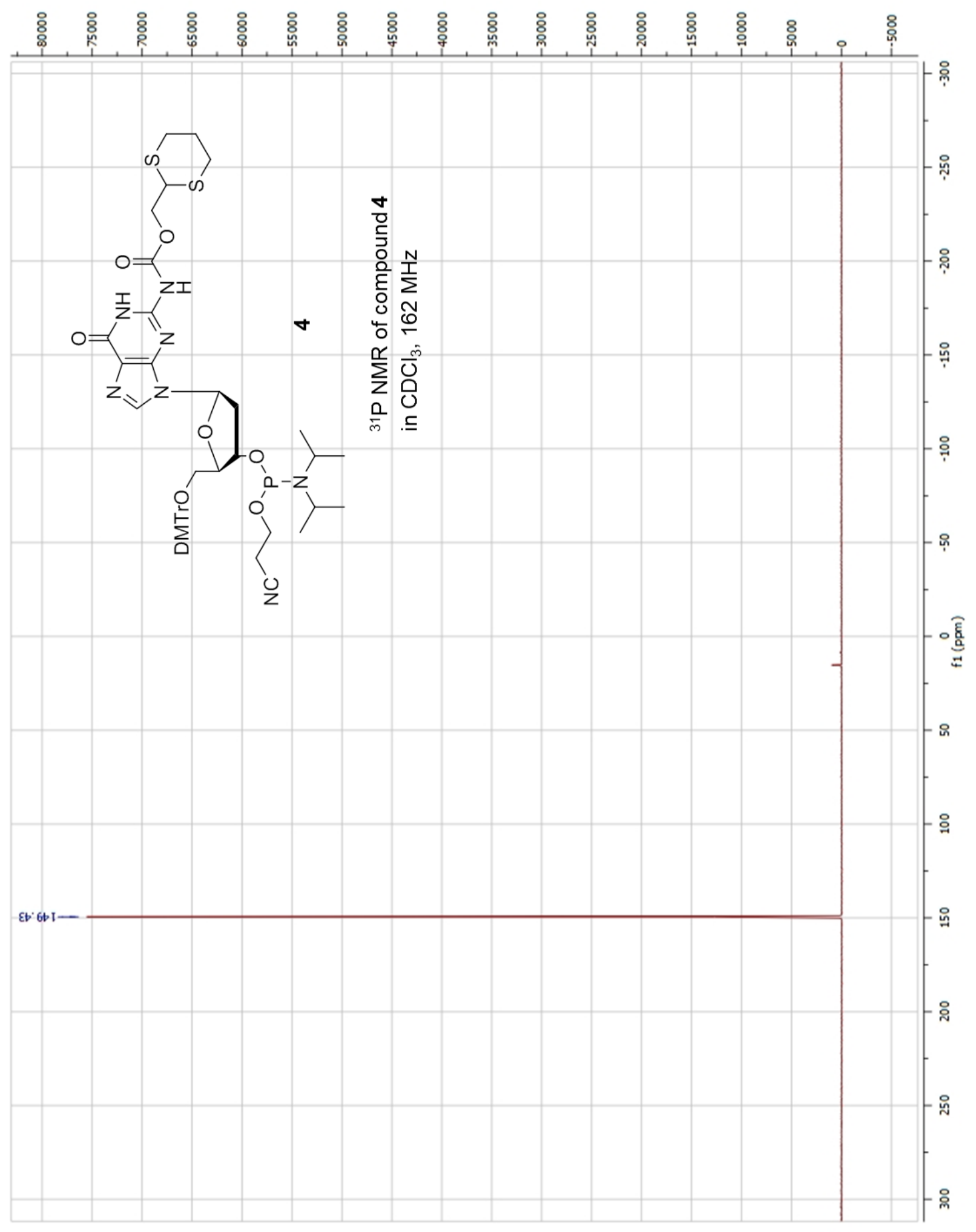




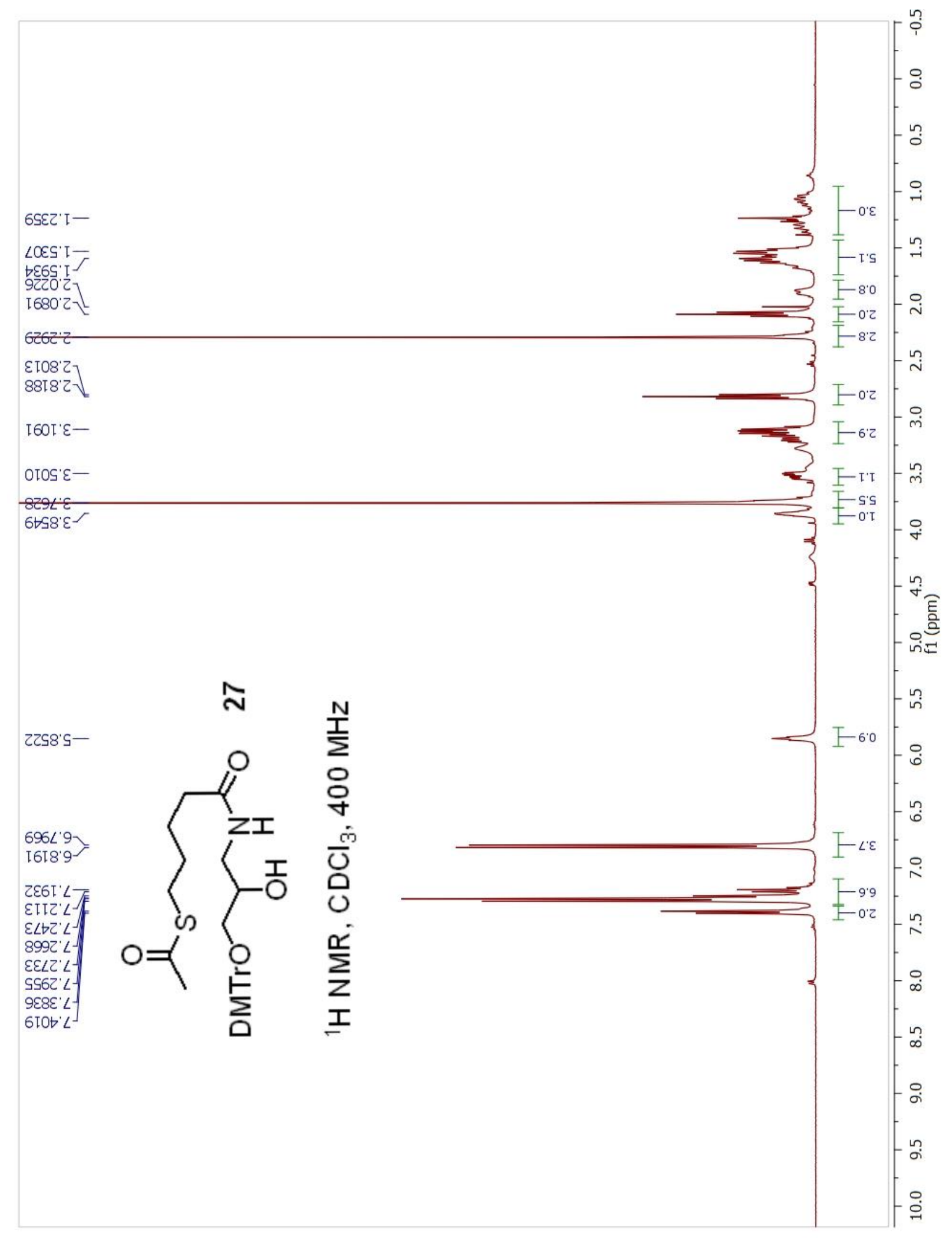




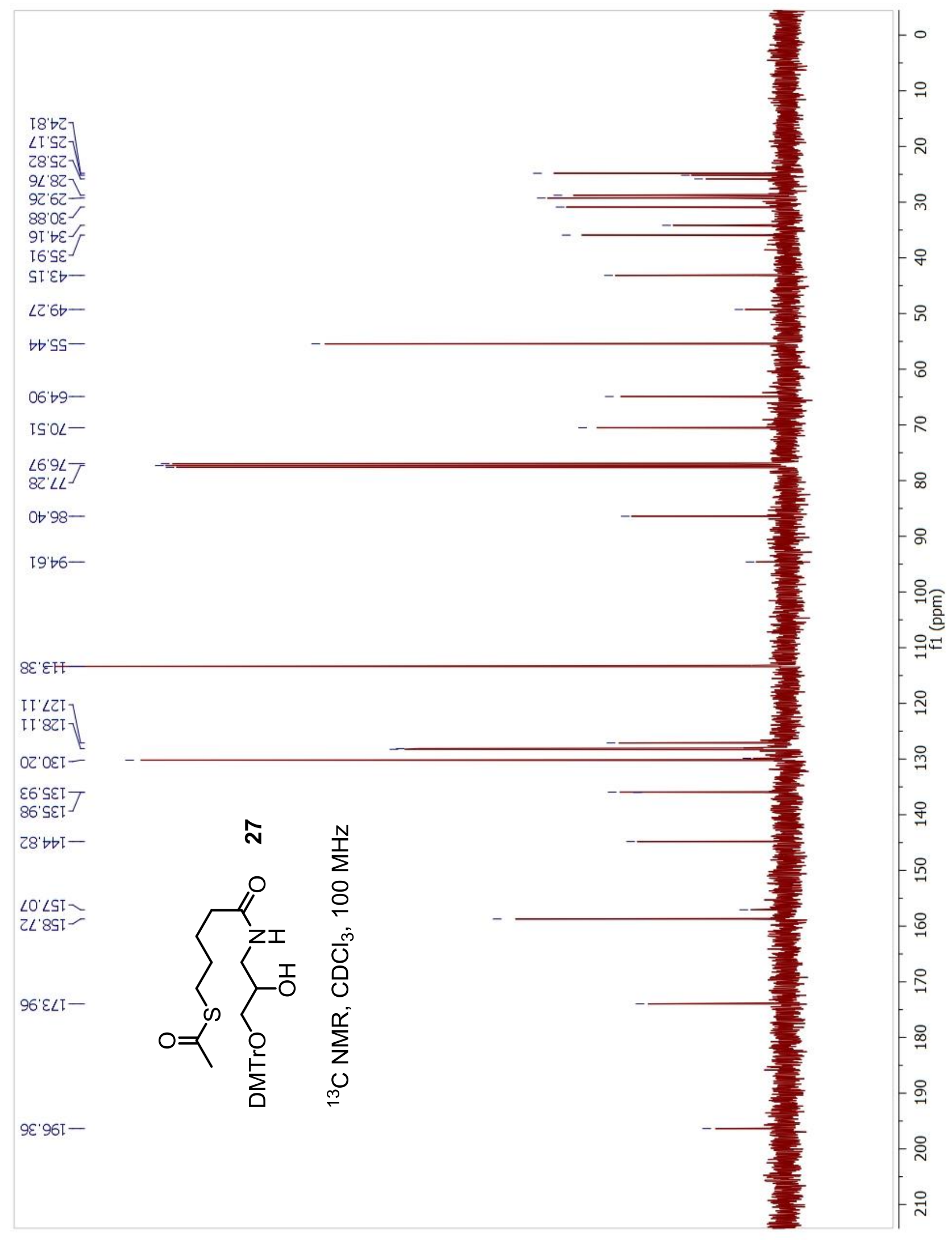




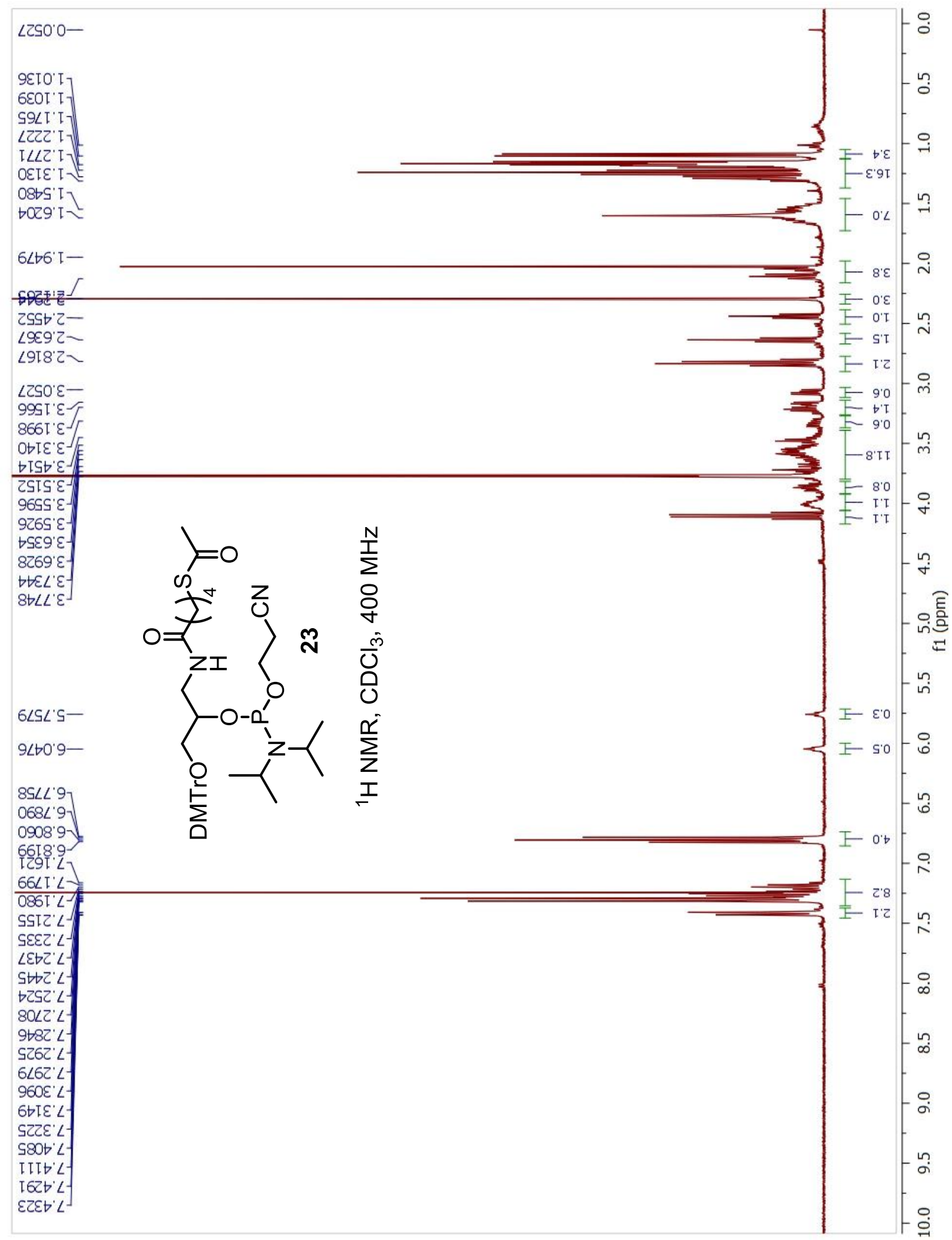




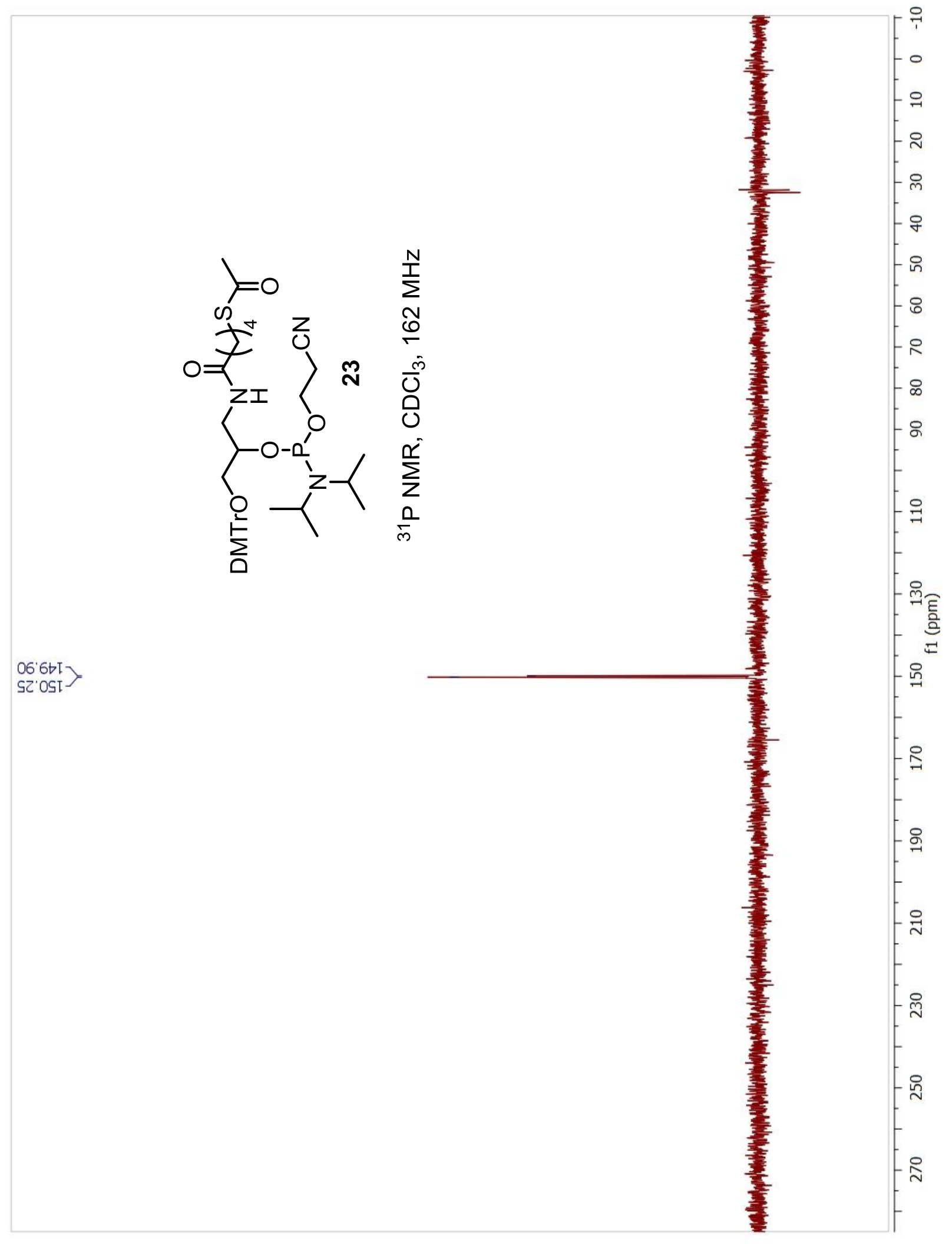




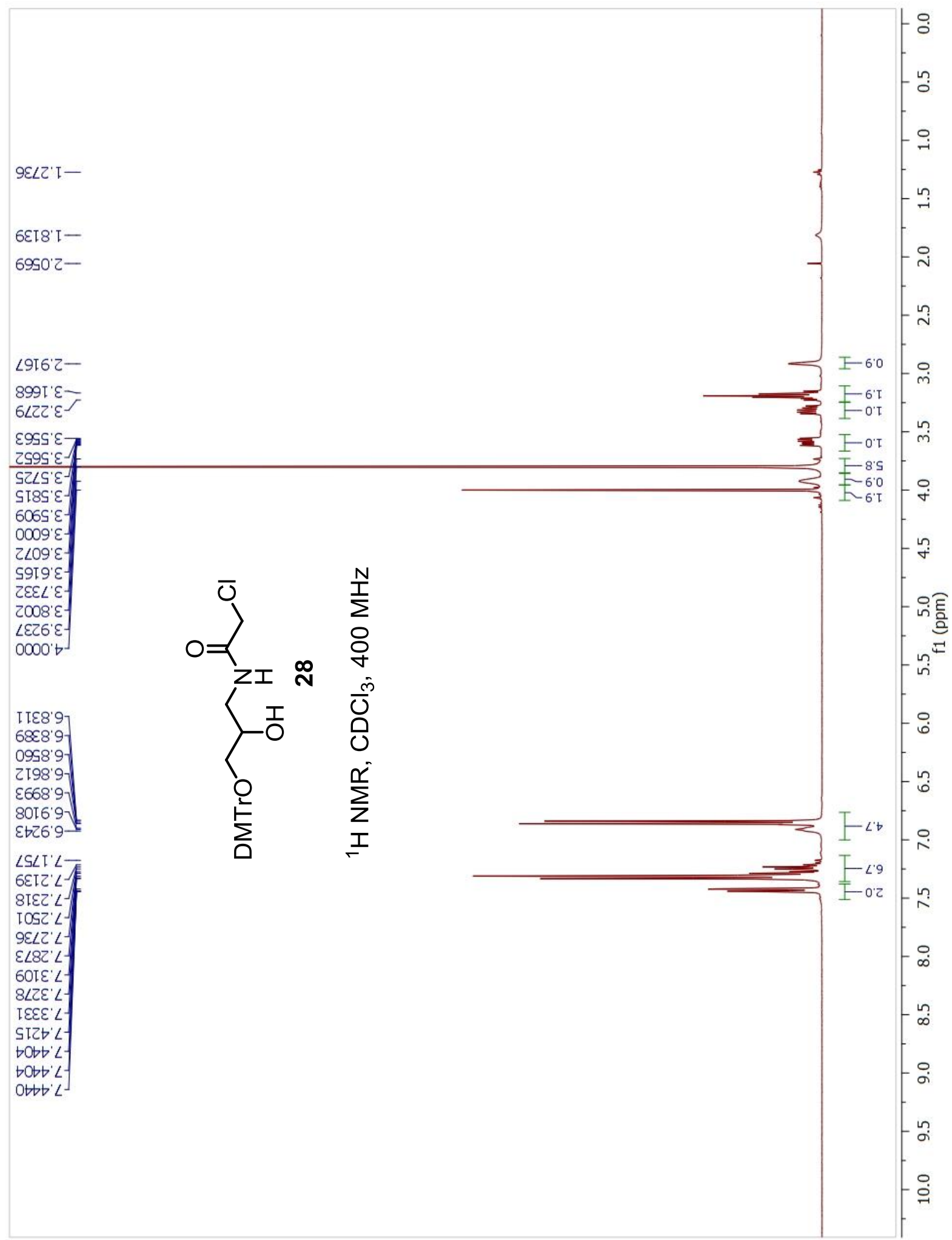




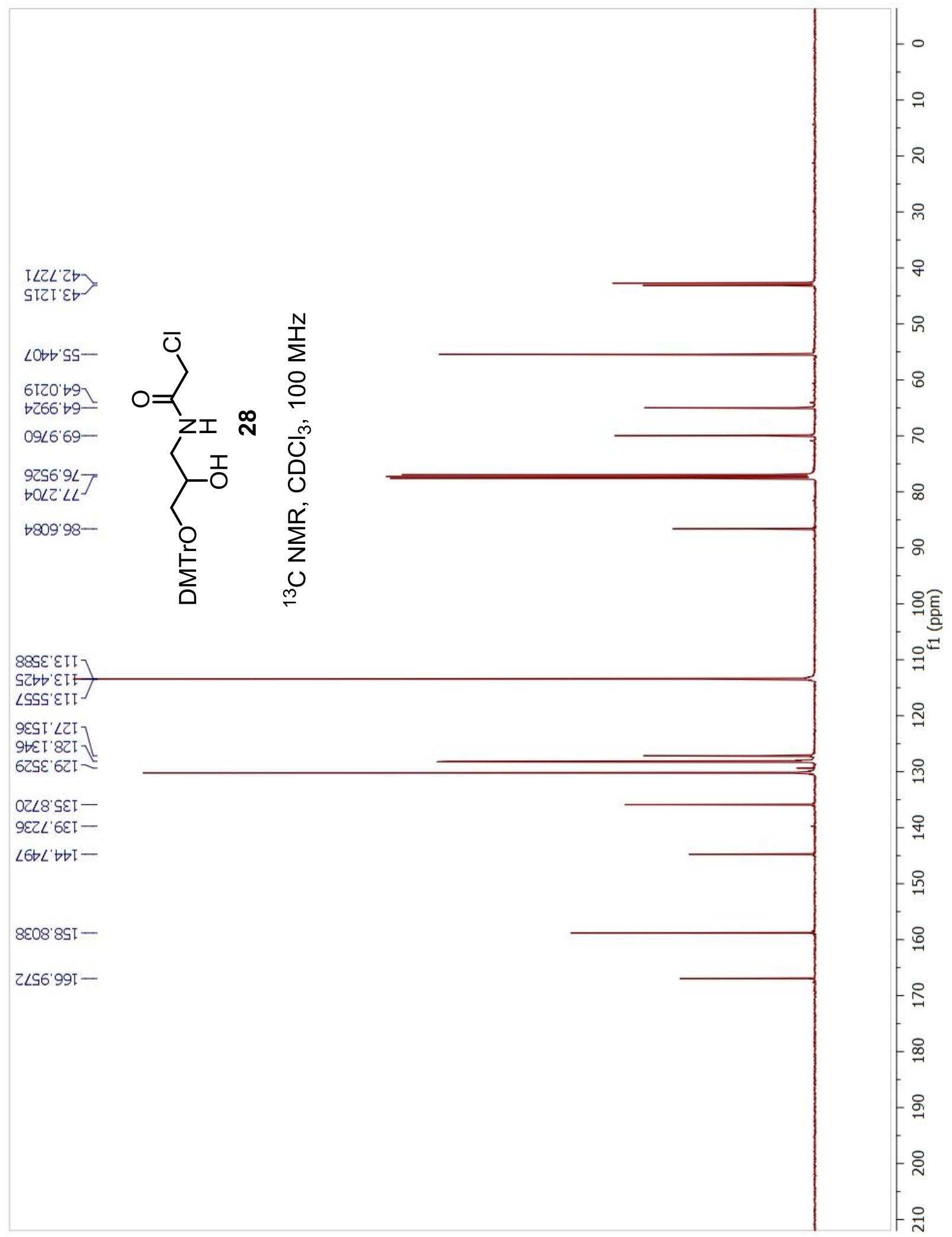




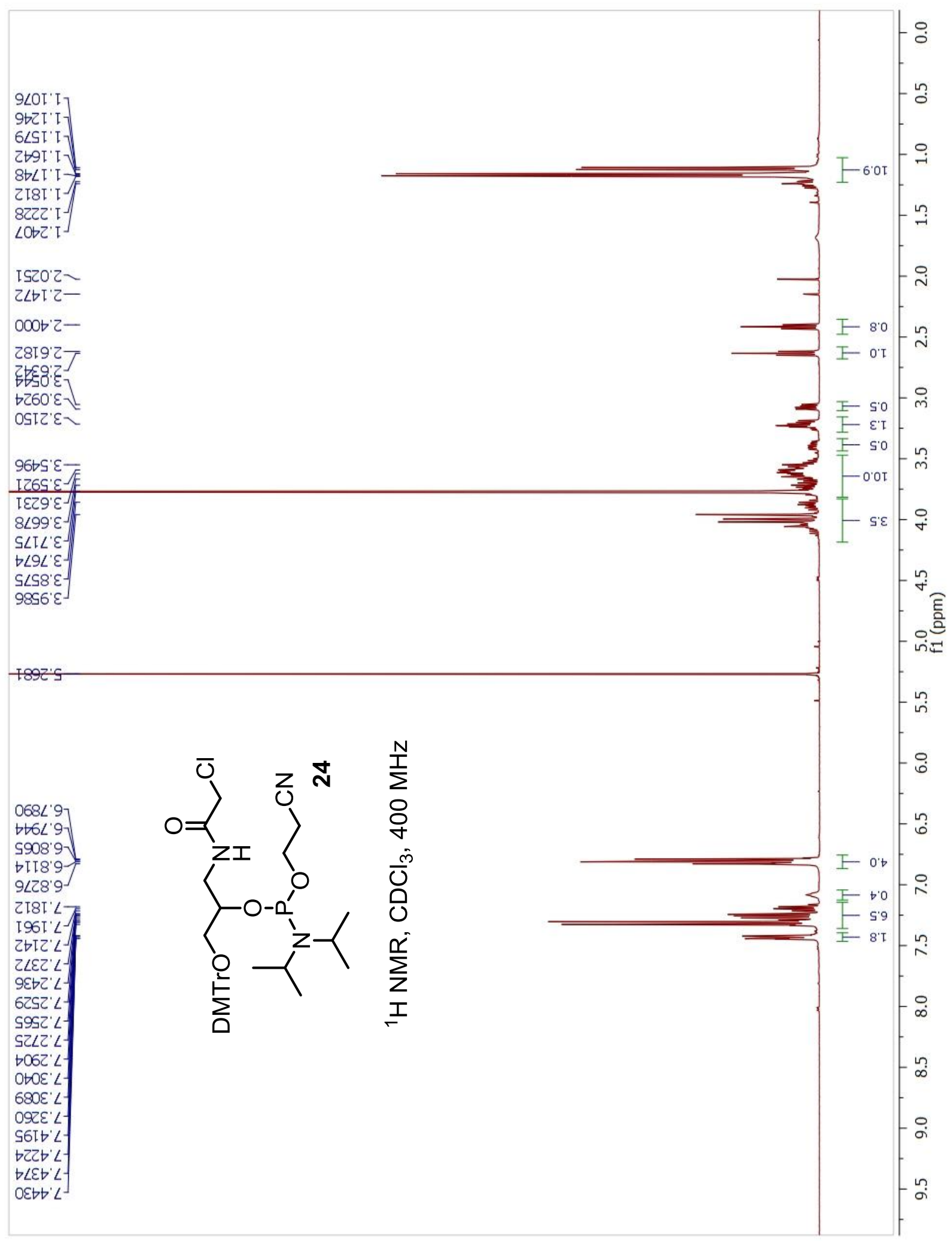




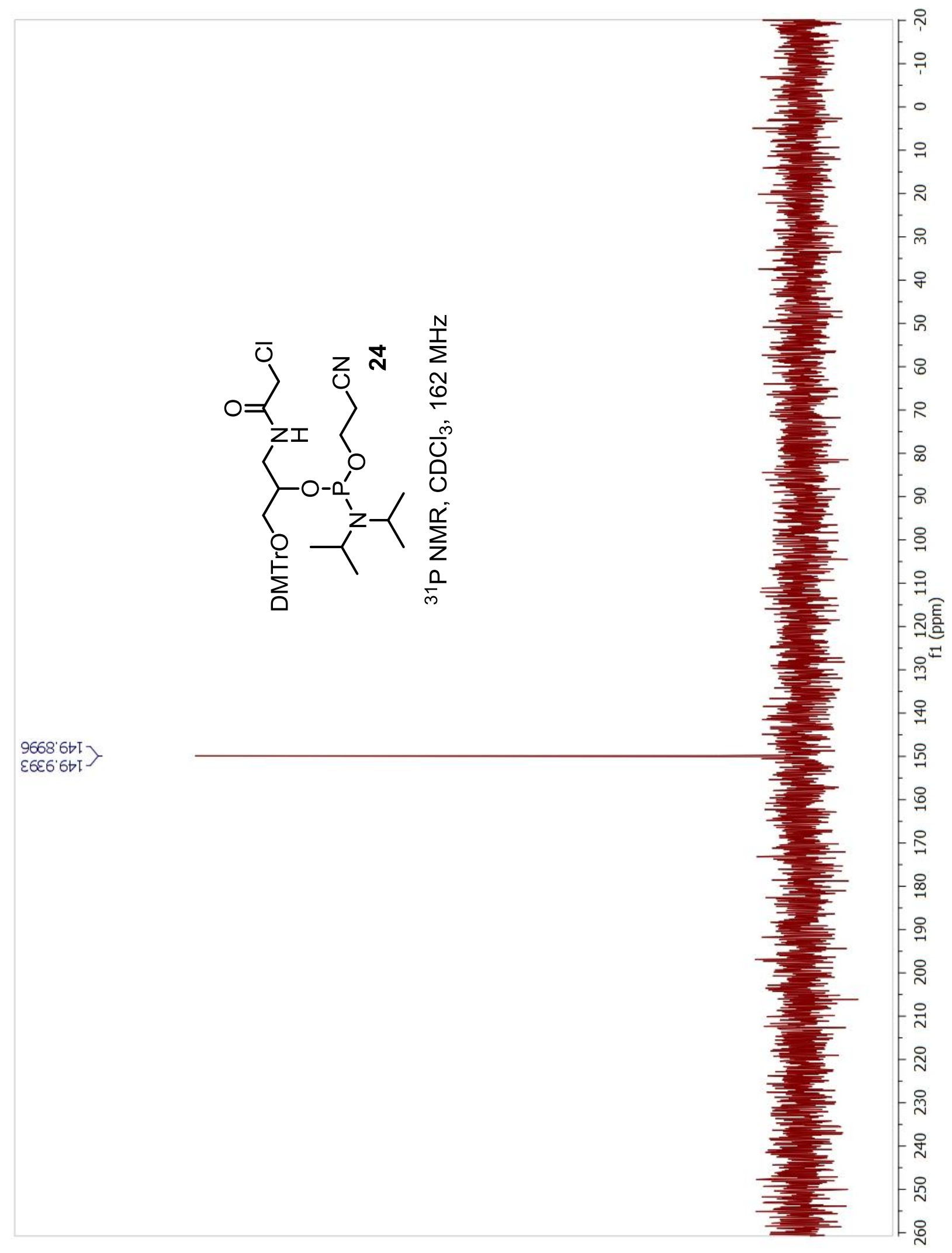




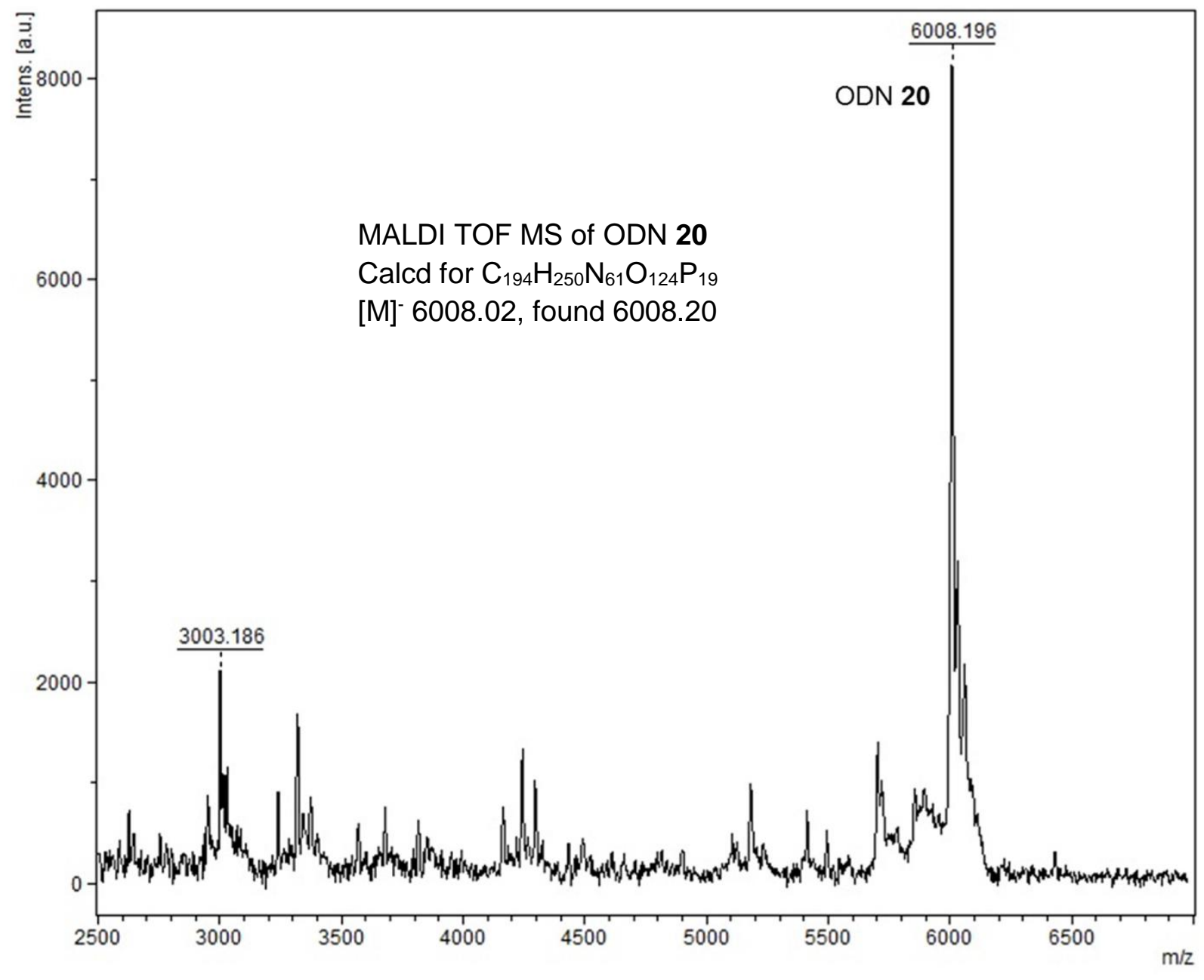




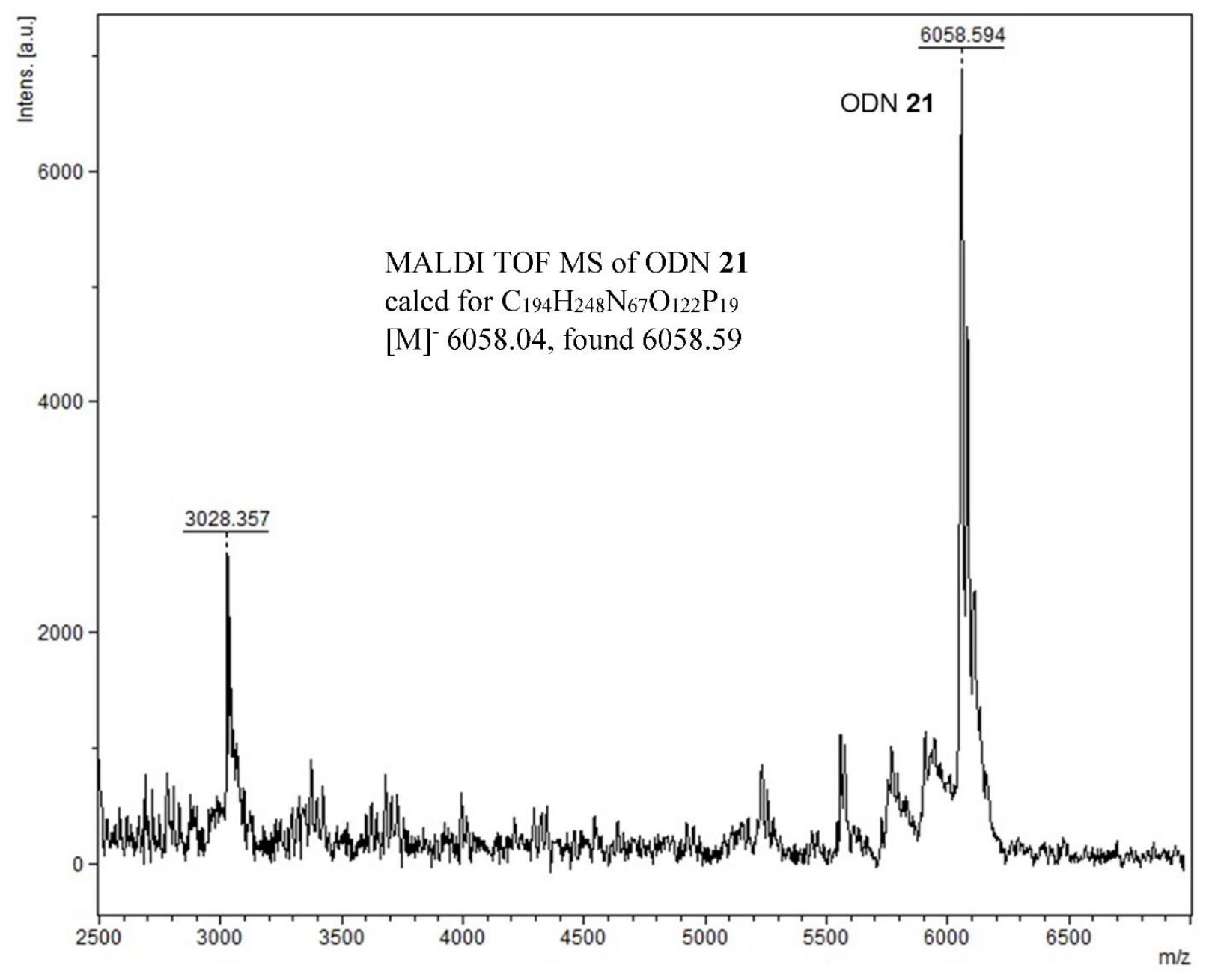




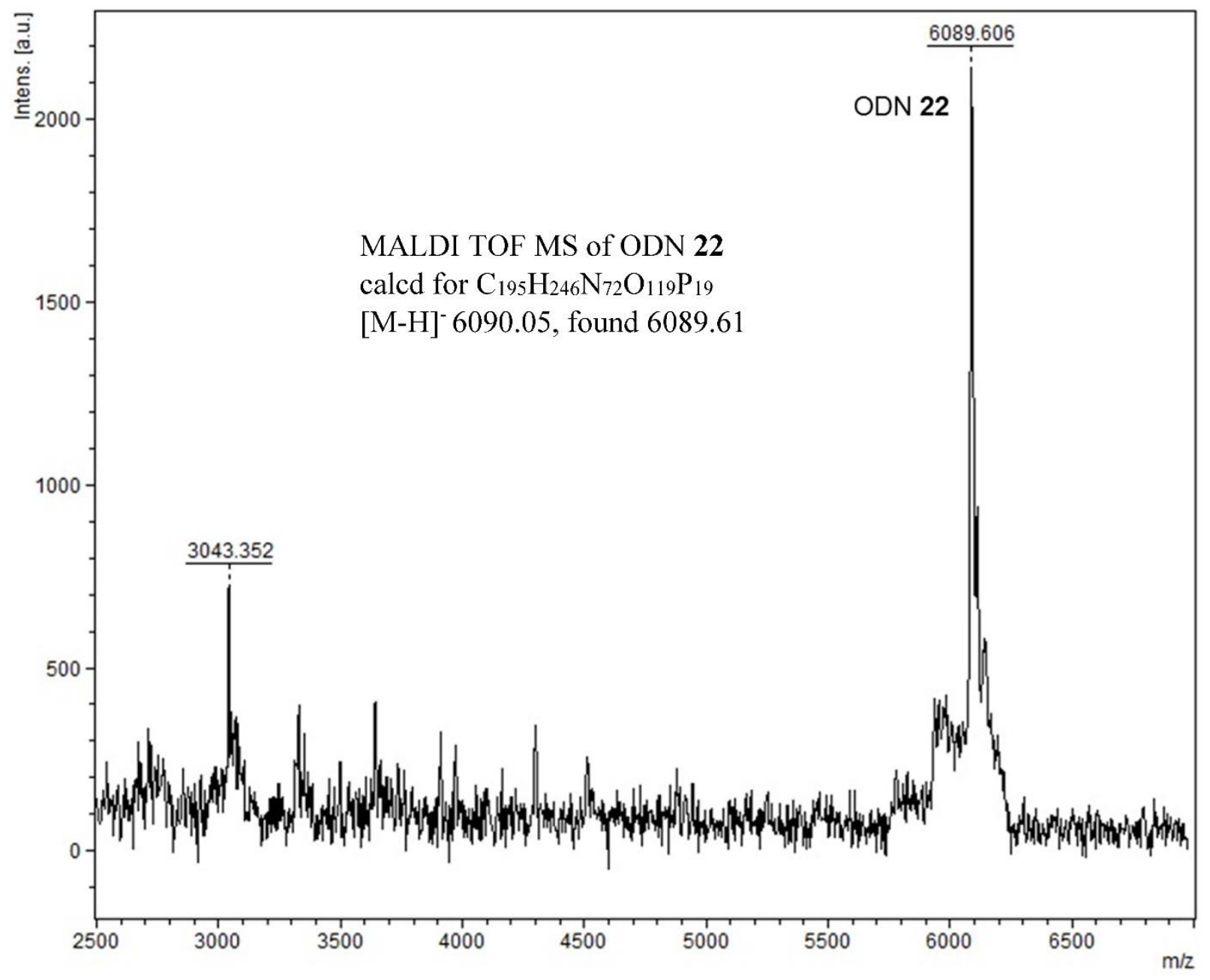




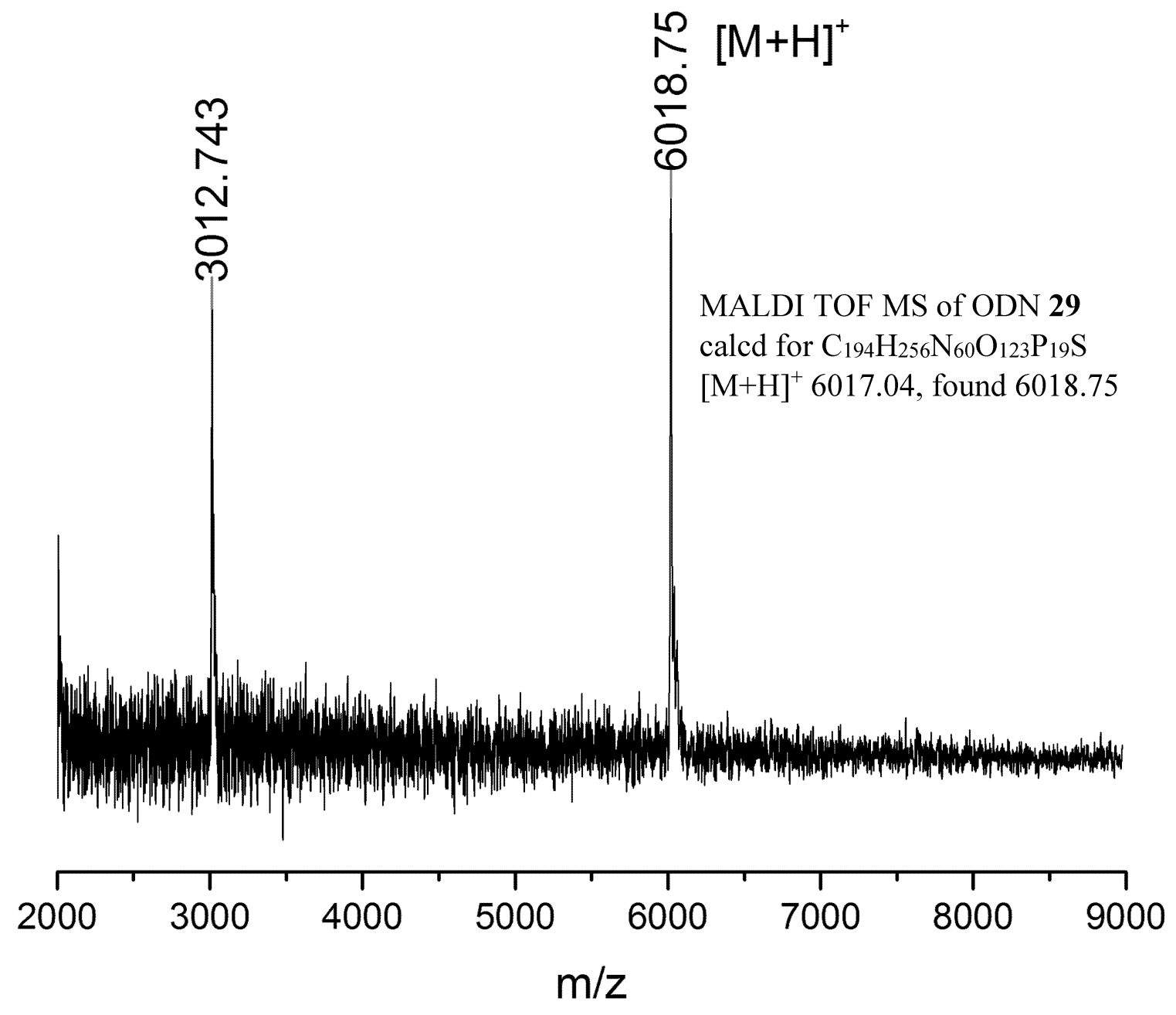




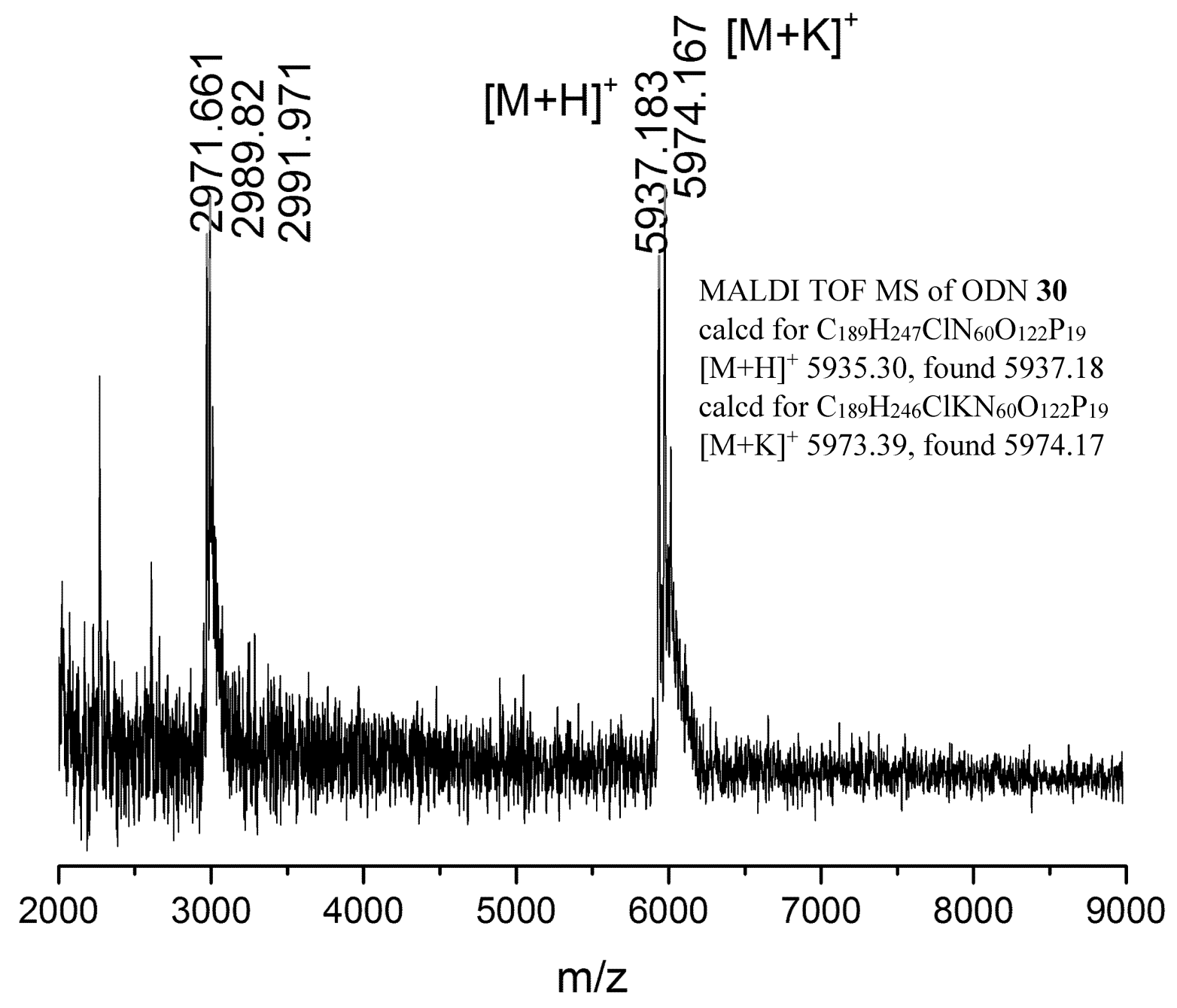


RP HPLC profile of crude ODN 21

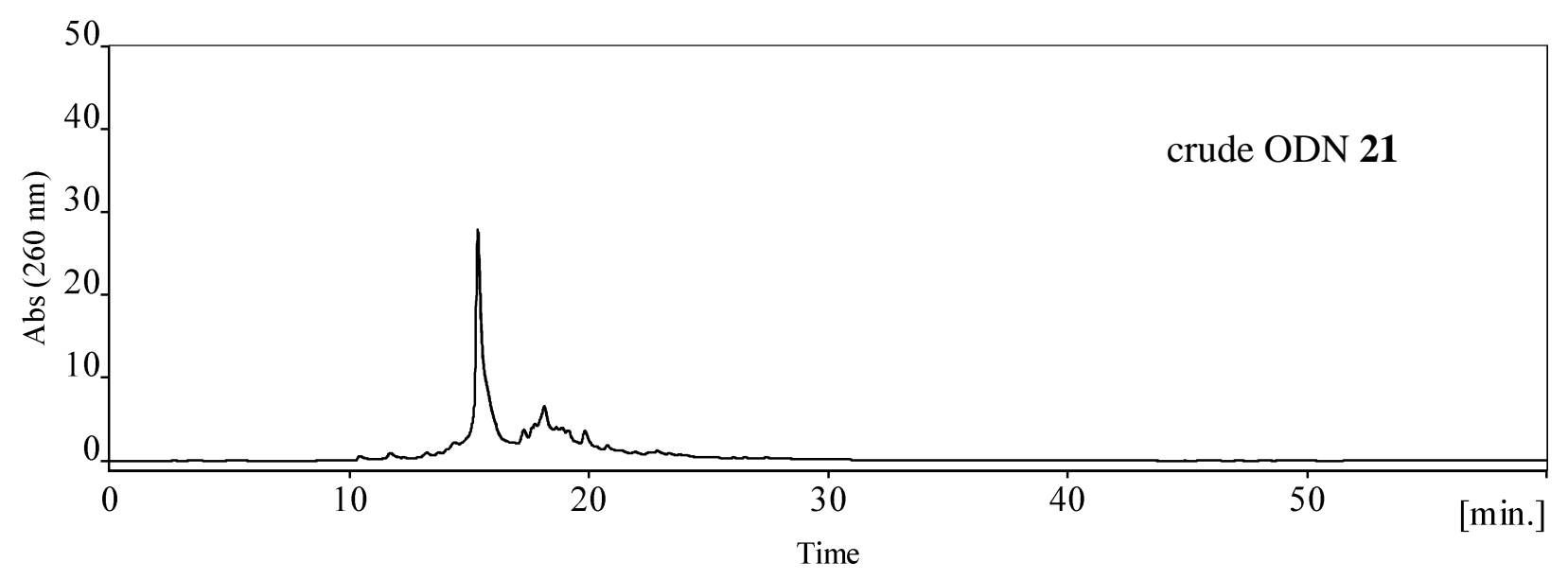

RP HPLC profile of pure ODN 21

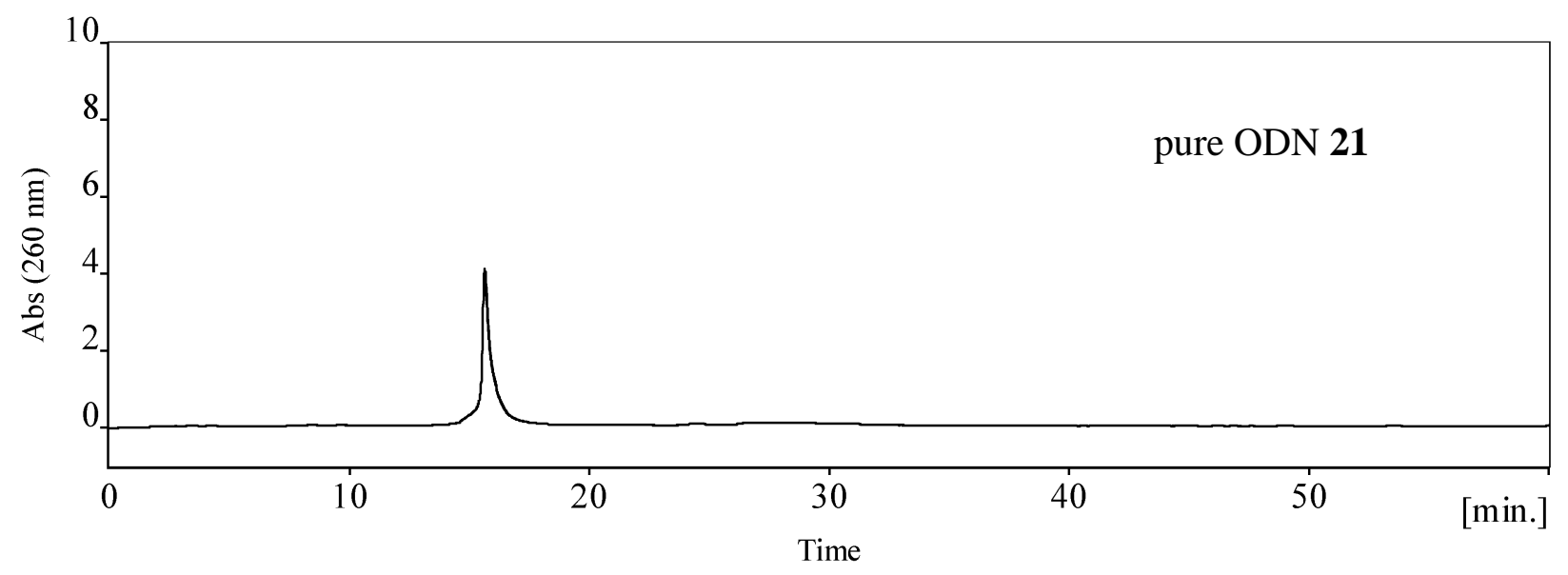


RP HPLC profile of crude ODN 22

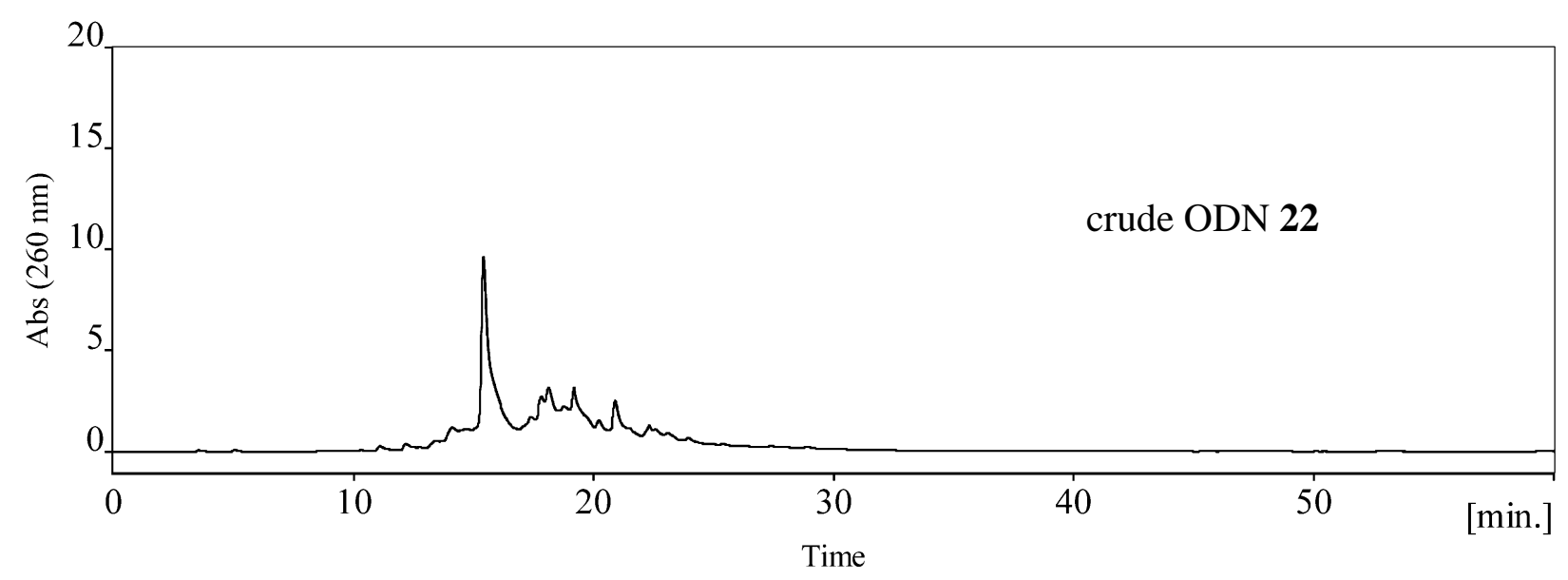

RP HPLC profile of pure ODN 22 (the column was heated to $60^{\circ} \mathrm{C}$ )

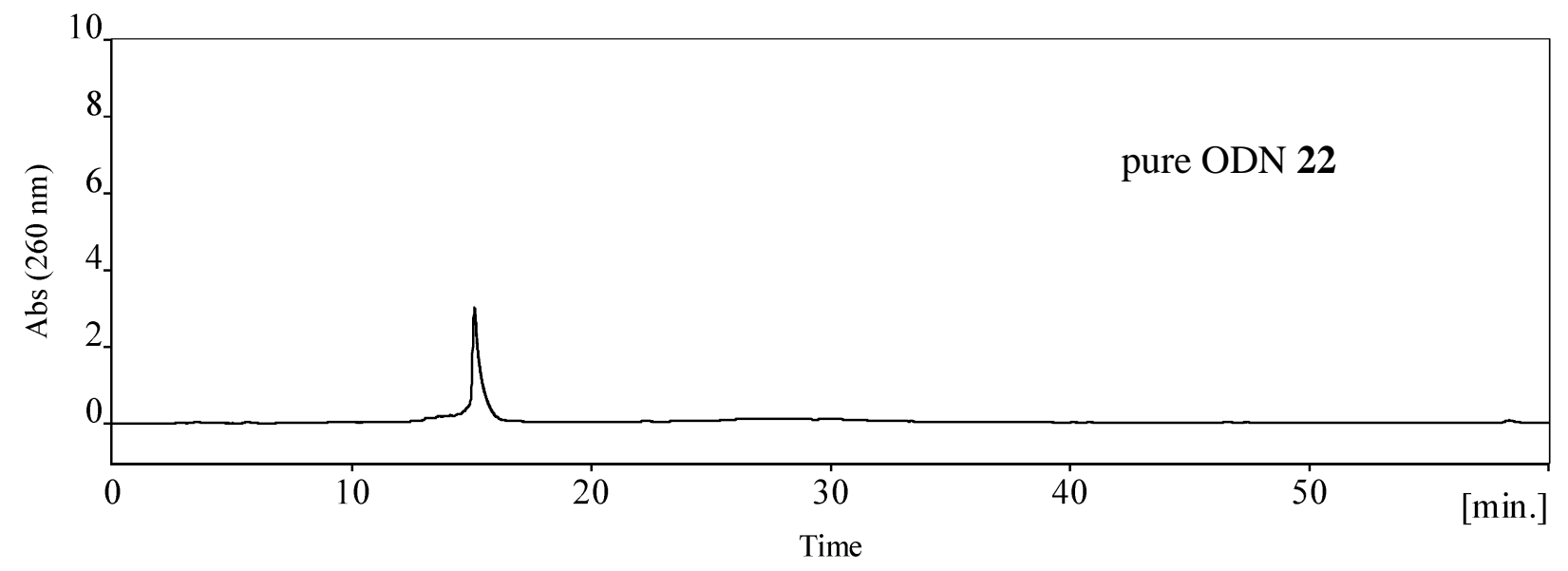


RP HPLC profile of crude ODN 30

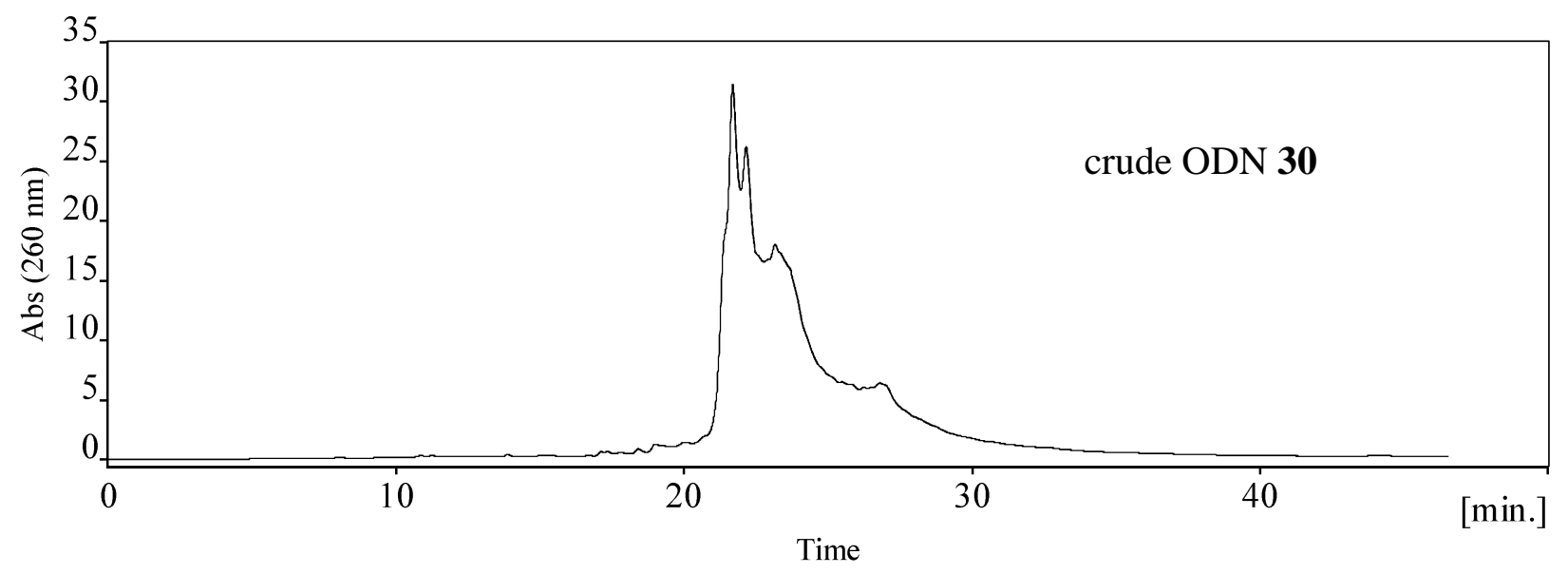

RP HPLC profile of pure ODN 30

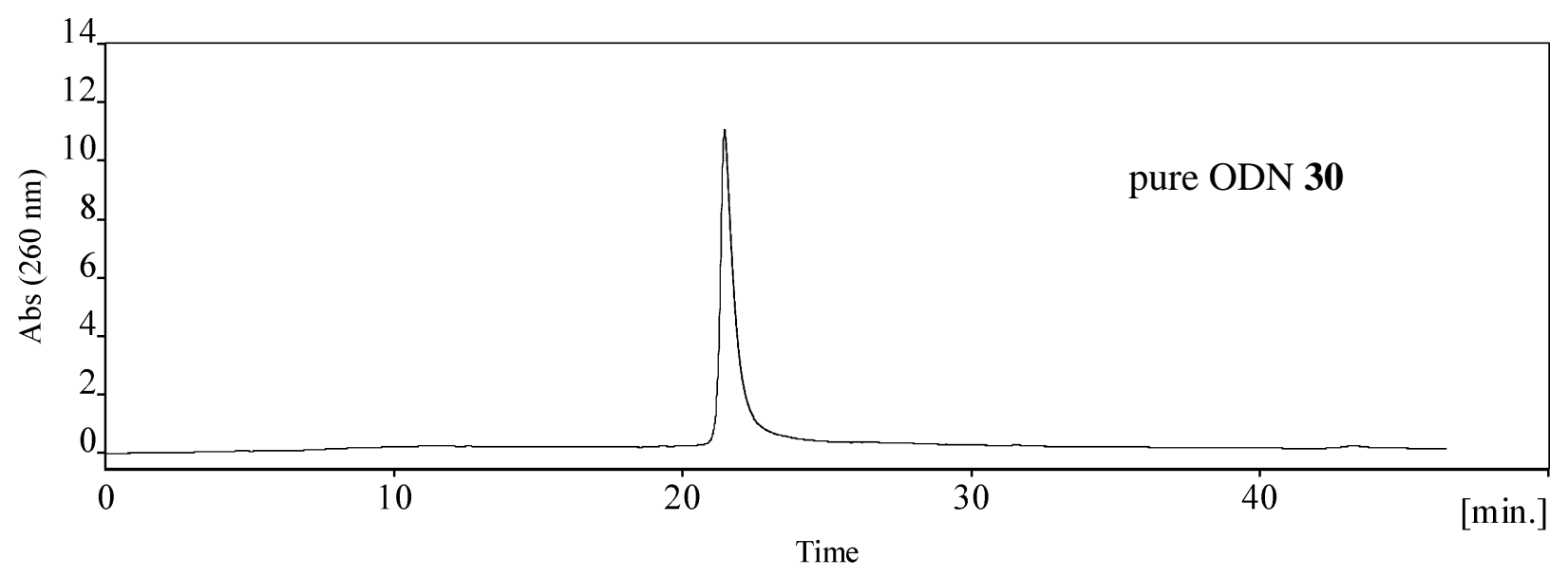




\section{Experiments for comparing Dmoc-amidites with commercial amidites:}

1. DNA synthesis with commercial amidites (Bz-dA, Ac-dC, $i \mathrm{Bu}-\mathrm{dG}$, and dT; $0.05 \mathrm{M}$ in acetonitrile) using $25 \mathrm{mg}$ CPG 1; DMTr-on

2. Took $11 \mathrm{mg} \mathrm{CPG}$, treated with con. $\mathrm{NH}_{4} \mathrm{OH}$ at $60{ }^{\circ} \mathrm{C}$ for $12 \mathrm{~h}$

3. Took supernatant, washed CPG with water, combined washes with supernatant

4. Evaporated to dryness

5. Added $50 \mu \mathrm{L}$ water, dissolved, added $450 \mu \mathrm{L} n \mathrm{BuOH}$, precipitated ODN

6. Dissolved ODN in $100 \mu \mathrm{L}$ water, injected $10 \mu \mathrm{L}$ into RP HPLC

7. Collected full-length ODN with DMTr-on

8. Evaporated

9. Treated with $80 \% \mathrm{AcOH}, 1 \mathrm{~h}, \mathrm{rt}$

10. Dried

11. Dissolved in $20 \mu \mathrm{L}$ water, all injected into RP HPLC to generate HPLC profile S1 (peak area 1095.360; see next pages)

12. Collected ODN

13. Dried

14. Dissolved in $2 \mathrm{~mL}$ water

15. Measured UV to generate UV spectrum S1 $\left(\mathrm{OD}_{260}=0.256\right.$; see next pages)

16. DNA synthesis with Dmoc-amidites 2-4 and commercial dT (0.05 M in acetonitrile) using 25 mg CPG 1; DMTr-on

17. The same steps 2-15 were applied to generate HPLC profile S2 (see next pages; peak area 1059.289) and UV spectrum S2 $\left(\mathrm{OD}_{260}=0.260\right.$; see next pages $)$

18. Took $11 \mathrm{mg}$ CPG from step 16

19. Treated with DBU, oxidized with $\mathrm{NaIO}_{4}$, treated with aniline according to the procedure described in the paper. Aniline was removed from the ODN using ultrafiltration with an Amicon ${ }^{\circledR}$ centrifugal filter unit. The crude ODN was dried.

20. Dissolved ODN in $100 \mu \mathrm{L}$ water, injected $10 \mu \mathrm{L}$ into RP HPLC

21. Collected full-length ODN

22. Dried

23. Steps 11-15 were followed to generate HPLC profile S3 (see next pages; peak area 268.950) and UV spectrum S3 $\left(\mathrm{OD}_{260}=0.066\right.$; see next pages $)$ 


\section{HPLC profile S1}

\begin{tabular}{|c|c|}
\hline Project & : WORK2 \\
\hline ISTD Amount & $: 0$ \\
\hline Sample ID & : cjs20160523 5-45-re-re \\
\hline Calibration & : \\
\hline
\end{tabular}

Chromatogram E:ICSW32 Jinsen Chenlcjs20160523 5-45-re-re

Page 1 of 1

By : None

Style : Chromatogram

Inj. Volume : 20

Sample : cjs20160523 5-45-re-re

Calibration : $\quad$ Chromatogram : E:ICSW32IVinsen Chenlcjs20160523 5-45-re-re

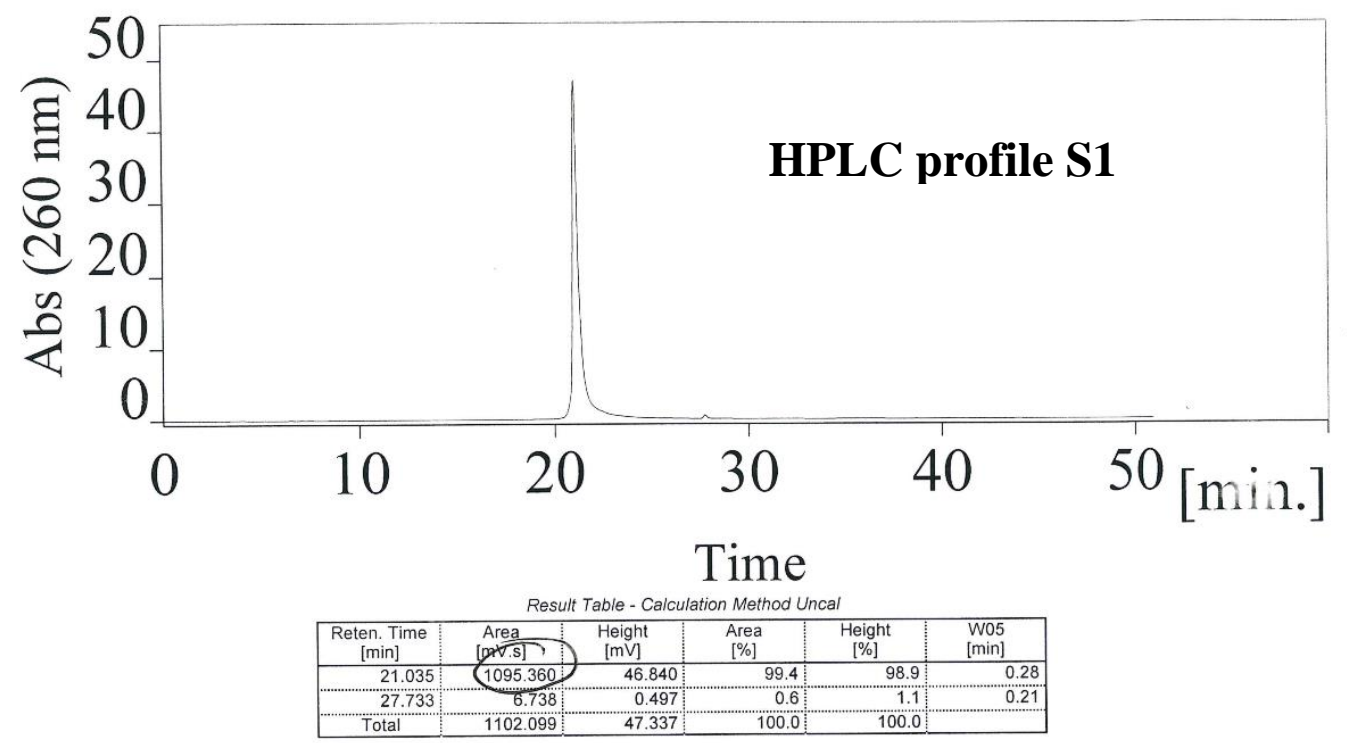

$\left\{\begin{array}{l}\text { Modified ept } \\ \text { Comencid } P . \\ M H_{3}-H_{10} 0\end{array}\right.$

$O D=0.256,2.0 \mathrm{ml}$ 


\section{UV spectrum S1}

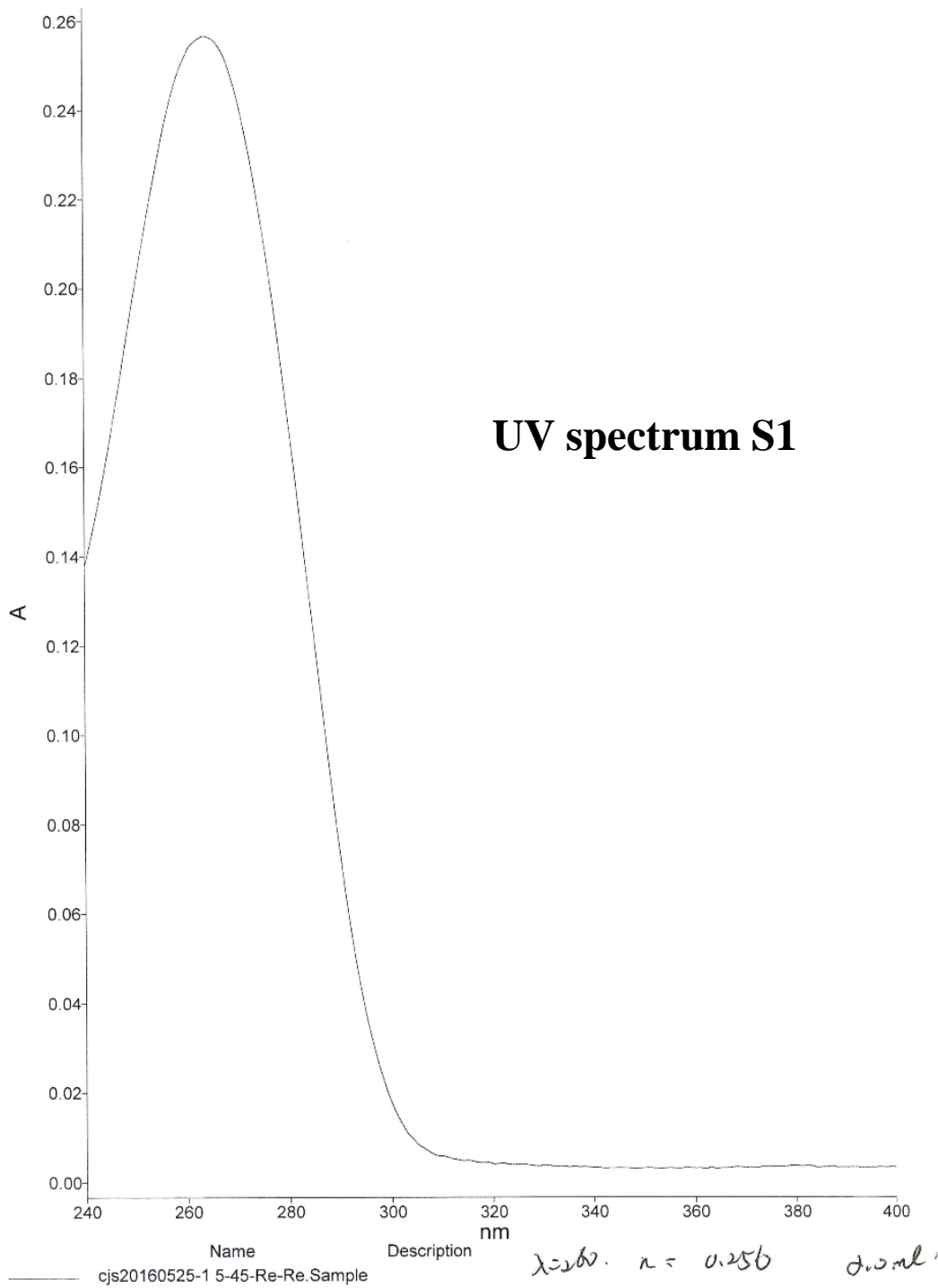




\section{HPLC profile S2}

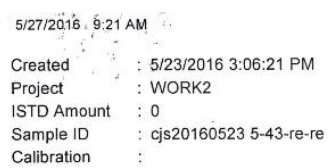

Chromatogram E:ICSW32Winsen Chenlcjs20160523 5-43-re-re

By

Style
Inj. Volum

Inj. Volume
Sample

Calibration

Chromatogram : E:ICSW32Winsen Chenlcjs20160523 5-43-re-re

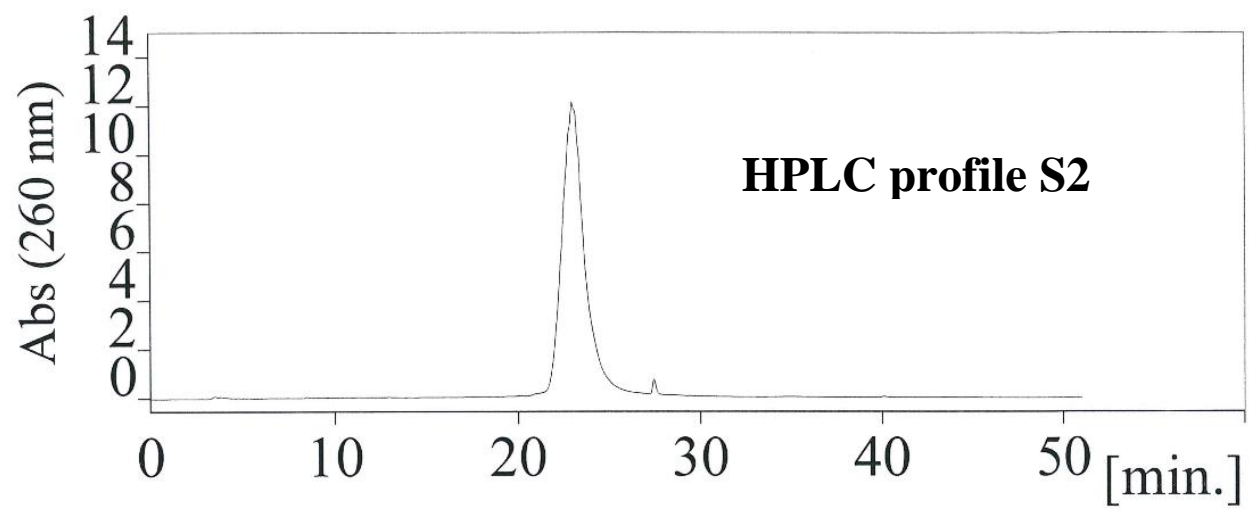

Time

\begin{tabular}{|c|c|c|c|c|c|}
\hline \multicolumn{6}{|c|}{ Result Table - Calculation Method Uncal } \\
\hline $\begin{array}{l}\text { Reten. Time } \\
\text { [min] }\end{array}$ & $\begin{array}{l}\text { Area } \\
\text { m }\end{array}$ & $\begin{array}{l}\text { Height } \\
{[\mathrm{mV}]}\end{array}$ & $\begin{array}{l}\text { Area } \\
{[\%]}\end{array}$ & $\begin{array}{l}\text { Height } \\
{[\%]}\end{array}$ & $\begin{array}{l}\text { W05 } \\
{[\mathrm{min}]}\end{array}$ \\
\hline 22.987 & 1059.289 & 12.077 & 98.9 & 94.8 & 1.25 \\
\hline 27.435 & 11.590 & 0.664 & 1.1 & 5.2 & 0.22 \\
\hline Total & 1070.819 & 12.741 & 100.0 & 100.0 & \\
\hline
\end{tabular}

$$
\begin{aligned}
& \text { nodifiend CP6 } \\
& \text { onace - } P \\
& \mathrm{NH}_{3} \text {. HWO } \\
& O D=0.260,20 \mathrm{ml}
\end{aligned}
$$




\section{UV spectrum S2}

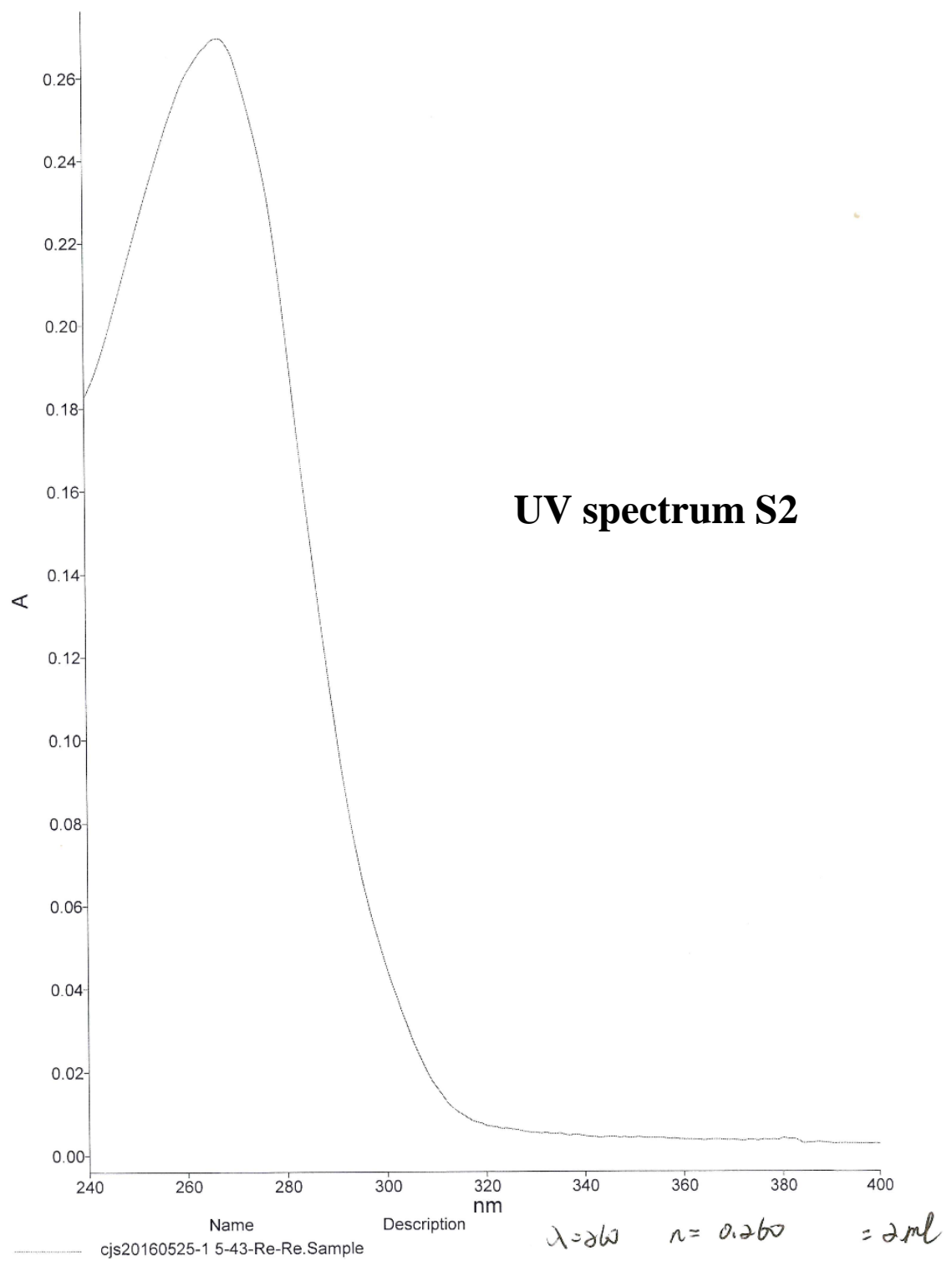




\section{HPLC profile S3}

Project : WORK2

ISTD Amount

Sample ID WORK2

Calibration
Chromatogram E:ICSW32Vinsen Chenicis20160526-2 5-44-2-re-re

Page 1 of 1

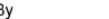

Style

Inj. Volume : :

Sample $\quad:$ cjs20160526-2 5-44-re-re

Chromatogram : E:ICSW32IJinsen Chenlcjs20160526-2 5-44-2-re-re

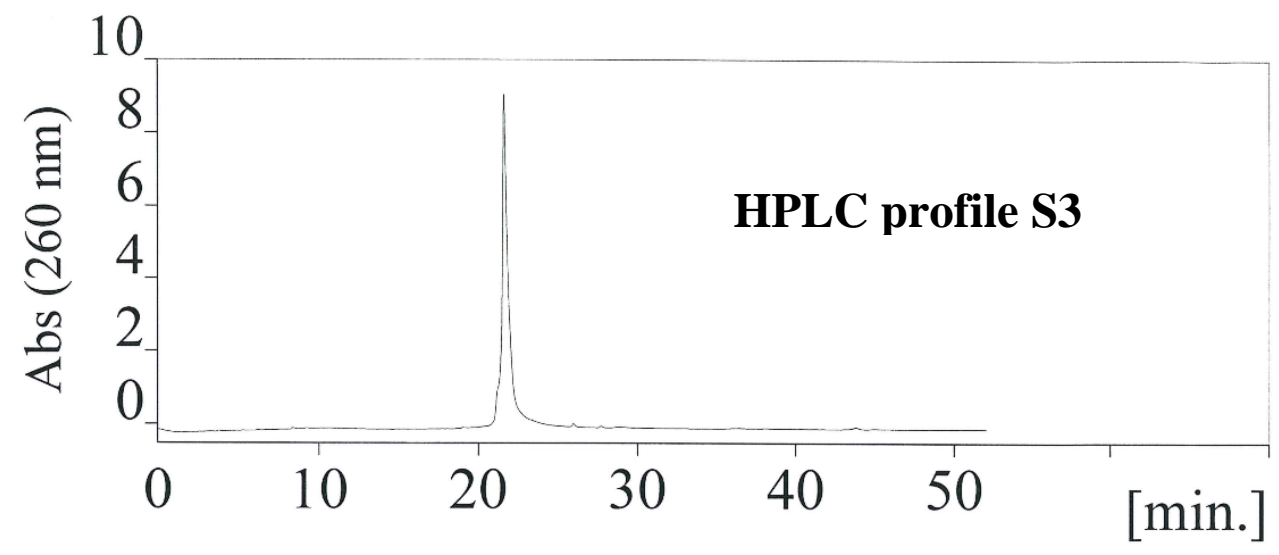

Time

\begin{tabular}{|c|r|r|r|r|r|}
\multicolumn{7}{|c|}{ Result Table - Calculation Method Uncal } \\
\hline $\begin{array}{c}\text { Reten. Time } \\
{[\mathrm{min}]}\end{array}$ & $\begin{array}{c}\text { Area } \\
{[\mathrm{my} / \mathrm{s}]}\end{array}$ & $\begin{array}{c}\text { Height } \\
{[\mathrm{mV}]}\end{array}$ & $\begin{array}{c}\text { Area } \\
{[\%]}\end{array}$ & $\begin{array}{c}\text { Height } \\
{[\%]}\end{array}$ & $\begin{array}{c}\text { W05 } \\
{[\mathrm{min}]}\end{array}$ \\
\hline 21.589 & $\mathbf{2 6 8 . 9 5 0}$ & 9.143 & 100.0 & 100.0 & 0.34 \\
\hline Total & 268.950 & 9.143 & 100.0 & 100.0 & \\
\hline
\end{tabular}

$$
\left\{\begin{array}{l}
\text { madfied cp } \\
\text { our pMioc- } p \\
\text { oxidution workup } \\
O D=0.066 .2 .0 \mathrm{ml}
\end{array}\right.
$$




\section{UV spectrum S3}

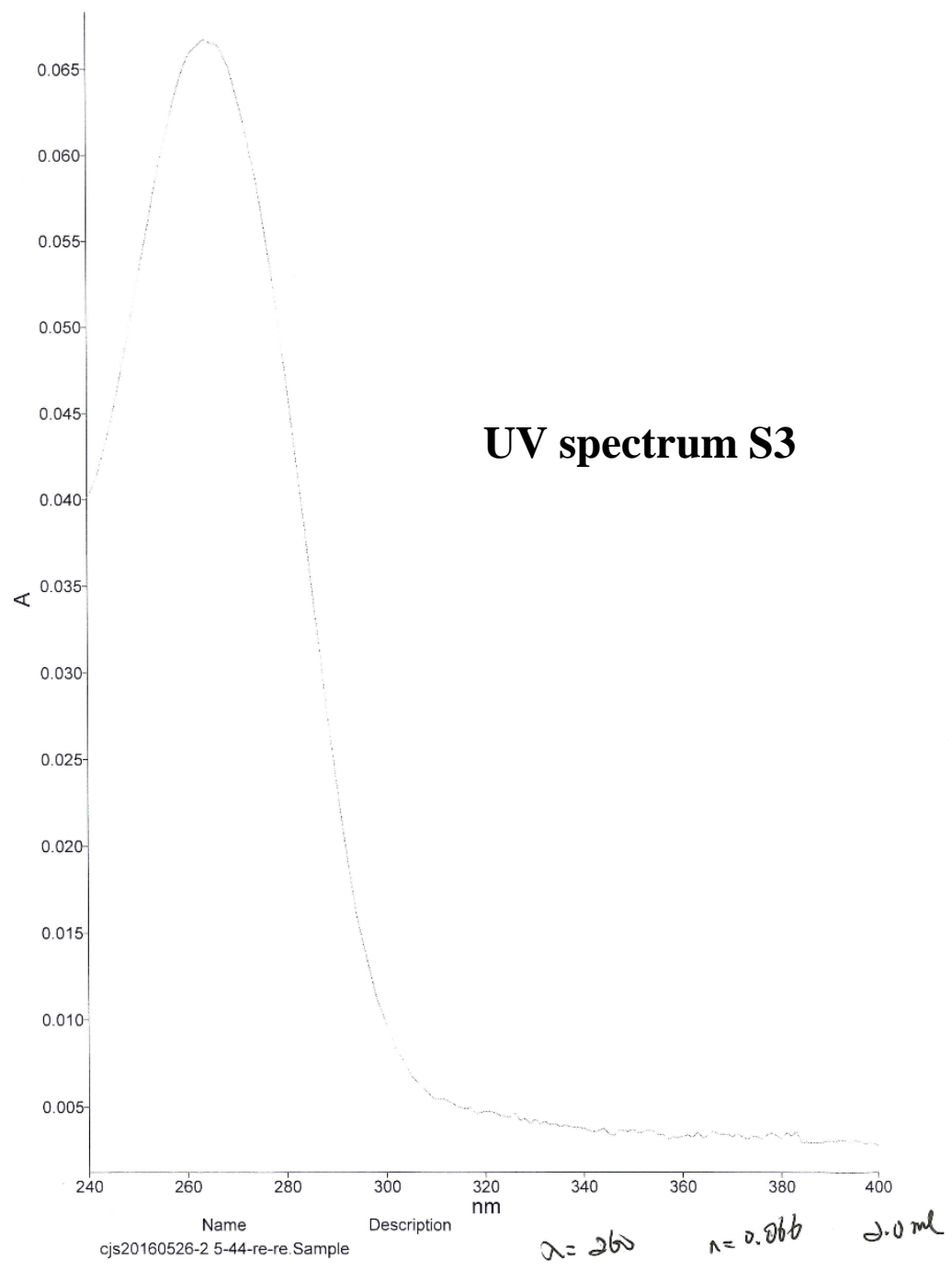




\section{Experiments confirming incompatibility of thioester and $\alpha$-chloroacetyl groups with $\mathrm{K}_{2} \mathrm{CO}_{3} / \mathrm{MeOH}$}

Thioester and $\alpha$-chloroacetyl groups are believed to be unstable even under the widely used mild ODN deprotection and cleavage conditions such as $0.05 \mathrm{M} \mathrm{K}_{2} \mathrm{CO}_{3} / \mathrm{MeOH}$ at $\mathrm{rt}$ for $16 \mathrm{~h}$ (usually called UltraMild conditions). For thioesters, this can be easily seen from the fact that the succinyl ester linkage and the $\alpha$-phenoxyacetyl nucleoside amino protecting groups are readily cleaved under these conditions when the UltraMild method is used for ODN synthesis. Thioesters are typically more labile toward nucleophilic attack than esters and $\alpha$-phenoxyacetyl aromatic amides. To further confirm that the thioester and $\alpha$-chloroacetyl groups are not compatible with the UltraMild conditions, we synthesized the ODNs 29-30, which contained a thioester and $\alpha$ chloroacetyl group, respectively, using the UltraMild amidites as identified below. As predicted, cleavage and deprotection using the UltraMild conditions converted the thioester in ODN 29 to a thiol, which was oxidized in the process to a sulfinic acid group $\left(-\mathrm{SO}_{2} \mathrm{H}\right)$ as indicated by MALDITOF MS. The resulting ODN is labeled as $\mathbf{S 1}$. The $\alpha$-chloroacetyl group in ODN $\mathbf{3 0}$ was converted to $\alpha$-methoxyacetyl group under the same cleavage and deprotection conditions. The resulting ODN is labeled as $\mathbf{S 2}$.

Both ODN syntheses were carried on commercial CPG with a succinyl ester linker at $1 \mu \mathrm{mol}$ scale on a MerMade 6 synthesizer. The commercial 5'-DMTr protected 2-cyanoethyl amidites Pac$\mathrm{dA}, \mathrm{Ac}-\mathrm{dC}, i \mathrm{Pr}-\mathrm{Pac}-\mathrm{dG}$ and $\mathrm{dT}$, and amidites 23-24 were used for the synthesis. Amidite concentrations were $0.1 \mathrm{M}$ (in acetonitrile). Typical ODN synthesis conditions were used. The last DMTr group was not removed on the synthesizer to assist subsequent RP HPLC purification. The $\mathrm{CPG}$ was incubated in the solution of $0.05 \mathrm{M} \mathrm{K}_{2} \mathrm{CO}_{3}$ in dry $\mathrm{MeOH}$ at $\mathrm{rt}$ for $16 \mathrm{~h}$. The supernatant was removed, and the CPG was washed with water. The supernatant and washes were combined and dried. The crude ODN was purified with RP HPLC. To remove the 5'-DMTr group, the purified ODN was treated with $80 \% \mathrm{AcOH}$ (rt, $40 \mathrm{~min}$ ). The solution was concentrated and injected to RP HPLC again. The pure ODN with DMTr-off was collected and analyzed with MALDI-TOF MS. ODN S1: Calcd for $\mathrm{C}_{192} \mathrm{H}_{253} \mathrm{~N}_{60} \mathrm{O}_{124} \mathrm{P}_{19} \mathrm{SNa}[\mathrm{M}+\mathrm{Na}]^{+} 6026.00$, found 6026.03. ODN S2: Calcd for $\mathrm{C}_{190} \mathrm{H}_{249} \mathrm{~N}_{60} \mathrm{O}_{123} \mathrm{P}_{19} \mathrm{H}[\mathrm{M}+\mathrm{H}]^{+}$5928.02, found 5928.09. Images of the spectra are on the next page. 


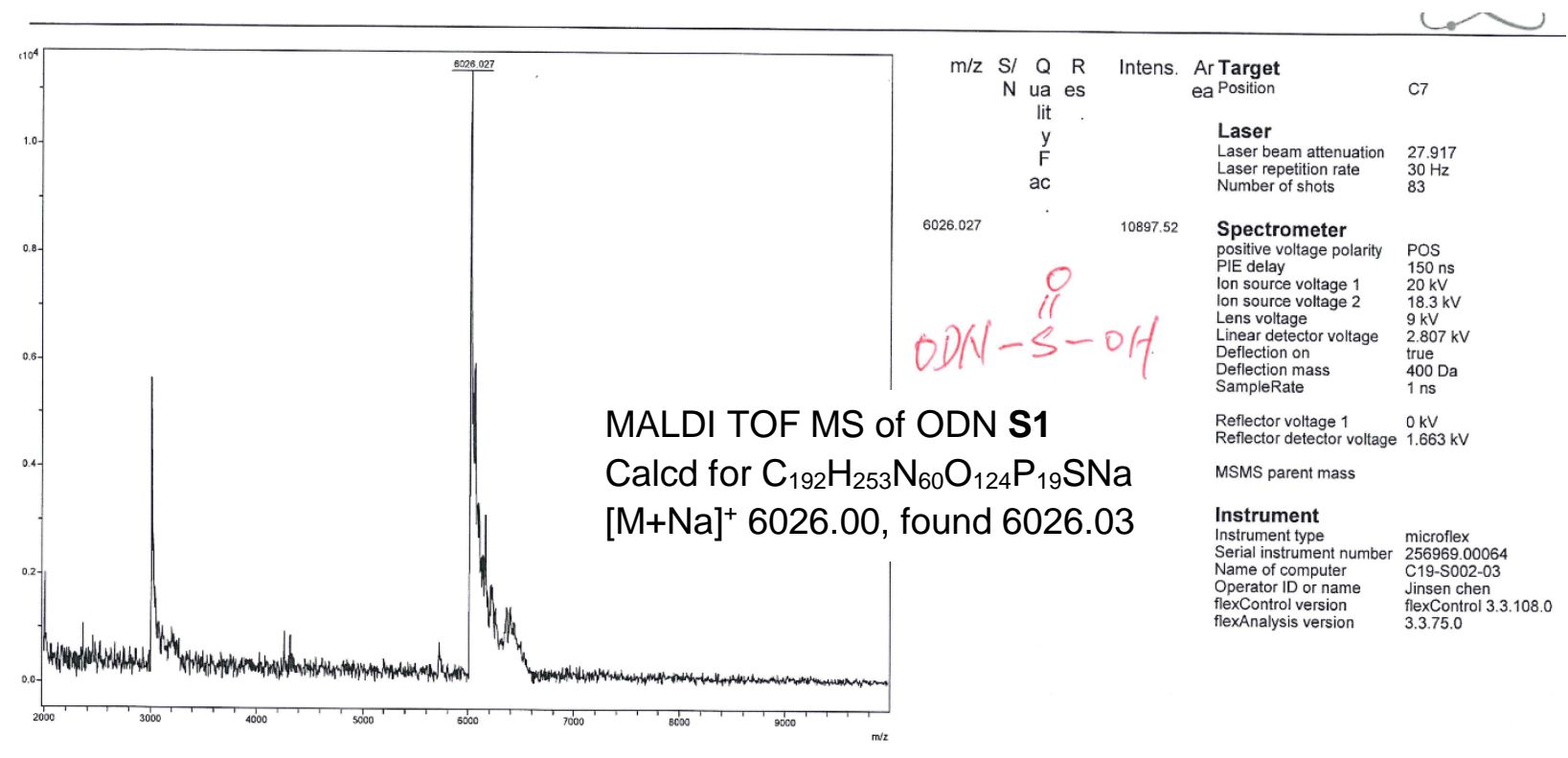

\begin{tabular}{ll|l|l|}
\hline $\begin{array}{l}\text { Date of Acquisition } \\
\text { Acquisition method }\end{array}$ & 2016-07-17T22:59:13.624-04:00 & \multicolumn{1}{c|}{ Performed by } \\
$\begin{array}{ll}\text { Processing method } \\
\text { File Name }\end{array}$ & D:IDatalShiyue Fang Winsen ChenlmethodLLP_12kDa.par & \\
\hline
\end{tabular}

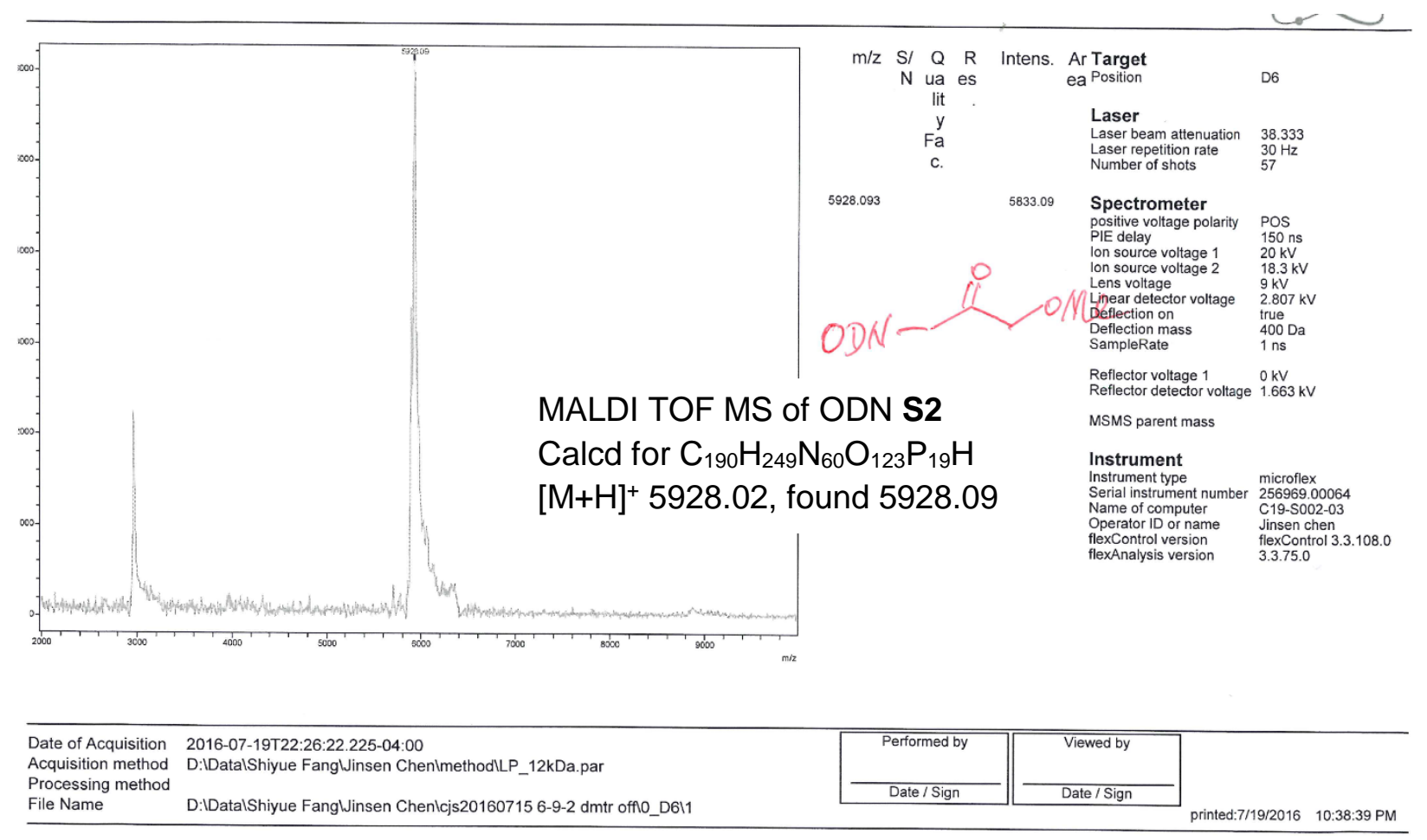

